Florida International University FIU Digital Commons

FIU Electronic Theses and Dissertations

University Graduate School

$11-3-2010$

\title{
Development of Face Recognition: Infancy to Early Childhood
}

Melissa Ann Argumosa

Florida International University, melissashuman@gmail.com

DOI: $10.25148 /$ etd.FI10120305

Follow this and additional works at: https://digitalcommons.fiu.edu/etd

\section{Recommended Citation}

Argumosa, Melissa Ann, "Development of Face Recognition: Infancy to Early Childhood" (2010). FIU Electronic Theses and Dissertations. 317.

https://digitalcommons.fiu.edu/etd/317

This work is brought to you for free and open access by the University Graduate School at FIU Digital Commons. It has been accepted for inclusion in FIU Electronic Theses and Dissertations by an authorized administrator of FIU Digital Commons. For more information, please contact dcc@fiu.edu. 


\title{
FLORIDA INTERNATIONAL UNIVERSITY
}

Miami, Florida

\section{DEVELOPMENT OF FACE RECOGNITION:}

INFANCY TO EARLY CHILDHOOD

\author{
A dissertation submitted in partial fulfillment of the \\ requirements for the degree of \\ DOCTOR OF PHILOSOPHY \\ in \\ PSYCHOLOGY \\ by \\ Melissa Ann Argumosa \\ 2010
}


To: Dean Kenneth Furton

College of Arts and Sciences

This dissertation, written by Melissa Ann Argumosa, and entitled Development of Face Recognition: Infancy to Early Childhood, having been approved in respect to style and intellectual content, is referred to you for judgment.

We have read this dissertation and recommend that it be approved.

Mary Levitt

Ana Gouvea

Robert Lickliter

Date of Defense: November 3, 2010

Lorraine E. Bahrick, Major Professor

The dissertation of Melissa Ann Argumosa is approved.

Dean Kenneth Furton

College of Arts and Sciences

Interim Dean Kevin O’Shea

University Graduate School

Florida International University, 2010 


\section{DEDICATION}

I dedicate this dissertation to my family. My parents have shown incredible support and encouragement throughout my entire graduate training. The completion of this dissertation would not have been possible without their continued love and devotion.

And to Kened Argumosa, my loving and supportive husband. You have been my shining light throughout this process. I am eternally grateful for your love and support. Your patience and confidence in me has been unwavering. Words cannot express how much it means to me to know that you are there for me every step of the way. I love you with all my heart. 


\section{ACKNOWLEDGMENTS}

This work has been conducted with the support and encouragement of my committee members, Dr. Ana Gouvea, Dr. Mary Levitt, and Dr. Robert Lickliter. Their guidance and thoughtful feedback have been very influential throughout my dissertation. I would also like to thank Dr. Lorraine E. Bahrick, my mentor and committee chair, for her valuable experience and for providing me with the skills necessary to continue challenging myself even beyond my graduate training. Her supervision and expertise in the field of infant perceptual development have been paramount to my success.

I am grateful for the MBRS-RISE program for funding 41/2 years of my graduate training and providing the opportunity to interact with other minority students majoring in biomedical fields. This program was critical to my achievements.

Special thanks are to be given to my fellow graduate students at the Infant Development Lab, Mariana Vaillant Molina and Irina Castellanos. I am grateful for their understanding, encouragement, and friendship. I truly appreciate our support system and will never forget the good and bad times we've shared. Mariana, I will always treasure our shared experiences beginning as undergraduate research assistants. Irina, your encouragement and help (particularly with your statistical consultations) have been extraordinary and extremely valued. Thank you both for long lasting friendships. Finally, I would like to thank the many parents who graciously allowed their children to participate in this research. Their efforts directly contributed to our knowledge about the development of face perception. 


\section{ABSTRACT OF THE DISSERTATION \\ DEVELOPMENT OF FACE RECOGNITION: INFANCY TO EARLY CHILDHOOD \\ by}

Melissa Ann Argumosa

Florida International University, 2010

Miami, Florida

Professor Lorraine E. Bahrick, Major Professor

Perception and recognition of faces are fundamental cognitive abilities that form a basis for our social interactions. Research has investigated face perception using a variety of methodologies across the lifespan. Habituation, novelty preference, and visual paired comparison paradigms are typically used to investigate face perception in young infants. Storybook recognition tasks and eyewitness lineup paradigms are generally used to investigate face perception in young children. These methodologies have introduced systematic differences including the use of linguistic information for children but not infants, greater memory load for children than infants, and longer exposure times to faces for infants than for older children, making comparisons across age difficult. Thus, research investigating infant and child perception of faces using common methods, measures, and stimuli is needed to better understand how face perception develops. According to predictions of the Intersensory Redundancy Hypothesis (IRH; Bahrick \& Lickliter, 2000, 2002), in early development, perception of faces is enhanced in unimodal visual (i.e., silent dynamic face) rather than bimodal audiovisual (i.e., dynamic face with synchronous speech) stimulation. 
The current study investigated the development of face recognition across children of three ages: $5-6$ months, $18-24$ months, and $3.5-4$ years, using the novelty preference paradigm and the same stimuli for all age groups. It also assessed the role of modality (unimodal visual versus bimodal audiovisual) and memory load (low versus high) on face recognition. It was hypothesized that face recognition would improve across age and would be enhanced in unimodal visual stimulation with a low memory load.

Results demonstrated a developmental trend $(F(2,90)=5.00, p=0.009)$ with older children showing significantly better recognition of faces than younger children. In contrast to predictions, no differences were found as a function of modality of presentation (bimodal audiovisual versus unimodal visual) or memory load (low versus high). This study was the first to demonstrate a developmental improvement in face recognition from infancy through childhood using common methods, measures and stimuli consistent across age. 


\section{TABLE OF CONTENTS}

CHAPTER

PAGE

I. INTRODUCTION 1

Introduction: The Development of Face Perception and Recognition 1

II. INFANT FACE PERCEPTION 7

Methods of Investigating Face Perception in Infancy 7

$\begin{array}{ll}\text { Habituation } & 7\end{array}$

Research Findings: Habituation - Static Stimuli 8

Research Findings: Habituation - Dynamic, Ecological Stimuli 9

Research Findings: Habituation - First Order, Holistic, \&

Second Order Face Processing $\quad 10$

Visual Paired Comparison (VPC) 12

Research Findings: VPC - Preferences for Mother's Face 13

Research Findings: VPC - Face Processing 14

$\begin{array}{ll}\text { Novelty Preference Procedure } & 15\end{array}$

Research Findings: Novelty Preference Procedure - Face

Recognition 16

Memory for Other Events: Infancy versus Early Childhood 18

$\begin{array}{ll}\text { Summary } & 19\end{array}$

III. CHILD FACE PERCEPTION 21

Methods Investigating Face Perception in Childhood 21

Storybook Format $\quad 22$

Eyewitness Format $\quad 25$

Physiological Measures 26

Summary: Infant versus Child Face Recognition Tasks 28

Variables Addressed by Current Study $\quad 29$

$\begin{array}{ll}\text { IV. BRIDGING THE GAP } & 31\end{array}$

Intersensory Redundancy Hypothesis $\quad 31$

The IRH and Face Perception $\quad 34$

The IRH and Ecological Stimuli 36

Is Face Recognition Better in Infancy than Early Childhood?

$\begin{array}{ll}\text { Alternative Hypotheses } & 37\end{array}$

Current Study: Bridging the Gap 39

Novelty Preference Paradigm: Validity of Using Same Method with Infants \& Children 40

Measures and Hypothesized Results 42

V. CURRENT STUDY 47

Introduction $\quad 47$

$\begin{array}{ll}\text { Methods } & 47\end{array}$ 
$\begin{array}{lr}\text { Participants } & 47\end{array}$

$\begin{array}{lr}\text { Stimuli } & 48\end{array}$

Apparatus $\quad 49$

Procedure $\quad 50$

VI. RESULTS AND DISCUSSION 53

Results: Infant Novelty Preferences 53

Results: Toddler Novelty Preferences $\quad 54$

Results: Preschool Novelty Preferences $\quad 55$

Results: Main Analyses $\quad 56$

Results: Analyses of Simple Effect for Each Age 59

Results: Secondary Analyses $\quad 62$

General Discussion $\quad 64$

$\begin{array}{ll}\text { Limitations } & 68\end{array}$

$\begin{array}{ll}\text { Future Directions } & 69\end{array}$

$\begin{array}{ll}\text { REFERENCES } & 70\end{array}$

$\begin{array}{lr}\text { APPENDICES } & 81\end{array}$

$\begin{array}{lr}\text { VITA } & 105\end{array}$ 


\section{LIST OF FIGURES}

TABLE

PAGE

1. Study Design

2. Example of low memory load familiarization and test trials

3. Example of high memory load familiarization and test trials

83

4. Predicted mean proportion of total looking time (PTLT) to the novel faces as a function of age (infant, toddler, preschool), stimulus modality (unimodal visual, bimodal synchronous), and memory load (low, high)

5. Mean proportion of total looking time (PTLT) to the novel faces as a function of age (infant, toddler, preschool)

6. Mean proportion of total looking time (PTLT) to the novel faces for all children as a function of stimulus modality (unimodal visual, bimodal synchronous)

7. Mean proportion of total looking time (PTLT) to the novel faces or all children as a function of memory load (low, high)

8. Mean proportion of total looking time (PTLT) to the novel faces as a function of age (infant, toddler, preschool), stimulus modality (unimodal visual, bimodal synchronous), and memory load (low, high)

9. Infants' mean proportion of total looking time (PTLT) to the novel faces as a function of stimulus modality (unimodal visual, bimodal synchronous), and memory load (low, high)

10. Toddlers' mean proportion of total looking time (PTLT) to the novel faces as a function of stimulus modality (unimodal visual, bimodal synchronous), and memory load (low, high)

11. Preschoolers' mean proportion of total looking time (PTLT) to the novel faces as a function of stimulus modality (unimodal visual, bimodal synchronous), and memory load (low, high) 


\section{Chapter I - Introduction}

Introduction: The Development of Face Perception and Recognition

Perception and recognition of faces is a fundamental cognitive ability that forms the basis for most of our social interactions. From birth we experience and participate in face-to-face interactions that contribute to our perception and knowledge of faces. Preferences for faces and face-like patterns occur hours after birth (e.g., Bushnell, 1998; Easterbrook, Kisilevsky, Hains, \& Muir, 1999; Goren, Sarty, \& Wu, 1975; Johnson, Dziurawiec, Ellis, \& Morton, 1991; Mondloch, Lewis, Budreau, Maurer, Dannemiller, Stephens, \& Kleiner-Gathercoal, 1999; Morton \& Johnson, 1991; Nelson, 2001; Simion, Valenza, \& Umilta, 1998). However, it remains unclear as to how face perception and recognition develop from preferences for face-like patterns into adult face expertise.

Face expertise refers to the ability to process and recognize faces using efficient processing styles, such as configural processing (Carey, 1992, 1996). Featural, configural, and holistic processing styles have been of great interest to face perception researchers. Featural processing refers to the perception and recognition of faces on the basis of the individual features themselves, such as the shape of the eyes or the size of the nose. Configural processing, a more advanced processing style than featural, refers to the perception and recognition of faces on the basis of not only the features but also the spacing between features, and holistic processing refers to the perception and recognition of faces as a whole rather than based on parts of the face. Configural and holistic processing have been attributed to developing expertise for faces as a result of experience (Carey \& Diamond, 1977; Diamond \& Carey, 1986; Inn, Walden, \& Solso, 1993; Wild, Barrett, Spence, O’Toole, Cheng, \& Brooke, 2000). It is generally suggested that infants 
process faces using immature styles, such as featural processing (e.g., Maurer \& Barrera, 1981; Turati, Macchi Cassia, Simion, \& Leo, 2006). On the other hand, school-aged children have more experience with faces and are thought to process them on the basis of configural information rather than featural information alone (McKone \& Boyer, 2006). Adults are considered experts on face perception as a result of extensive experience perceiving and recognizing faces as well as advanced processing of faces.

Researchers often investigate face expertise by assessing perception of first- and second-order relations. First-order relations refer to the basic structure of a face (i.e., eyes are above the nose which is above the mouth). Second-order relations refer to the spacing between features within a face (i.e., the space between the eyes or between the nose and the mouth). It is generally suggested that perception or recognition of a face on the basis of first-order relations is an immature skill, and perception or recognition of a face on the basis of second-order relations is evidence of developing face expertise (Diamond \& Carey, 1986).

Face expertise has been investigated using a variety of methods. One widely used method for assessing face expertise is the inversion effect (Diamond \& Carey, 1986). This effect is typically demonstrated by impaired face recognition when faces are inverted as compared to when faces are presented upright. The logic behind this task is that perception of the first- and second-order relations is altered when the face is inverted. For example, an inverted face presents the mouth above the nose rather than below the nose, which leads to a distorted perception of the structure of the face as well as the relationship between features (i.e., second-order relations) and impairs face recognition. 
Another method of assessing face expertise involves assessing the other-race effect. The other-race effect refers to individuals being better able to discriminate faces within their own race than within another race (e.g., Kelly, Liu, Lee, Quinn, Pascalis, Slater, \& Ge, 2009; Kelly, Quinn, Slater, Lee, Ge, \& Pascalis, 2007; Hayden, Bhatt, Joseph, Tanaka, 2007; Sangrigoli \& de Schonen, 2004). As one gains experience with faces within their own race, discrimination of faces within other races diminishes. The other-race effect is considered to be evidence of developing face expertise. The otherrace effect has even been extended to other primate species. For example, Pascalis, de Haan, \& Nelson (2002) found that 6-month-old, but not 9-month-old human infants, were able to discriminate between two monkey faces. These findings were attributed to a perceptual narrowing phenomenon. Perceptual narrowing is most commonly discussed in the area of speech perception. Young infants discriminate phonetic variations within native and nonnative languages, however, with increased language perception and production, older infants can only discriminate phonetic variations within their native language. Perceptual narrowing can be attributed to increased exposure to the infants' own language throughout their first year and the development of expertise for their native language.

Nelson (2001) suggests that a perceptual narrowing effect also occurs for the perception of faces. According to this phenomenon, face perception narrows with development as a result of increased experience with faces and eventually leads to development of a face prototype. A face prototype refers to an average of numerous faces. Averaged faces are perceived by adults as more attractive than any one of the individual faces (Langlois \& Roggman, 1990; Valentine, Darling, \& Donnelly, 2004). 
Research has demonstrated prototype formation in early infancy (de Haan, Johnson, Maurer, \& Perrett, 2001; Rubenstein, Kalakanis, \& Langlois, 1999; Walton \& Bower, 1993). Prototypes are created as a result of experience perceiving many faces and averaging these faces across experiences. As a result of early prototype formation, Pascalis, et al. (2002) suggest that face recognition becomes narrower and "human face specific" after 3 months of age. The inversion effect, other-race effect, other-species effect, and prototype formation all provide evidence for the development of face expertise.

Despite the vast research investigating perception of faces, little evidence has demonstrated how face perception and recognition develop across infancy to childhood. Two separate literatures address infant versus child face perception and recognition. The infant face perception literature typically investigates preferences for faces, processing styles, and face recognition using methods such as habituation and novelty preference. For example, infants demonstrate the ability to form prototypes (de Haan et al., 2001; Rubenstein, et al., 1999; Walton \& Bower, 1993), recognize unfamiliar faces (Bahrick, Lickliter, Vaillant, Shuman, \& Castellanos, 2004; Pascalis, de Haan, Nelson, \& de Schonen, 1998; Slater \& Quinn, 2001), and process faces on the basis of second-order relations (i.e., a more advanced basis from which to perceive faces; Cohen \& Cashon, 2001; Schwarzer, Zauner, \& Jovanovic, 2007; Thompson, Madrid, Westbrook, \& Johnston, 2001). The child face perception literature typically investigates processing styles and face recognition using methods such as a storybook format and eyewitness identification tasks. Evidence from studies using these methods suggests that early childhood face recognition is poor, and young children process faces on the basis of 
featural (i.e., an immature method of face processing) and configural information (Carey \& Diamond, 1977; Diamond \& Carey, 1986; Inn, et al., 1993; Newell, Bahrick, \& Sternstein, 2007; Wild, et al., 2000). There is little continuity between the findings of face perception and recognition of faces in infancy versus childhood. Research findings addressing similar issues across infancy and childhood frequently contradict one another. For example, research investigating infant perception of faces suggests that infants as young as 6 months can process the face as a whole rather than simply on the basis of features (Cohen \& Cashon, 2001; Schwarzer \& Zauner, 2003; Schwarzer, et al., 2007), whereas, investigations of children's perception of faces argue that holistic and configural processing emerge across the toddler years (Carey \& Diamond, 1977; Diamond \& Carey, 1986).

Different methods, exposure times, memory loads, and task complexity contribute to differential findings across infant and child face perception research and result in difficulty drawing conclusions regarding the development of face perception across infancy and childhood. The use of consistent methods across cohorts is very important for drawing conclusions regarding developmental changes in face perception and recognition. Exposure time and memory load are also important factors to assess and control for when investigating how face perception and recognition change from infancy to early childhood. Many studies investigating infant face perception and recognition use extensive familiarization to a single face and test with a single novel face (see Bahrick, et al., 2004; Cohen, DeLoache, \& Pearl 1977; Pascalis, et al., 1998; Thompson, et al., 2001). On the other hand, studies investigating face recognition in preschoolers often present many different faces for brief exposure times (see Brace, Hole, Kemp, Pike, Van 
Duuren, \& Norgate, 2001; McKone \& Boyer, 2006; Mondloch, Leis, \& Maurer, 2006; Newell, et al., 2007). Similarly, memory loads often differ drastically in infant versus child face perception tasks. For example, infants are typically required to remember one face and tested with one novel face, whereas, children are often required to remember a set of several faces (e.g., 3-6 faces) and tested with another set of several faces. Memory load increases task difficulty and may contribute to inconsistent findings across infant and child studies. Differing task complexity is another factor which is often overlooked by face perception researchers. Infant face recognition tasks tend to be simpler than face recognition tasks presented to young children. Greater task difficulty may result in findings of immature face perception. The mismatched methods, exposure times, memory loads, and task complexity across infant and child studies does not allow for direct comparisons and developmental progressions cannot be accurately inferred. No single study to date has addressed the nature of the transition from infant to child face perception taking into account these variables.

This paper presents one of the first studies to directly compare face recognition skills of infants to young children while controlling for method, exposure time, and memory load. It also provides a review of the current literature (see Table I) on face perception and recognition across infancy to early childhood, with a special emphasis on methodology. 


\section{Chapter II - Infant Face Perception}

Methods of Investigating Face Perception in Infancy

Visual attention paradigms used in the field of infancy research take advantage of infants’ preferences for novelty. These paradigms include habituation (Horowitz, Paden, Bhana, \& Self, 1972), visual paired comparison (VPC; Fantz, 1963, 1964), and novelty preference (Fagan, 1974). Increased looking to novel events in habituation, visual paired comparison, and novelty preference method is interpreted as evidence of discrimination and memory for the familiarized event.

\section{Habituation}

Habituation is the decrease in a behavioral response such as looking or orienting to a particular stimulus after repeated exposure to that stimulus over a period of time (DeLoache, 1976; Pancratz \& Cohen, 1970). The decrease in looking or orienting is generally thought to reflect a developing memory representation of the habituated stimulus. Dishabituation refers to an increase in looking or orienting to a novel stimulus following habituation. Habituation is a common procedure used to investigate infants' attention and perception of objects, people, and events around them (Caron \& Caron, 1968; Cohen, et al., 1977; Martin, 1975). Typically, infants are repeatedly presented with a particular stimulus until their looking time or orienting response has decreased by a preset criterion (e.g., 50\% decrease in looking from their initial level of visual interest). Habituation is followed by a test presenting a novel stimulus and looking time is recorded. It is predicted that infants' increase in looking time to the novel stimulus (called "visual recovery") indicates discrimination between the novel and the familiarized stimulus. Infant-controlled habituation is credited to Horowitz, Paden, Bhana, \& Self 
(1972) and is used quite commonly within infancy research. Infant-controlled habituation differs from fixed trial habituation in that it allows each infant to control the duration of the presentation and allows for individual differences in rates of habituation across infants. The studies reviewed below refer to infant-controlled habituation. Research Findings: Habituation - Static Stimuli

Infant discrimination of faces has been investigated using the habituation paradigm. As demonstrated in Table I, even though social interactions are typically multimodal, most research investigating infants' discrimination and recognition of faces has been conducted with unimodal visual stimuli (e.g., static photographs). Three- to 4month-old infants discriminate photographs of two unfamiliar adult women following habituation (Cohen, et al., 1977; Barrera \& Maurer, 1981). Similarly, 3- and 6-month-old infants were habituated to several photographs of different poses of an unfamiliar adult woman's face whose hair was masked. Infants subsequently looked longer to a photograph of a novel adult woman's face in a novel pose than to a photograph of the familiarized woman's face in a novel pose, after 2-minute and 24-hour retention intervals (Pascalis, et al., 1998). Even newborns discriminate photographs of two unfamiliar adult female faces following habituation (Turati, et al., 2006). Furthermore, Turati, et al. (2006) discovered that inner features and outer contours alone were sufficient for newborns to discriminate two photographs of unfamiliar adult female faces. Taken together, very young infants demonstrate face discrimination of unimodal visual stimuli. However, infant discrimination of photographs does not provide information regarding how infants perceive and discriminate faces in the natural environment. 


\section{Research Findings: Habituation - Dynamic, Ecological Stimuli}

Dynamic faces provide more information than static faces, such as movement and different visual perspectives, which can contribute to face recognition. Newborn infants demonstrate preferences for live presentations of their mothers' face over the face of an unfamiliar woman (Bushnell, 2001; Bushnell, Sai, \& Mullin, 1989; Field, Cohen, Garcia, \& Greenberg, 1984; Pascalis, de Schonen, Morton, Duruelle, \& Fabre-Grenet, 1995; Sai, 2005). Blass \& Camp (2004) investigated 2- to 5-month-old infants' face discrimination of two unfamiliar adult women in person, rather than photographs, in a habituation procedure. They found that infants discriminated the two unfamiliar adult women's faces even when the external contours of the faces were hidden. More recently, research using dynamic stimuli found that 2-month-old infants discriminated two unfamiliar adult female faces following habituation in dynamic silent and dynamic asynchronous audiovisual presentations (i.e., dynamic faces with temporally misaligned speech and mouth movements; Vaillant-Molina, Newell, Castellanos, Bahrick, \& Lickliter, 2006), and by 3-months they discriminated two unfamiliar adult female faces in dynamic synchronous audiovisual presentations (i.e., naturalistic female faces with synchronous speech and mouth movements). Similarly, 3-month-old infants demonstrated memory across a 15-minute retention interval for an unfamiliar adult female face following habituation to a dynamic silent unfamiliar adult female face, but not following habituation to a dynamic unfamiliar adult female face with a synchronous voice (Bahrick, Newell, Shuman, \& Ben, 2007). These findings were attributed to infants' selective attention to particular properties of the dynamic synchronous audiovisual event (e.g., rhythm and tempo of the speech) at the expense of the facial configuration, or facial 
identity. Using dynamic stimuli allows for a better understanding of how infants perceive faces in their everyday environments.

Taken together, these studies provide evidence for discrimination of photographs of unfamiliar adult female faces by newborn infants (seemingly on the basis of outer contours and inner features), preferences for live presentations of mothers' versus unfamiliar adult female faces by newborn infants, and discrimination of dynamic, silent, unfamiliar adult female faces (even with the external contours masked) by 2-month-old infants. It also appears that 3-month-olds demonstrate memory for an unfamiliar adult female face following habituation to a dynamic silent face. These findings highlight the importance of using dynamic stimuli when investigating infant perception of faces, which are most often perceived in dynamic multimodal interactions.

Research Findings: Habituation - First Order, Holistic, \& Second Order Face Processing

One fundamental issue related to the development of expertise in face perception addressed in infancy research is whether infants process faces based on first-order relations (i.e., eyes are above a nose, which is above a mouth), holistic information (i.e., perceiving the features and configuration together as a gestalt), or second-order relations (i.e., the spacing between features). Maurer \& Barrera (1981) found that following habituation, 2- but not 1-month-old infants discriminated between a schematic face with intact first-order relations and a schematic face with scrambled features. This study demonstrates 2-month-old infants' perception of first-order relations within a habituation procedure.

Several habituation studies have demonstrated holistic processing of faces in infancy (Cohen \& Cashon, 2001; Schwarzer \& Zauner, 2003; Schwarzer, et al., 2007). 
One method of investigating holistic processing of faces is by using a "switch" habituation paradigm. The "switch" paradigm has been used to investigate infants' abilities to integrate information (e.g., perception of complex patterns or perception of word-object associations; see Younger \& Cohen, 1986; Werker, Cohen, Lloyd, Casasola, \& Stager, 1998). With respect to how infants process faces, the "switch" paradigm involves habituating infants to two alternating stimuli (e.g., two female faces). Following habituation of the two stimuli, tests are presented in which there is a switch in the pairing of two particular properties, such as internal and external features of a face (e.g., a composite of the two habituated faces, consisting of internal features from one face and the external features of the other face). In this example, the only novel variable during the test trials is the relationship between the internal and external features of the two female faces. If infants process faces on the basis of features, they should not look longer during the test trials because all the features are familiar. However, if infants process faces holistically, they should look longer during the test trials because the switched features have changed the perception of the face as a whole. Schwarzer, et al. (2007) found that 6and 10-month-old infants (but not 4-month-olds) looked longer to a habituated photograph of an adult woman's face when the mouth had been switched from that of another habituated photograph of an adult woman's face. Similarly, Cohen \& Cashon (2001) found that 7-month-old infants looked longer to a composite photograph of an adult woman's switched face than to a photograph of one of the familiar faces following habituation when the photographs of adult women's faces were presented upright but not when the faces were inverted. The authors concluded that 7-month-old infants process faces as a whole rather than as features when presented with upright faces. In contrast, if 
the faces are presented inverted, infants process faces on the basis of independent features (similar to the pattern shown by adults). These results suggest that infants as young as 6 months of age have the ability to process upright faces holistically and demonstrate the inversion effect.

Fewer studies have used habituation to address infants' perception of secondorder relations within faces. Bhatt, Bertin, Hayden, \& Reed (2005) found that 5- but not 3-month-old infants discriminated a photograph of an unfamiliar adult woman's face with manipulations of the spacing between the eyes and the spacing between the nose and mouth from that of a photograph of the same adult woman's unmanipulated face when presented upright but not when the faces were inverted. These results suggest that 5month-old infants can perceive upright faces on the basis of second-order relations. Visual Paired Comparison (VPC)

The visual paired comparison (VPC) method (Fantz, 1963) is most commonly used to determine visual preferences for one stimulus over another (see Rose, Feldman, \& Jankowski, 2004 for a review). For example, this procedure has been used to investigate infants' preferences for their mothers' face over that of an unfamiliar woman’s face (Bushnell, 2001; Bushnell et al., 1989; Field et al., 1984; Pascalis et al., 1995; Sai, 2005). In this procedure infants are presented either with a photograph or a live presentation of their mother's face (silent) side-by-side with that of an unfamiliar adult woman's face (silent). Infants' looking time and head turns to each face are used as the dependent measures. Preferences can be expressed as a proportion by dividing the looking time to one face over the total looking time to both faces. This measure is referred to as the proportion of total looking time (PTLT). A significant PTLT (i.e., 
greater than $50 \%$, or the chance value) to the mother's face is indicative of discrimination and a visual preference for the mother's face

\section{Research Findings: VPC - Preferences for Mother’s Face}

Research indicates a clear preference for the mother’s face soon after birth. Findings from these studies demonstrate newborns' preferences for a silent live display of their mother's face over that of an unfamiliar woman’s face (Field, et al., 1984; Pascalis, et al., 1995), even with hair color, hair length, and olfactory cues controlled (Bushnell, 2001; Bushnell, et al., 1989). Sai, 2005 assessed the role of experience with the mother's voice leading to preferences for her face by controlling newborns' exposure to their mother's voice after birth. Interestingly, exposure to the mother's synchronous face and voice following birth seems to be necessary in order for preferences for the mother's face to emerge. Furthermore, Burnham (1993) found that 1-month-old infants preferred their mothers' face over that of an unfamiliar woman's face only in the presence of a synchronous voice. Prenatal experience with the mother's voice seems to play an important role in young infant preferences for their mother's face over the face of an unfamiliar woman. These early experiences in the womb consist of hearing the mother's voice, feeling the vibration of her voice, and feeling her body movements, often all experienced in synchrony with the same temporal patterning (i.e., intersensory redundancy). Intersensory redundancy refers to the presence of the same information available across more than one sense modality and allows for perception of a unified event (Bahrick \& Lickliter, 2000, 2002). Following birth, the infant is able to match a visual image of the mother's face to the familiar event of the mother speaking and moving. As a result, the mother's face becomes very salient and meaningful to the 
newborn. Together these studies suggest that the presence of intersensory experiences early in development with the mother's face and her voice are salient and may contribute to young infants’ preferences for the mother’s face.

\section{Research Findings: VPC - Face Processing}

Evidence from the VPC method demonstrating preferences for face-like patterns over non face-like patterns suggests that even newborns perceive first-order relations of a face (Goren, et al., 1975; Johnson, et al., 1991; Johnson \& Morton, 1991; Mondloch, et al., 1999; Simion, Farroni, Macchi Cassia, Turati, \& Dalla Barbra, 2002). It has been shown that newborns even preferred face-like patterns with contours other than headshaped, such as square contours, over non face-like patterns (Simion, et al., 1998). Similarly, 3-month-old infants preferred to look at upright rather than inverted photographs of unfamiliar women’s faces (Turati, Valenza, Leo, \& Simion, 2005). Thompson, et al. (2001) found that 7-month-old infants preferred to look to a photograph of an unfamiliar woman's face with "normal” second-order relations rather than with manipulated spacing between the eyes and the nose and the mouth. The authors concluded that 7-month-old infants are capable of perceiving faces configurally. However, the authors did not directly test whether infants could perceive faces configurally but rather whether they could discriminate two faces that differed on secondorder relations. Taken together, findings derived from the VPC method suggest that faces are salient to young infants, synchrony between mothers' face and voice is important for preferences for the mother's face to emerge, and 7-month-old infants show evidence of discriminating two unfamiliar female faces on the basis of second-order relations. 


\section{Novelty Preference Procedure}

The novelty preference procedure (Fantz, 1964) is used to investigate infants' discrimination of two or more stimuli. This procedure, an extension of the VPC method, is similar to the habituation paradigm in that it relies on infants' preferences for novel stimuli. In the novelty preference procedure infants are familiarized with one stimulus for a fixed period of time. Following familiarization, infants are tested with the familiar stimulus side-by-side with a novel stimulus. The dependent measure is proportion of total looking time (PTLT) to the novel stimulus during the test trial as a function of their total looking time to both stimuli. This measure reflects infants' discrimination of the familiarized versus novel stimuli and a PTLT score significantly greater than chance (0.50) would indicate that infants discriminated and preferred the novel stimulus over the familiar stimulus. A PTLT score significantly less than chance (0.50) would indicate a familiarity preference, which could indicate incomplete processing or long term memory (see Bahrick, Hernandez-Reif, \& Pickens, 1997; Bahrick \& Pickens, 1995; Courage \& Howe, 1998; Rose, Melloy-Carminar, Gottfried, \& Bridger, 1982; Rose, et al., 2004).

The novelty preference procedure can also be used to assess infants' memory for a particular stimulus by introducing a delay between familiarization and test trials (see Bahrick, et al., 1997; Bahrick \& Pickens, 1995; Courage \& Howe, 1998; Pascalis \& de Haan, 2003). Bahrick \& Pickens (1995) demonstrated that infants’ preferences for novel versus familiar object motion shifted from a novelty preference after a short delay (1 minute) to a null preference after a moderate delay (1 day) to a familiarity preference following a longer delay (1 and 3 months). Their four-phase attention function suggests that more recent memory is reflected by novelty preferences (phase 1); null preferences 
may reflect a transition between novelty and familiarity preferences (phase 2); familiarity preferences reflect a remote memory (phase 3); and inaccessible memory is also demonstrated by null preferences (phase 4). Therefore, novelty, null, or familiarity preferences emerge as a function of the length of the delay. Courage \& Howe (1998) replicated this four-phase attention function finding that 3-month-old infants demonstrated novelty preference for nonsocial events that differed from the familiarized event on the dimensions of form, color, and motion following a delay of 1-minute and 1day. Null preferences were found after a delay of 1 -week, and familiarity preferences were found after a delay of 1-month and 3-months. These results suggest that expression of memory as demonstrated by novelty, null, or familiarity preferences varies as a function of memory accessibility. Research Findings: Novelty Preference Procedure - Face Recognition

The novelty preference method has been used to investigate infant visual recognition memory for a wide variety of objects and events, including faces. Three-dayold infants demonstrated novelty preferences after a 2-minute delay for a novel photograph of an adult woman's face following familiarization to a photograph of a different adult woman’s face (Pascalis \& de Schonen, 1994). Similarly, following 40 seconds of accumulated looking to a photograph of an adult woman's face, 7-month-old infants demonstrated novelty preferences to a novel photograph and to a novel caricature of a different adult woman's face (Tyrrell, Anderson, Clubb, \& Bradbury, 1987). These findings suggest even very young infants demonstrate recognition memory for photographs of faces in the novelty preference paradigm. 
Perception and recognition of faces in naturalistic social interactions occurs in the presence of dynamic moving, speaking faces. Social events are rarely perceived without facial movement and speech. However, most research investigating infant perception and recognition of faces use static photographs as stimuli. Although this research provides information regarding infants' perception and recognition of static silent faces, it does not provide an understanding of how infants' perceive and recognize faces in the real world. Bahrick, Gogate, \& Ruiz (2002) investigated 5-month-old infants’ novelty preferences for dynamic faces and actions. Following familiarization to a dynamic video of an adult woman performing a repetitive action (e.g., brushing her teeth), infants demonstrated significant preferences for a novel action but not for a novel woman's face. Significant preferences for a novel woman's face did not emerge until the movement was eliminated and the actions were presented as static images. In this study, infants' preferences for novel actions over novel dynamic faces suggest that infants were selectively attending to the movement of the actions over the facial configuration or facial identity of each woman. Infants' attention was then guided to the facial configuration when the action movements were eliminated. These findings reflect the salience of actions over faces for 5-month-olds and highlight the importance of using ecological stimuli.

Taken together, these findings suggest infants as young as 3 days old can discriminate between two photographs of unfamiliar adult female faces following familiarization. In comparison to the habituation and VPC methods, the novelty preference method can provide insight into how infant memory for faces changes as a function of exposure time and delay of test. Few studies have investigated novelty preferences for faces using dynamically speaking faces. However, 5-month-old infants 
demonstrate novelty preference for actions over dynamic faces suggesting the salience of movement and dynamic stimuli. As apparent in Table I, no research to date has used the same method to compare preschoolers' and toddlers' memory for faces with infants' memory for faces. The use of the novelty preference paradigm to assess face recognition skills across infants, toddlers, and preschoolers provides a basis from which to draw developmental predictions regarding how face expertise emerges from infancy through early childhood.

Memory for Other Events: Infancy versus Early Childhood

Other methods for investigating memory for stimuli other than faces that span across infancy and childhood include the mobile conjugate reinforcement paradigm (Rovee-Collier, 1997), deferred imitation (Collie \& Hayne, 1999), and elicited imitation (Meltzoff, 1990). These procedures have been used to investigate and understand infants' memory for contingency, action sequences, and specific events. Although these methods have typically not been used to investigate memory for faces, they could be used to investigate face recognition. For example, the mobile conjugate reinforcement paradigm (Rovee \& Rovee, 1969; Rovee-Collier, 1997) is typically used to investigate infant memory for particular aspects of a mobile, such as color or number of items that make up the mobile. A ribbon is tied from the mobile to the infants' leg following a training session. Infant leg kicking is then reinforced by movement of the mobile. This procedure could be modified where reinforcement of leg kicks could be the visual image of a face, and face recognition could be assessed following a delay or change of context. Implementing these methods in face recognition tasks could lead to converging results 
from different methodologies with regard to the development of face perception as well as how the retention of memory for faces changes from infancy to early childhood.

\section{Summary}

Habituation, visual paired comparison, and novelty preference procedures have been used to assess infants' preferences, discrimination, and processing of mostly static faces (i.e., photographs or schematic faces). The use of dynamic, more ecological stimuli will provide a better understanding of how infants perceive faces in their natural environment. Research suggests that infants learn to discriminate and process faces very early in postnatal development (Bahrick, et al., 2004; Pascalis \& de Schonen, 1994; Turati, et al., 2006). Infants demonstrate abilities to process faces on the basis of first(Goren, et al., 1975; Johnson, et al., 1991; Maurer \& Barrera, 1981; Simion, et al., 2002) and second-order relations (Bhatt, et al., 2005; Thompson, et al., 2001), as well as holistic information (Cohen \& Cashon, 2001; Schwarzer, et al., 2007). These findings, as demonstrated through habituation, VPC, and novelty preference procedures, suggest that the development of face expertise emerges rapidly across the first year of postnatal life.

Despite the similar questions that are addressed with these three popular methods of investigating infants' perception, discrimination, and memory for faces, little research has investigated how face expertise develops across infancy. The use of a common method is needed when investigating this question across multiple age groups in order to clearly understand the developmental trends that emerge as a result of increased social interactions and experiences. The current study used the novelty preference procedure to assess the developmental course of face recognition across three points in development: 5- to 6-month-old infants, 18- to 24-month-old toddlers, and 3.5- to 4-year-old children. 
In order to integrate infancy face recognition with older children's face recognition, this study provided an identical test for infants, toddlers, and preschoolers. 


\section{Chapter III - Childhood Face Perception}

\section{Methods Investigating Face Perception in Childhood}

Research investigating face perception and memory in childhood often uses quite different methodologies from that used in infancy research, typically involving photographs of faces, complex tasks, and linguistic components (see Chung \& Thomson, 1995). The following section will describe the methodologies that have typically been used to investigate face perception in children older than 18 months of age (including toddlers and preschoolers). These procedures consist of storybook or eyewitness line-up paradigms, in which children are asked about their recognition of faces (Brace, et al., 2001; Davies, 1993; Mondloch, et al., 2006). In the storybook procedure photographs of faces are typically presented to participants within the context of an interactive story, such as children going on a school trip. Participants are asked to help the experimenter finish the story by pointing out (e.g., with a "magic wand") familiar (target) faces. There are typically between 1-3 familiar (target) faces of children and between 2-8 distractor faces (Brace, et al., 2001; Newell, et al., 2007). The storybook procedure is well designed to keep the interest of young children. It investigates incidental learning of experimentally familiarized faces because children are not directly asked to remember the faces but rather point out familiar faces within the context of a story. Dependent measures include accuracy and reaction times during the test trials. In the eyewitness paradigms, children are asked to look at a set of several photographs for a fixed period of time, and then presented with forced-choice test trials in which the familiarized faces are presented side-by-side with novel distractor faces. Children are typically asked to point out the familiar faces and accuracy and reaction times are measured. 


\section{Storybook Format}

Using the storybook format, Newell, et al. (2007) found that 31/2- but not 3-yearold children demonstrated face recognition when familiarized to silent, dynamic adult female faces with hair hidden by a baseball cap worn backwards. The task was relatively difficult since cues such as hair color and length were not available to use for face recognition and the faces were presented for 4-seconds each during familiarization. These results contrast with infancy research which suggests that 3-month-old infants display face recognition for silent, dynamic faces (Bahrick, et al., 2007; Pascalis, et al., 1998). However, the task in Bahrick, et al. (2007) was much easier than that in Newell, et al. (2007) because infants were habituated to one face (average seconds to habituation = 205 seconds), whereas, children who participated in Newell, et al. (2007) had only 4 seconds of familiarization to each of the three faces followed by three consecutive 4second forced-choice tests.

Similar to the infant literature on face perception, research on perception of faces in childhood has assessed the strategies used in processing faces (i.e., perception of firstand second-order relations, featural processing, configural processing, and holistic processing). Mondloch, et al. (2006) found that 4-year-old children accurately discriminated target faces (e.g., one photograph of an unfamiliar boy and one photograph of an unfamiliar girl were familiarized as the target faces within a storybook format) from distractor faces when the faces differed in the shape of the external contour (i.e., hair, ears, and chin) but not when the faces differed in the spacing of internal features. The participants in this experiment were exposed to the target faces at least 10 times over the course of 2 weeks. The authors concluded that children at this age did not show evidence 
of processing faces on the basis of second-order relations. In contrast, McKone \& Boyer (2006) found that 4-year-old children were equally sensitive to changes of features and spacing between features in photographs of children's faces following 30 minutes of testing. The authors concluded that children of this age can process faces on the basis of second-order relations. Conversely, Mondloch, et al. (2006) did not find evidence of processing faces on the basis of second-order relations. One possible explanation for these inconsistent results could be the degree of manipulation to the spacing between features (i.e., task difficulty). For example, it was suggested that, in the study conducted by Mondloch, et al. (2006), 4-year-old children showed differential recognition to the target face based on featural information rather than second-order relations because the featural changes were larger in degree than the changes in the second-order relations. These discrepant findings highlight the need for consistent manipulations of task difficulty within face perception research.

With regards to holistic processing, 4- to 6-year-old children demonstrate evidence of holistic rather than featural processing of faces (de Heering, Houthuys, \& Rossion, 2007; Pellicano \& Rhodes, 2003; Pellicano, Rhodes, \& Peters, 2006). Brace, et al. (2001) found that children between the ages of 2 and 4 years did not demonstrate face recognition for photographs of two boy's faces following familiarization with three photographs of the target faces within a storybook format. They also found a few children who showed face recognition demonstrated faster reaction times to inverted faces than to upright faces. The authors attributed the faster reaction times to inverted than upright faces as an indicator of immature face processing (e.g., perceiving faces on the basis of first-order relations rather than second-order relations or configural processing). 
Taken together, some researchers suggest that 2- to 4-year-old children do not process faces on the basis of second-order relations (Brace, et al., 2001; Mondloch, et al., 2006). In contrast, the infancy research shows evidence that 5-month-old infants process faces on the basis of second-order relations (Bhatt, et al., 2005). Again, methodological differences exist for infant versus child research on face perception and recognition. As these studies used different methods, types of stimuli, and varying degrees of manipulation of the stimuli, it is evident there is a need to control for methods and manipulations of stimuli (i.e., task difficulty) within one study in order to draw appropriate conclusions regarding face processing abilities in infants and children.

In contrast to the infancy literature which suggests that infants demonstrate more advanced processing of faces, such as processing based on second-order relations (Bhatt, et al., 2005; Thompson, et al., 2001) and prototype formation (de Haan, et al., 2001; Walton \& Bower, 1993), research with children suggests that they have poor face recognition skills (Brace, et al., 2001; Mondloch, et al., 2006). Brace, et al. (2001) concluded that some children between the ages of 2 and 4 years used featural rather than configural processing of faces based on their failure to show the inversion effect and faster response times to recognize inverted faces over upright faces within a storybook format. In contrast, research suggests that 5- and 7-month-old infants demonstrate the inversion effect, with impaired discrimination of inverted faces but not upright faces (Bhatt, et al., 2005; Cohen \& Cashon, 2001). The inversion effect has been considered evidence of the development of face expertise. Furthermore, 2- to 3-year old children failed to recognize photographs of caregivers with whom they had considerable interactions following a 3-month retention interval (Cain, Baker-Ward, \& Eaton, 2005). 
Evidence of advanced face perception in infancy and poor face recognition skills in early childhood may be due to greater attention to faces in infancy than in early childhood. Alternatively, it may be due to more flexible processing skills in early childhood and the ability to fluidly switch between immature processing skills and advanced processing skills depending on the task demands. It is also likely that these inconsistent developmental patterns of face perception can be attributed to different methodologies used to ask similar questions.

\section{Eyewitness Format}

Within the legal system, young children are often asked to identify criminals from a lineup. As a result, children's memory for faces plays an important role in some criminal cases. Eyewitness formats typically present children with a set of photographs of unfamiliar adults, with an exposure time anywhere between $5-20$ seconds, and test with a series of forced-choice tests in which the familiarized faces and novel distractor faces are intermixed (Davies, 1993). Typically there is a delay (e.g., 5 - 20 minutes) between familiarization and test. Research suggests that memory for faces approaches adult like levels around 6 years of age. However, this procedure does not easily lend itself to testing toddlers or preschoolers (see Davies, 1993 for review). Children younger than 6 years often display poor face recognition skills within eyewitness formats following delays ranging between 1- to 2-weeks (see Goodman, Rudy, Bottoms, \& Aman, 1990; Parker \& Myers, 2001; Rudy \& Goodman, 1991). Since use of this procedure with younger children is impractical, it remains difficult to draw conclusions from this task regarding the development of face expertise. 
Research investigating the processing and memory of faces in young children most often ask children to point out the "target” face, whereas, infancy research obviously does not incorporate the use of language. As stated above, different methods and task difficulty (e.g., increased memory load for children compared to infants) present confounds in identifying developmental change in face expertise. Some of the infancy literature suggests that young infants process faces on the basis of advanced strategies, whereas some of the child literature suggests that preschool-aged children process faces on the basis of immature strategies. These conclusions are difficult to reconcile because the two fields of research use different methods.

\section{Physiological Measures}

Several studies have investigated young children's responses and recognition of faces using physiological measurements, such as neurological responses. Despite the vast research which suggests that infants prefer to look at their mothers' face over that of an unfamiliar woman's face, few studies have investigated if this preference continues throughout early childhood. Carver, Dawson, Panagiotides, Meltzoff, McPartland, Gray, \& Munson (2003) found that 18- to 24-month-old children demonstrated significantly larger neurological responses (i.e., event related potentials or ERPs) to photographs of their mother than to photographs of an unfamiliar woman. Conversely, 31/2- to 4-year-old children demonstrated significantly larger neurological responses to an unfamiliar woman than to their mothers. The authors suggest the results reflect a developmental shift in that the younger children were still in the process of developing expertise with their mothers' face, and the older children were more interested in processing the faces of others. 
Research suggests that physiological measures of face perception and recognition may provide insight into these skills that cannot be addressed with traditional methods. For example, Stormark (2004) found that preschoolers demonstrated a significant decrease in heart rate while viewing photographs of former playmates, even though their verbal responses indicated they did not show significant recognition of these faces. A deceleration in heart rate has been linked to engagement of attention (Richards \& Casey, 1991). Therefore, these results were attributed to implicit memory in young children that appears to be independent of their verbal memory. The Stormark study has important implications considering the use of the storybook and eyewitness formats and the importance of children's verbal responses in these tasks. If children's verbal memory differs from physiological measures regarding memory and attention, more research is needed to ensure that these types of tasks are accurately measuring what they intend to measure.

Investigating physiological measures of children's perception of first-order relations, Henderson, McCulloch, \& Herbert (2003) presented 4- to 10-year-old children with schematic upright, inverted, and scrambled faces. Event related potentials (ERPs) were measured as a response to each stimulus. The authors did not find any differential responses to the upright or inverted faces in the 4-year-old children. However, the older children had increased responses to the inverted faces than to the upright faces. These findings were attributed to developmental changes in configural processing that appear to occur between 4 and 10 years of age. Since the inversion effect (i.e., poor face recognition with inverted faces as opposed to upright faces) is considered evidence of configural rather than featural processing and 4-year-olds did not demonstrate ERP 
responses indicating the inversion effect, the authors concluded that 4-year-olds processed the faces on the basis of featural information rather than configuration (i.e., indicating immature face processing). No evidence of the inversion effect in 4-year-old children is inconsistent with the findings that 5- and 7-month-old infants demonstrate the inversion effect (Bhatt, et al., 2005; Cohen \& Cashon, 2001). Similarly, other evidence suggests that 4-year-old children can process the second-order relations of a face (McKone \& Boyer, 2006). Evidence of the inversion effect in infants but not older children may be attributed to different methods used when testing children versus infants, including less exposure time to stimuli, increased memory load, and language used during the procedures. The lack of integration between infancy and older children's face perception highlight the need for a single study to control for method, exposure time, and memory load.

\section{Summary: Infant versus Child Face Recognition Tasks}

As demonstrated in Table I, there are several contradictory results between the child face recognition research and infancy face recognition research. For example, processing faces on the basis of second-order relations has been demonstrated by 7month-old infants (Thompson, et al., 2001) but not by 4-year-old children (Mondloch, et al., 2006). As a result, it is difficult to determine how face expertise develops from infancy to early childhood. These differences can most likely be attributed to varying methods and task difficulty or the advanced ability in older children to flexibly switch between types of face processing within a particular task. Task difficulty and flexible processing strategies are not directly addressed in much of the research investigating infant and early childhood face perception. Many aspects of task difficulty can be 
manipulated to increase or decrease the difficulty of the task. Similarly, evidence of switching processing styles within one task would provide information regarding the flexibility of young children's selective attention and processing skills. To better understand how face expertise develops, a consistent method is needed in which there is careful control of important variables that might affect face recognition including memory load, exposure time, and stimulus modality.

\section{Variables Addressed by Current Study}

The proposed study will directly address three specific variables which influence task difficulty: memory load, exposure time, and stimulus modality. Memory load refers to the number of faces infants or children are required to retain in their working memory before they are asked to demonstrate face recognition. Memory load in the tasks for young children is often greater than in tasks for infants. For example, children who participated in Newell, et al., (2007) were required to remember three target faces during familiarization and tested with three novel faces, resulting in a more difficult task than the task presented in Bahrick, et al. (2007), in which infants were habituated to one face and tested with one novel face. The current study assessed the role of two levels of memory load (i.e., low memory load $=1$ familiarized face; high memory load $=3$ familiarized faces) for infants, toddlers, and preschool-aged children.

Exposure time refers to the amount of time infants or children are allowed to become familiarized to a particular face(s). The exposure time also differs drastically across infancy and preschool face perception research. For example, research investigating face perception in infancy often provides substantial familiarization or even habituation to a particular face (see Blass \& Camp, 2004; Cohen, et al., 1977; Turati, et 
al., 2006). On the other hand, research investigating face perception in preschool-aged children often provides brief familiarization to many faces (see Brace, et al., 2001; Mondloch, et al., 2006). The current study controlled for and equated the exposure time for infants, toddlers, and preschool-aged children by presenting each age group with 10second familiarization and test trials.

Stimulus modality refers to the presentation of dynamic stimuli with synchronous speech (i.e., bimodal audiovisual) and without synchronous speech (i.e., unimodal visual). The use of dynamically speaking faces rather than static photographs of faces is a third variable that is often overlooked in research investigating infant and preschoolers' perception of faces. Research suggests that dynamic displays capture and maintain infants' attention longer than static displays (Bahrick, Sorondo, Castellanos, Todd, Argumosa, \& Vaillant-Molina, 2008; Haith, Bergman, \& Moore, 1977; Shaddy \& Colombo, 2004). Much of the research on face perception and recognition uses static photographs of faces, but this does not provide information regarding how infants and children perceive faces in real world dynamic, multimodal settings. A dynamic display of a face provides for more opportunities to observe the face in varying poses, angles, and expressions. Dynamic faces facilitate detection of invariants (e.g., facial configuration) that remain constant across transformations and contexts and therefore facilitate perception and recognition of the face (Gibson, 1969). Controlling for facial movement and presenting faces in the presence of synchronous speech is essential when assessing how infants, toddlers, and preschoolers develop face expertise in the real world. The current study presented both dynamic multimodal and dynamic silent displays of faces to infants, toddlers, and preschoolers. 


\section{Chapter IV - Bridging the Gap}

Intersensory Redundancy Hypothesis

The Intersensory Redundancy Hypothesis (IRH; Bahrick \& Lickliter, 2000, 2002)

is a framework describing how selective attention is allocated to properties of events (i.e., amodal versus modality specific properties) under different conditions (i.e., multimodal redundant versus unimodal nonredundant). Amodal properties refer to information that can be perceived through more than one sense modality. For example, rhythm or tempo can be perceived in both auditory and visual stimulation. Modality specific properties refer to information that can be perceived through only one sense modality. For example, color or facial configuration can only be perceived through visual stimulation.

Intersensory redundancy is the presence of temporally aligned amodal information available to multiple senses simultaneously. For example, the speech sounds from a person talking are synchronized with their mouth movements. The redundancy between the speech sounds and the mouth movements allows the amodal properties (e.g., rhythm and tempo of speech) to "pop out" and the event to be perceived as unified (e.g., a speaking person) rather than two separate events (e.g., a moving person and speech sounds).

The IRH provides a developmental perspective of attentional salience, which can not only be applied to infant development but across the lifespan. According to the IRH, amodal properties are better perceived in multimodal redundant stimulation than the same information presented in unimodal nonredundant stimulation. This prediction has been referred to as intersensory facilitation. Much research has supported the concept of intersensory facilitation (Bahrick, Flom, \& Lickliter, 2002; Bahrick \& Lickliter, 2000; 
Bahrick \& Lickliter, 2002; Flom \& Bahrick, 2007). For example, three-month-old infants discriminated changes in the tempo of a toy hammer following multimodal redundant habituation (i.e., bimodal synchronous display) but not unimodal nonredundant habituation (i.e., silent, dynamic, visual only display; Bahrick, et al., 2002).

The IRH also predicts that modality specific properties are better perceived in unimodal nonredundant stimulation than the same information presented in multimodal redundant stimulation because redundancy present in multimodal stimulation allows for amodal properties to compete for attention at the expense of modality specific properties. This has been referred to as unimodal facilitation. Research has supported this prediction by demonstrating that two-month-old infants discriminated dynamic displays of two unfamiliar women's faces following unimodal nonredundant (i.e., unimodal visual) and multimodal nonredundant (i.e., bimodal asynchronous display in which the auditory and visual information were temporally misaligned thus eliminating audiovisual redundancy) habituation but not multimodal redundant habituation (i.e., bimodal synchronous) (Vaillant-Molina et al., 2006).

Greater perceptual differentiation, as a result of increased experience and efficiency of processing, should lead to perception of both amodal and modality specific properties in both multimodal redundant and unimodal nonredundant stimulation. Infant research has supported this prediction in several studies. For example, 5-month-old infants discriminated changes in the tempo of a toy hammer following both multimodal redundant and unimodal nonredundant habituation (Bahrick \& Lickliter, 2004). Similarly, 3-month-old infants discriminated dynamic displays of two unfamiliar women’s faces following both multimodal redundant and unimodal nonredundant habituation (Bahrick, 
et al., 2004). Thus, in early development, dynamic faces are better perceived when presented without a synchronous voice. However, with development, the same faces are perceived in both multimodal redundant and unimodal nonredundant stimulation (Bahrick, et al., 2004).

Another important prediction of the IRH addresses the role of task difficulty. As stated earlier, more experienced perceivers detect modality specific information in both multimodal redundant and unimodal nonredundant stimulation. However, if an experienced perceiver is presented with a difficult task, unimodal facilitation should then be apparent and, similar to young infants, perception of modality specific properties should then be better in unimodal nonredundant stimulation than in multimodal redundant stimulation. This has been supported in a study assessing 5-month-old infants' perception of tempo (Bahrick, Lickliter, Castellanos, \& Vaillant-Molina, 2010). Therefore, the IRH predicts that unimodal facilitation for face perception based on modality specific information for facial configuration should be a function of task difficulty. In other words, for more skilled perceivers, if a face perception task is difficult (e.g., high cognitive load or short exposure time) unimodal nonredundant stimulation should enhance face perception as compared to the same face perception task presented in multimodal redundant stimulation.

According to the IRH, selective attention is allocated to salient properties of events depending on how those events are experienced (i.e., multimodal redundant versus unimodal nonredundant). Greater attention to the salient properties of an event leads to greater processing and in turn better memory for those properties. This has been supported in a study assessing infants' memory for a modality specific property (i.e., 
visual orientation of a toy hammer; Flom \& Bahrick, 2010). Three-month-old infants demonstrated memory for the orientation (i.e., upward versus downward) of a toy hammer following unimodal visual habituation but not following multimodal redundant habituation. In contrast, five-month-old infants demonstrated memory for the orientation of the toy hammer following both unimodal and multimodal habituation.

The current study assessed infants', toddlers', and preschoolers' memory for faces in multimodal redundant and unimodal nonredundant stimulation. Because unimodal stimulation recruits attention to modality specific properties such as facial configuration and more attention results in increased processing and better memory, it is predicted that memory for faces should be enhanced in unimodal nonredundant stimulation as compared with multimodal redundant stimulation. For the purposes of the current study, multimodal redundant stimulation will be referred to as bimodal synchronous and unimodal nonredundant stimulation will be referred to as unimodal visual.

\section{The IRH and Face Perception}

With respect to face perception, the IRH provides insight into what infants or children may be attending while observing a moving/speaking face. Bahrick, et al. (2004) and Vaillant-Molina et al. (2006) tested predictions of the IRH by investigating young infants' face discrimination under three conditions: unimodal visual; bimodal asynchronous; and bimodal synchronous. Consistent with the predictions of the IRH, Bahrick, et al. (2004) and Vaillant-Molina, et al. (2006) found that 2-month-old infants discriminated between two unfamiliar adult female faces in a unimodal visual condition and a bimodal asynchronous condition, but they did not discriminate the faces in a bimodal synchronous condition. The bimodal asynchronous condition was of particular 
interest because it assessed the interfering effect of redundancy for perceiving faces in early development. Asynchronous faces and voices do not provide the opportunity for salient amodal properties to "pop out.” Therefore, infants could attend to less salient modality specific properties including facial configuration and subsequently discriminate the two faces from each other. In contrast, older infants (i.e., 3-month-olds) discriminated the two unfamiliar adult female faces in both bimodal synchronous and unimodal visual conditions. Therefore, face perception is enhanced in early development in unimodal nonredundant stimulation and is later extended to multimodal redundant stimulation.

Taken together with the literature reviewed and as seen in Table I, the IRH provides insight into what aspects of faces infants and young children attend and perceive. In early development, unimodal facilitation contributes to face processing and recognition because amodal properties are not competing for attention and selective attention can focus on the modality specific properties of the face (e.g., facial configuration). On the other hand, intersensory facilitation results in attentional competition from salient amodal properties and less attention to the modality specific properties of faces. Increased task difficulty (i.e., greater memory load and shorter exposure time) can lead to unimodal facilitation of modality specific properties in older, more experienced perceivers. The current infant and child face perception literature does not address the issues of modality of stimulation with respect to face perception and recognition (see Table I). These differences may contribute to the lack of integration across studies and developmental perspectives on face perception and recognition. 


\section{The IRH and Ecological Stimuli}

Face expertise emerges as a result of everyday experience in social settings. This requires discrimination and memory for many faces including family members, friends of the family, peers, and teachers. These faces are most often perceived in multimodal experiences including audiovisual speech. As illustrated in Table I, research investigating infant and child perception of faces has typically investigated perception of photos of faces rather than more ecological dynamic face events (e.g., Barrera \& Maurer, 1981; Brace, et al., 2001; Cohen \& Cashon, 2001; Cohen, et al., 1977; Mondloch, et al., 2006; Pascalis, et al., 1998; Schwarzer, et al., 2007; Slater \& Quinn, 2001; Turati, et al., 2006). Recent research has used stimuli that are either live or video presentations of dynamic faces with and without audiovisual speech (e.g., Bahrick, et al., 2004; Bahrick, et al., 2007; Blass \& Camp, 2004; Bushnell, 2001; Sai, 2005; Vaillant-Molina, et al., 2006).

Consistent with predictions of the IRH, Bahrick, Hernandez-Reif, \& Flom (2005) found that 4- and 6-month-olds, but not 2-month-olds, detected the relationship between specific faces and voices following a bimodal synchronous habituation. It was suggested that 2-month-old infants did not detect the relationship between the faces and voices because amodal properties competed for attention at the expense of modality specific properties (i.e., facial configuration or pitch/timbre of the voice). A follow up study revealed that 2-month-old infants discriminated the two unfamiliar adult faces from each other following a unimodal visual habituation, and they also discriminated the two unfamiliar adult voices from each other following a unimodal auditory habituation (i.e., static face presented with audible speech). This study provides further evidence of the importance of using more ecological stimuli in investigating how infants perceive and 
remember faces. Relatively little research has investigated infant memory for multimodal, dynamic faces (but see Bahrick, et al., 2007). The use of more ecological stimuli will provide a better understanding of how infants and young children discriminate among different faces, what processing styles are used for faces in everyday experiences, and how face recognition develops within the natural environment.

\section{Is Face Recognition Better in Infancy than Early Childhood? Alternative Hypotheses}

Research suggests that infants demonstrate advanced face processing skills, such as perception of faces on the basis of configural and holistic information (Bhatt, et al., 2005; Cohen \& Cashon, 2001; Schwarzer, et al., 2007; Thompson, et al., 2001). However, research also suggests that preschoolers demonstrate immature face recognition skills, such as perception of faces on the basis of featural information (Henderson, McCulloch, \& Herbert, 2003). Given the role of experience in face perception, it is unlikely that infants perceive, process, and recognize faces better than preschoolers. The literature reviewed in the previous sections of this paper suggests that different methodologies and lack of standardized experimental controls contribute to a lack of integration from infancy to early childhood. There may be alternative hypotheses for these findings.

The developmental periods of infancy and early childhood are focused around different events. Infants typically focus on discovery of the self and participation in faceto-face interactions especially with their caregiver (Rochat, 2001; Striano \& Rochat, 1999). In contrast, preschoolers typically attend to other domains such as literacy, development of relationships, and symbolic play (Che \& Siegler, 2000; Piaget, 1962; Striano, Tomasello, \& Rochat, 2001). Infancy is a period of rapid developmental change 
including the development of the infants' social world (Rochat, 2001). The socialization of infants involves highly salient face-to-face interactions with an emphasis on eye contact, vocalizations, and coordinated give-and-take social interchanges (Bigelow, 2001; Hains \& Muir, 1996; Reddy, Hay, Murray, \& Trevarthen, 1997; Rochat, 2001; Striano, Henning, \& Stahl, 2006, Striano \& Stahl, 2005; Trevarthen, 2002). Prosody of speech is highly salient for young infants garnering attention, modulating arousal, and facilitating segmentation and word learning (Fernald, 1989; Soderstrom, 2007; Soderstrom, Seidl, Nelson, \& Jusczyk, 2003). As a result, infants may attend more frequently and show more interest in faces and their appearance than older children.

Children between the ages of 18-24 months are generally focused on developing expertise in language production and comprehension. Attention to language production and comprehension may be at the expense of attending to facial configuration and identity in face-to-face interactions. Consequently, this age group may demonstrate poorer performance on face recognition tasks as a result of their focused attention on other stimuli. Thus older children's poor performance on face recognition tasks as compared with infants may be a result of different selective attention patterns.

Another possibility for why differences exist between findings of face processing in infancy versus early childhood is that older children may be able to easily and fluidly modify the type of strategies they use to process faces. As mentioned earlier, featural processing of faces is considered an immature method or strategy, whereas, configural or holistic processing is considered a more advanced strategy (Carey \& Diamond, 1977; Diamond \& Carey, 1986). Older children have more experience than infants with all of these strategies. Research suggests that toddlers and preschoolers have more flexible 
processing abilities and can switch between strategies not only across different periods of exploration but even within one bout of exploration (Che \& Siegler, 2000). Therefore, they may switch between featural and configural processing even within the same event. Infants have less flexible processing strategies and may depend on one particular strategy for face perception. Thus there are at least two alternative hypotheses (focused attention versus strategy flexibility) that may explain the different findings of face perception in infancy to early childhood.

\section{Current Study: Bridging the Gap}

Reviewing the face perception and recognition literature leads to several conclusions (see Table I). Infants quickly develop face perception skills in the first year of life. Little research has investigated face perception skills for children between the ages of 18- to 24-months of age. Preschoolers demonstrate advanced face recognition skills in unimodal visual, nonredundant presentations. Intersensory processing most likely plays an important role in the perception and recognition of faces in that unimodal visual stimulation facilitates face perception in early development. Research guided by the IRH provides a developmental perspective regarding how infant face perception and recognition skills lead to the development of face expertise. According to the predictions of the IRH, a developmental framework for face perception and recognition that takes into account redundancy should be a priority for researchers. The IRH provides a new developmental and more comprehensive approach to the study of face expertise, in that it addresses the importance of type of task, cognitive load, and stimulus modality (i.e., redundant versus nonredundant) for face discrimination and memory. These variables have typically been ignored in the infancy and early childhood face perception literature. 
It is also important to include more ecological stimuli (i.e., films of dynamic faces presented with speech) in order to generalize research findings to the natural environment.

The current study tested the predictions from the IRH and extended them to development of face recognition from infancy to early childhood. It assessed infants', toddlers', and preschoolers' recognition of faces following familiarization in a novelty preference paradigm in bimodal synchronous and unimodal visual stimulation. The current study equated type of task (novelty preference paradigm), exposure time (length of familiarization to target faces), and stimulus modality (bimodal synchronous versus unimodal visual) across all age groups. The present study also assessed the role of memory load (low versus high) on infants', toddlers', and preschoolers' recognition of faces by manipulating the number of target faces presented during familiarization within participants.

Novelty Preference Paradigm: Validity of Using Same Method with Infants \& Children

The visual paired comparison (VPC) method or novelty preference procedure will be used in the current study. It has been used to assess visual preferences for one stimulus over another and to reveal infant discrimination and memory for one stimulus over another. The VPC paradigm has also been used with 14- to 18-month-old children to assess their learning and memory in domains other than face perception (Cleveland \& Striano, 2008). There are three major advantages to using this type of task to investigate the development of face recognition from infancy to early childhood. First, this procedure measures nonverbal behavior (i.e., looking time), so infant lack of verbal communication is not a limitation. Many procedures, such as the storybook format or eyewitness lineups, 
used with older children rely on language comprehension in order to assess face recognition. These obviously cannot be used in studies investigating face recognition in nonverbal infants. The novelty preference procedure eliminates this problem and allows for the same procedure to be used across development. Second, differences in motor skills do not influence the results of this procedure. Some tasks require children to have more advanced cognitive and motor skills (e.g., deferred imitation), however, the novelty preference procedure requires only looking behavior, a skill that is well developed in infants. As a result, this procedure can be used from infancy to early childhood. Finally, a version of the VPC procedure has been successfully used in comparative developmental research with nonhuman primates and rats (Ennaceur \& Delacour, 1988; Gunderson \& Swartz, 1986). For example, novelty preferences for patterns have been found in 4-weekold pigtail macaques following a delay of 30 seconds (Gunderson \& Sackett, 1984). Interestingly, older monkeys demonstrated novelty preferences with less familiarization time than younger monkeys, a similar pattern found with human infants (Gunderson \& Swartz, 1986; Rose, 1983). The use of this task in comparative research makes important contributions to our understanding of development and memory. It allows for a systemic approach to understanding how recognition develops across age and what brain structures are responsible for performance on the VPC tasks.

Similarly, the VPC task has been used to assess memory in adults with brain damage (McKee \& Squire, 1993). Findings suggest that adults with brain damage demonstrate novelty preferences after short delays but are impaired relative to controls after longer delays. In general, adults have demonstrated patterns of looking to familiar versus novel events similar to those observed in infancy, in which they first look briefly 
to the familiar stimulus and then look longer to the novel stimulus. This has even been observed within one test trial (Manns, Stark, \& Squire, 2000). The fact that the VPC task can be used with populations ranging from infancy to adults provides a unique opportunity to reliably assess age-related changes in face recognition skills. Measures and Hypothesized Results

Proportion of total looking time (PTLT) to the novel face served as the dependent measure and was calculated by dividing the total looking time to the novel face by the total looking time to both the novel and familiar faces. Using SPSS version 17, single sample $t$ tests were used to statistically compare the PTLTs to a chance value of $50 \%$. It was predicted that if children sufficiently processed the faces during familiarization, then they would demonstrate significant visual preferences for the novel faces during test trials. Since the unimodal visual modality facilitates detection of modality specific properties, this stimulus modality condition was considered easier than the bimodal synchronous modality condition, in which redundancy provided competition for attention to amodal properties at the expense of modality specific properties. The low memory load was also considered easier than the high memory load condition since children were required to remember one face rather than three faces prior to testing. Predicted results are depicted in Figure IV. It was predicted that infants would demonstrate a significant PTLT (against chance) to the novel faces in the unimodal visual modality condition with the low memory load but not in the unimodal high memory load or bimodal, low or high memory load conditions.

Since toddlers have more experience than infants perceiving and recognizing faces but little research has been conducted with this age group, it was predicted that they 
would demonstrate significant PTLT (against chance) to the novel faces in the unimodal visual modality condition with low and high memory loads and in the bimodal synchronous modality condition with the low memory load but not in the bimodal synchronous modality condition with the high memory load. It was expected that redundancy in the bimodal synchronous modality condition coupled with a high memory load would recruit attention to the amodal properties at the expense of the modality specific properties (i.e., facial configuration) and would result in no evidence of face recognition.

Since preschoolers have more flexible attention and more efficient processing of faces than younger children, it was predicted that preschoolers would demonstrate a significant PTLT (against chance) to the novel faces in the unimodal visual modality condition with the low and high memory loads and in the bimodal synchronous modality condition with the low memory load but not in the bimodal synchronous modality condition with the high memory load. Bimodal synchronous stimulation with a high memory load was predicted to be the most difficult task within this procedure.

As indicated in Table I, some research suggests that older children demonstrate immature face processing skills, whereas other research suggests that younger children demonstrate advanced face processing skills. Despite the lack of integration of findings between these age groups, it is assumed that face recognition improves with age as a result of increased experience perceiving faces and increased processing efficiency. However, no single study to date has demonstrated a developmental improvement in face recognition from infancy to early childhood holding constant the methodology, exposure time, stimulus modality, and memory load. Under these conditions, the present study 
predicted a main effect of age in which older children would demonstrate better face recognition than younger children (see Figure IV).

According to the predictions of the IRH, bimodal synchronous stimulation recruits attention to amodal properties at the expense of modality specific properties. The lack of redundancy in unimodal visual stimulation eliminates attentional competition of amodal properties and allows attention to be directed to modality specific properties. Thus, a main effect of stimulus modality condition was predicted in which children in the unimodal visual modality condition would demonstrate better face recognition than children in the bimodal synchronous modality condition.

Since the low memory load required children to remember one face prior to testing and the high memory load required children to remember three faces prior to testing, a main effect of memory load was predicted in which all groups would demonstrate better face recognition with the low memory load as compared to the high memory load.

According to the IRH, more efficient processers should demonstrate increased attentional flexibility and detect modality specific properties in both redundant and nonredundant stimulation. Thus, an interaction was predicted between age and stimulus modality in which older children would demonstrate better face recognition than younger children in the bimodal synchronous but not in the unimodal visual modality condition because all children should demonstrate memory in the unimodal visual modality condition.

Since processing efficiency improves with age, an interaction was predicted between age and memory load in which older children would demonstrate better face 
recognition than younger children in the high memory load but not in the low memory load condition because children of all ages should demonstrate memory with the low memory load condition. An age and memory load interaction was predicted because younger children were expected to have more difficulty processing and remembering three familiarized faces for 10 seconds each across three sequential test trials, whereas, older children have had more experience perceiving and remembering faces.

It was also predicted that stimulus modality and memory load would both influence task difficulty. Thus, an interaction between stimulus modality and memory load was predicted in which children in the unimodal visual modality condition would demonstrate better face recognition than children in the bimodal synchronous modality condition with the high memory load but not with the low memory load because face recognition was expected to be enhanced in the unimodal visual modality and the low memory load conditions.

Since older children were expected to demonstrate better face recognition than younger children, the unimodal visual modality condition was expected to enhance face recognition as compared to the bimodal synchronous modality condition, and the low memory load was expected to enhance face recognition as compared to the high memory load, a three-way interaction was predicted for age x stimulus modality x memory load. Older children should demonstrate better face recognition than younger children in the unimodal visual modality condition with the high memory load but not with the low memory load. Older children were also predicted to demonstrate better face recognition than younger children in the bimodal synchronous modality condition with the low 
memory load but not with a high memory load. These predictions are summarized in Figure IV.

A secondary measure of overall relative interest in the faces and fatigue, proportion of available looking time (PALT), was calculated by dividing the total looking time to both the novel and familiar faces by the total presentation time for both faces. Secondary analyses were conducted investigating lateral positioning of the novel faces during the test trials as well as the order of presentation of the low versus high memory load blocks. No significant differences were expected from these analyses. 


\section{Chapter V - Current Study}

Introduction

The present study is the first to investigate infants', toddlers', and preschoolers' face recognition skills holding constant type of task, exposure time, stimulus modality and memory load. The goals of the current study were to assess the developmental improvement in face recognition from infancy to early childhood and investigate the roles of stimulus modality and memory load on face recognition across age.

Methods

Participants

Thirty-two healthy 5- to 6-month-old infants, thirty-two healthy 18- to 24-monthold toddlers, and thirty-two healthy 3.5- to 4-year-old preschoolers participated in the current study. All participants were recruited through birth records from the Miami-Dade County Health Department. Inclusion criteria for all participants consisted of birth weight equal to or greater than five pounds, gestational age at birth of 38 weeks or greater, APGAR scores of 9 or above, and no complications during the prenatal period or delivery. Parents were contacted by phone to inform them of the study and ask for their participation. Parents with unlisted phone numbers were sent a recruitment letter informing them of the study.

All participating parents filled out an IRB-approved consent form and a background questionnaire, which asked basic demographic and family structure information, such as ethnicity of the parents and child, number of siblings the participating child has, number of days before or after the due date the child was born, and the primary language spoken in the home. Participating children received a certificate 
of appreciation from Florida International University, a small toy, and \$10 in compensation for their participation.

Stimuli

Stimuli consisted of videos of twenty-four women filmed from the shoulders up wearing a black t-shirt and a black baseball cap worn backwards, in order to disguise hair styles. All women were Caucasian with varying hair and eye color. Each actress was filmed reciting the nursery rhyme, "Hickory Dickory Dock. The mouse ran up the clock. The clock struck one, the mouse ran down.” The actresses were filmed against a light blue background, and head sizes were approximately equal. For the unimodal visual condition, the dynamic videos were presented without sound. For the bimodal synchronous condition, the dynamic videos were presented with synchronous audiovisual speech.

The stimuli chosen for the current study were selected from a larger database of faces and voices. Because task difficulty is an important variable to control and similar looking faces would result in a more difficult task, it was necessary to get a subset of faces rated by adult judges for discriminability. From this larger set, thirty pairs of faces and voices were rated by adult judges for discriminability using a 5-point Likert scale, with 1 = very discriminable, $2=$ somewhat discriminable, $3=$ neutral, $4=$ somewhat similar, and 5 = very similar. Discriminability was defined as "how easy or difficult it is to tell these two faces from each other?” Results suggest that all pairs of faces were rated between very discriminable and somewhat similar (range $=1.0-4.3$ ). In order to control the discriminability of pairs of faces in the current study, two sets of six equally discriminable pairs of faces (24 total faces) were selected that had mean discriminability 
ratings between very discriminable and somewhat discriminable. Set A had a mean discriminability rating of $1.29(\mathrm{SD}=0.27)$ and set $\mathrm{B}$ had a mean discriminability rating of $1.36(\mathrm{SD}=0.22)$. The pairing of each set of faces and memory load was counterbalanced across participants. Each participant received all possible faces across the low and high memory load conditions. In other words, a quarter of the participants received set A with low memory load followed by set B with high memory load, and a quarter of the participants received set B with low memory load followed by set A with high memory load. Similarly, a quarter of the participants received set A with high memory load followed by set B with low memory load, and a quarter of the participants received set B with a high memory load followed by set A with a low memory load. Apparatus

The stimuli for the current study were filmed with a Panasonic (WV 3170) video camera and a Sony (EMC 150T) microphone. The films were edited using Adobe Premiere 1.5 and were presented with a Panasonic (VHS NV-A500) editing controller connected to four Panasonic video decks (AG-6300 and AG-7500). The video decks were connected to two 19-inch (48-cm) television screens (Sony KV-20M10). Each participant sat approximately 55 centimeters away from the television screens. The television screens were surrounded by black cloth with small peepholes through which observers recorded looking time. Participants’ peripheral vision was blocked with two partitions on each side of the televisions covered in black cloth. Peepholes were available for the parents to watch their child during the procedure. Looking time to each trial was recorded by reliable observers, naïve to the condition, using computer joysticks. The joysticks were connected to a computer program which calculated looking time across trials. The 
experimenter who presented the stimuli wore a small earphone, which played a tone indicating when each trial ended. The observations of the primary observer were used to control the presentation of the stimuli. The observations of the secondary observers were used to calculate interrater reliability.

Procedure

The current study investigated face recognition using a 3 (age: infants, toddlers, preschoolers) x 2 (stimulus modality: unimodal visual, bimodal synchronous) x 2 (memory load: low, high) design with age and stimulus modality as between subject factors and memory load as a within-subject factor (see Figure I). Exposure time to each stimulus was controlled so that all participants received equal exposure (10 seconds) to the familiarized faces. Although infancy research typically presents stimuli for an extended period of time, the current study provided only 10 seconds of exposure to each of 12 familiarized faces in order to better understand how face recognition differs from infancy to early childhood when exposure time and stimuli are held constant across age. A novelty preference paradigm was used to investigate face recognition for all participants. Following familiarization to single target faces (low memory load) or three sequential target faces (high memory load), participants received pairs of faces depicting the target face side-by-side with a novel face. Each participant received six familiarization and six test trials for each memory load block for a total of twelve familiarization and twelve test trials. In order to equate procedures across infants, toddlers, and preschoolers, an experimenter provided the children with minimal instructions simply stating that they were going to watch some videos. Children were 
praised throughout the procedure and chose a small toy from a "treasure chest" once they completed the testing session.

Participants were randomly assigned to either the bimodal synchronous or unimodal visual stimulus modality condition. For the bimodal synchronous stimulus modality condition, soundtracks for the nursery rhyme were presented at $65 \mathrm{~dB}$ in synchrony with the mouth movements of each actress and emanated from a speaker centrally located between the two television screens. For the unimodal visual stimulus modality condition, the visual displays of women speaking were presented without any soundtracks. Presentation of each trial was controlled by the experimenter.

In order to assess the role of memory load on face recognition, each participant received blocks of low and high memory loads. The order of blocks was counterbalanced across participants (low memory load followed by high memory load or high memory load followed by low memory load). Across both memory load conditions, a total of twelve faces of women speaking were presented for familiarization and twelve pairs of faces of women speaking (novel versus familiar) were presented for test. The low memory load block consisted of a sequence of six faces with one face presented for familiarization immediately followed by one novelty preference test trial in which the familiarized face was presented side-by-side with a novel woman’s face (i.e., familiarization $\rightarrow$ test, familiarization $\rightarrow$ test, familiarization $\rightarrow$ test, familiarization $\rightarrow$ test, familiarization $\rightarrow$ test, familiarization $\rightarrow$ test; see Figure II). The high memory load block consisted of a sequence of six faces, with a series of three sequentially presented faces during familiarization followed by a series of three novelty-preference test trials. Each of the three familiarized faces was presented side-by-side with a novel woman's 
face. This entailed greater memory load because children were required to hold three faces in memory before recognition testing rather than one face. In the high memory load condition, two blocks of three familiarization trials and three novelty-preference test trials were presented (i.e., familiarization, familiarization, familiarization $\rightarrow$ test, test, test; familiarization, familiarization, familiarization $\rightarrow$ test, test, test; see Figure III). 


\section{Chapter VI - Results and Discussion}

All analyses for the current study used SPSS for Windows, version 17 . In order to ensure sufficient processing of the faces during familiarization, children with less than $20 \%$ overall attention to the familiarized faces throughout the procedure were not included in the analyses ( $n=1$ infant; $n=2$ toddlers; $n=2$ preschoolers). The primary index of memory was the mean proportion of total looking time (PTLT) to the novel faces. Results are depicted in Table II. Single-sample t-tests were conducted on PTLTs for each age group and each stimulus modality and memory load condition against a chance value of .50 to determine whether children demonstrated significant novelty preferences at each age. The following sections address the main research question, at what ages and under which memory load and stimulus modality conditions do infants and children show memory for faces.

\section{Results: Infant Novelty Preferences}

Results indicate that for the unimodal visual modality condition, infants' mean PTLT to the novel faces for the low $(M=0.53, S D=0.12)$ and the high memory load blocks $(M=0.48, S D=0.09)$ did not differ from chance, $t(15)=0.871, p>0.05 ; t(15)=-$ 1.117, $p>0.05$, respectively. For the bimodal synchronous modality condition, infants’ mean PTLT to the novel faces for the low $(M=0.48, S D=0.08)$ and the high memory load blocks $(M=0.52, S D=0.12)$ also did not differ from chance, $t(15)=-0.85, p>0.05$, $t(15)=0.742, p>0.05$, respectively (see Table II). Infants did not demonstrate memory for faces following 10 second exposure although some previous research suggests that infants can demonstrate memory for static faces after such brief familiarizations (Fagan, 1974). These results suggest that infants showed no evidence of memory for the 
familiarized faces with low or high memory load in either the unimodal visual or bimodal synchronous modality conditions.

As indicated in Table III, there were also no differences between infants' mean proportion of available looking time (PALT) to the unimodal visual $(M=0.73, S D=$ $0.12)$ and the bimodal synchronous modality conditions $(M=0.79, S D=0.18 ; t(30)=$ $1.271, p>0.1)$. This finding contrasts with some previous research suggesting that infants attend to multimodal stimulation more than unimodal stimulation (Bahrick, et al., 2008; Shaddy \& Colombo, 2004). There were also no differences in PALT as a function of memory load.

Results: Toddler Novelty Preferences

Results indicate that for both the unimodal visual and bimodal synchronous modality conditions, toddlers' mean PTLT to the novel faces for the low memory load block ( $M=0.60, S D=0.11, M=0.56, S D=0.09$, respectively) differed significantly from chance, $t(15)=3.392, p=0.004 ; t(15)=2.368, p=0.032$, respectively. In contrast, for both the unimodal visual and bimodal synchronous modality conditions, toddlers' mean PTLT to the novel faces for the high memory load block $(M=0.52, S D=0.12, M=$ $0.52, S D=0.09$, respectively) did not differ from chance, $t(15)=0.615, p>0.05 ; t(15)=$ 1.073, $p>0.05$, respectively (see Table II). These results suggest that, under both stimulus modality conditions, toddlers showed evidence of memory for the familiarized faces in the low memory load task (requiring memory for only one face at a time) but not when they were required to remember three faces at once. Thus, toddlers' memory for faces was impaired by the high memory load but not by the low memory load task. 
No differences were found in PALT for toddlers in the unimodal visual $(M=$ $0.56, S D=0.20)$ as compared to the bimodal synchronous modality condition $(M=0.64$, $S D=0.15 ; t(30)=1.417, p>0.1$; see Table III). Although means were in the direction of previous research indicating that multimodal stimulation of social events maintains attention in young children longer than unimodal stimulation (Bahrick, et al., 2008; Shady \& Colombo, 2004), differences did not reach significance. Further, no differences in PALT were found as a function of memory load.

Results: Preschool Novelty Preferences

Results indicate that for the unimodal visual modality condition, preschoolers' mean PTLT to the novel faces for the low memory load block $(M=0.55, S D=0.08)$ differed significantly from chance, $t(15)=2.587, p=0.021$. Preschoolers' mean PTLT to the novel faces for the high memory load block $(M=0.57, S D=0.13)$ was marginally significant, $t(15)=2.103, p=0.053$. These results suggest that preschoolers showed evidence of memory for the familiarized faces for the unimodal visual modality condition in the low memory load task and marginal evidence of memory in the high memory load task when they were required to remember three faces at once. Results indicated that for the bimodal synchronous modality condition, preschoolers' mean PTLT to the novel faces for the low memory load block $(M=0.54, S D=0.11)$ did not differ from chance, $t(15)=1.377, p>0.1$. In contrast, preschoolers' mean PTLT to the novel faces for the high memory load block $(M=0.54, S D=0.07)$ differed significantly from chance, $t(15)$ $=2.465, p=0.026$ (see Table II). These results suggest that in the presence of redundant audiovisual information preschoolers showed evidence of memory for three familiarized 
faces at once but did not show evidence of memory for a single face at a time. This latter finding can most likely be explained by the high variability in the group PTLT scores.

Preschoolers in the bimodal synchronous modality condition $(M=0.80, S D=$ 0.10) demonstrated significantly greater PALT to the dynamic faces than preschoolers in the unimodal visual modality condition $(M=0.66, S D=0.16$; $t(30)=2.94, p=0.006$; see Table III). Consistent with previous literature, this finding suggests that synchronous multimodal stimulation maintains attention better than unimodal visual stimulation during the preschool years.

\section{Results: Main Analyses}

In order to determine whether older children demonstrated better face recognition than younger children (i.e., main effect of age), whether children in the unimodal visual modality condition demonstrated better face recognition than children in the bimodal synchronous modality condition (i.e., main effect of modality), and whether face recognition in the low memory load block was enhanced as compared to the high memory load block across age (i.e., main effect of memory load), a repeated measures three-way analysis of variance (ANOVA) was conducted on PTLTs with age (infants, toddlers, preschoolers) and stimulus modality (bimodal synchronous, unimodal visual) as between subject factors and memory load (low, high) as the within subject factor. Results indicate a significant main effect of age $(F(2,90)=5.000, p=0.009$; see Figure V). Planned comparisons indicated that PTLTs in the toddler $(M=0.55)$ and preschool $(M=$ 0.55) age groups were significantly greater than the PTLT in the infant group $(M=0.50)$ (toddler versus infant: $p=0.01$, preschool versus infant: $p=0.006$ ). These results support 
the hypothesis that older children demonstrate better face recognition than younger children.

No significant main effect of stimulus modality was found $(F(1,90)=0.692, p>$ 0.1; see Figure VI), indicating that, contrary to predictions, overall children did not show evidence of better face recognition in the unimodal visual as compared to the bimodal synchronous modality condition. No significant main effect of memory load was found $(F(1,90)=1.214, p>0.1$; see Figure VII), indicating that, contrary to predictions, overall children did not show evidence of better face recognition with the low memory load block as compared to the high memory load block.

In contrast to predictions, results reveal no significant interaction of age and stimulus modality $(F(2,90)=0.241, p>0.1)$. This finding does not support the prediction that older children demonstrate better face recognition than younger children in the bimodal synchronous but not in the unimodal visual modality condition. Rather, older children showed better memory than younger children regardless of modality condition. This age effect was significant for the unimodal visual condition alone ( $F(2$, $45)=3.656, p=0.034)$ and did not reach significance for the bimodal condition $(F(2,45)$ $=1.55, p>0.1)$.

Results also revealed no significant interaction of age and memory load $(F(2,90)$ $=1.633, p>0.1)$. This finding does not support the hypothesis that older children would demonstrate better memory than younger children in the high memory load but not the low memory load condition. However, planned comparisons revealed that the mean PTLT for preschoolers $(M=0.56)$ was significantly greater than the mean PTLT for infants $(M=0.50 ; p=0.03)$ in the high memory load block. For the low memory load 
block, the mean PTLT for toddlers $(M=0.58)$ was also significantly greater than the mean PTLT for infants $(M=0.50 ; p=0.006$ ). These findings suggest a (nonsignificant) trend in which older children show better memory for faces than younger children with both high and low memory load conditions.

Results also revealed, in contrast to predictions, no significant interaction between stimulus modality and memory load $(F(1,90)=1.911, p>0.1)$. These findings suggest that children in the unimodal visual modality condition did not show evidence of better face recognition than children in the bimodal synchronous modality condition for the high memory load but not the low memory load blocks. The mean PTLTs for the unimodal visual modality condition with the low memory load $(\mathrm{M}=0.56)$ as compared to the mean PTLT for the bimodal synchronous modality condition with the low memory load $(M=0.53)$ were in the predicted direction with a nonsignficant trend of better memory in the unimodal visual than in the bimodal synchronous modality condition. No differences were found between the unimodal visual and bimodal synchronous modality conditions for the high memory load condition.

Results revealed no significant three-way interaction for age, stimulus modality, and memory load $(F(2,90)=0.881, p>0.1$; see Figure VIII). This finding does not support the hypothesis that older children would demonstrate better face recognition than younger children in the unimodal visual modality condition with the high memory load but not with the low memory load. However, the mean PTLTs to the novel faces were in the predicted direction for the unimodal visual modality condition with the high memory load (infant: $M=0.47$; toddler: $M=0.52$; preschool: $M=0.57$ ). Preschoolers demonstrated significantly better face recognition than infants in the unimodal visual 
modality condition with the high memory load $(p=0.01)$. It also does not support the hypothesis that older children would demonstrate better face recognition than younger children in the bimodal synchronous modality condition with the low memory load but not with the high memory load. However, the mean PTLTs to the novel faces were in the predicted direction for the bimodal synchronous modality condition with the low memory load (infant: $M=0.48$; toddler: $M=0.56$; preschool: $M=0.54$ ). Toddlers demonstrated significantly better face recognition than infants in the bimodal synchronous modality condition with the low memory load $(p=0.05)$. These findings suggest a trend in which older children appear to demonstrate better face recognition than younger children in the unimodal visual modality condition with the high memory load and in the bimodal synchronous modality condition with the low memory load.

Results: Analyses of Simple Effect for Each Age

In order to better understand the effects of stimulus modality and memory load at each age, 2 (stimulus modality: unimodal visual versus bimodal synchronous) x 2 (memory load: low versus high), ANOVAs were conducted for each age separately. As depicted in Figure IX, results for infants revealed no significant main effect of stimulus modality $(F(1,30)=0.007, p>0.1)$, no main effect of memory load $(F(1,30)=0.048, p$ $>0.1)$ and no significant interaction between stimulus modality and memory load $(F(1,30)=2.844, p=0.102)$. No differences were found for infants in the unimodal visual as compared to the bimodal synchronous modality condition with the low memory load block ( $M=0.53 ; M=0.48$, respectively) or with the high memory load block ( $M=$ $0.47 ; M=0.52$, respectively). These findings suggest that overall infants in the unimodal visual modality condition did not show better memory for faces than infants in the 
bimodal synchronous modality condition. Without the presence of intersensory redundancy, infants demonstrated a nonsignficant trend of slightly better memory for faces with the low memory load as compared with the high memory load. However, overall the task appeared to be too difficult for infants to show memory for faces.

As depicted in Figure $\mathrm{X}$, results for toddlers revealed no main effect of stimulus modality $(F(1,30)=0.645, p>0.1)$. No significant differences were found between the mean PTLT to the unimodal visual $(M=0.56)$ versus the bimodal synchronous modality condition $(M=0.54)$, however, the means were in the predicted direction with higher mean PTLTs to the novel faces in the unimodal visual as compared to the bimodal synchronous modality condition. A marginally significant main effect of memory load was found $(F(1,30)=3.778, p=0.061)$, with the mean PTLT to the novel faces in the low memory load block ( $M=0.58)$ marginally significantly greater than the mean PTLT to the novel faces in the high memory load block $(M=0.52 ; p=0.061)$. This finding suggests that toddlers demonstrated better face recognition with the low memory load as compared to the high memory load across unimodal visual and bimodal synchronous modality conditions. No significant interaction was found for condition and memory load $(F(1,30)=0.663, p>0.1)$. However, the mean PTLT to the novel faces in the unimodal visual modality condition for the low memory load block $(M=0.60)$ was marginally significantly greater than for the high memory load block $(M=0.56 ; p=0.06)$. There were no differences between the mean PTLT to the novel faces in the bimodal synchronous modality condition for the low $(M=0.52)$ versus high $(M=0.52)$ memory load blocks. These findings suggest that memory for faces was enhanced with a low 
memory load as compared to a high memory load only when no intersensory redundancy was present.

As depicted in Figure XI, results for preschoolers revealed no main effect of stimulus modality $(F(1,30)=0.538, p>0.1)$, no main effect of memory load $(F(1,30)=$ $0.172, p>0.1)$, and no interaction between stimulus modality and memory load $(F(1,30)$ $=0.035, p>0.1)$. These findings suggest that overall preschoolers demonstrated relatively consistent evidence of memory for faces across stimulation with intersensory redundancy and without as well as across low and high memory loads.

Taken together, the findings suggest that face recognition improves with age from infancy to early childhood. The developmental improvement in face recognition was carried by the unimodal visual modality condition in which toddlers and preschoolers demonstrated better memory for faces than infants. With respect to the low versus high memory load conditions, toddlers demonstrated significantly better face recognition than infants with the low memory load condition, whereas, preschoolers demonstrated significantly better face recognition than infants with the high memory load condition. The memory load findings also imply a developmental improvement in cognitive processing efficiency in which older children demonstrated better face recognition in the presence of a relatively high cognitive load than younger children. Similarly, toddlers demonstrate better face recognition with the low cognitive load than infants. This suggests that even the low memory load task may have been too difficult for infants to demonstrate memory for faces. 


\section{Results: Secondary Analyses}

Secondary observers were present for 29 out of the total 96 children (i.e., 10 out of the 32 infants (31\%), 9 out of 32 toddlers (28\%), and 10 out of 32 preschoolers (31\%)) included in the final analyses. Interobserver reliability was calculated by a Pearson product-moment correlation for each age group and averaged $r=0.95(S D=0.05)$ for infants, $r=0.93(S D=0.06)$ for toddlers, and $r=0.97(S D=0.02)$ for preschoolers. The interobserver reliability across all age groups averaged $r=0.95(S D=0.05)$.

Research suggests that attention in infancy becomes more efficient across development with decreases in looking time and increased disengagements (Ruff \& Rothbart, 1996). Further, dynamic audiovisual events maintain attention for longer periods of time than unimodal visual stimulation (Bahrick, et al., 2008). Thus, a two-way ANOVA was conducted on the PALT for each age to determine whether infants looked longer to the dynamic faces than older children (main effect of age) and whether greater attention was evident in the bimodal synchronous than the unimodal visual modality condition (main effect of stimulus modality). Consistent with previous research, results revealed a significant main effect of age $(F(2,90)=9.655, p<0.0002)$ with infants $(M=$ $0.76)$ demonstrating significantly greater PALT than toddlers $(M=0.60 ; p=0.00007$; see Figure XII). Interestingly, preschoolers $(M=0.73)$ also demonstrated significantly greater PALT than toddlers $(p=0.001)$. This may be attributed to preschoolers being more compliant than toddlers in sitting through the procedure. Also consistent with previous research, a significant main effect of stimulus modality $(F(1,90)=9.724, p=$ 0.002) with children demonstrating significantly greater PALT in the bimodal synchronous $(M=0.75)$ than the unimodal visual modality condition $(M=0.65 ; p=$ 
0.002). This finding suggests that a bimodal synchronous stimulation maintains attention more than a unimodal visual stimulation across infancy to early childhood.

Further secondary analyses were conducted on the lateral positioning of novel faces during test trials. Lateral positioning of the novel faces during test trials refers to whether the novel face was presented on the left versus right side of the screen during test trials. Results revealed a significant interaction between lateral position of novel faces and age $(F(2,48)=6.619, p=0.003)$. Of the two lateral position patterns presented, toddlers $(M=0.58)$ and preschoolers $(M=0.57)$ demonstrated significantly greater mean PTLT to the novel face than infants $(M=0.47)$ for pattern 2 only (i.e., left, right, left, left, right, right, left, left, right, right, left, right) ( $p=0.0001, p=0.0002$, respectively). No significant differences between age groups were found with pattern 1 (i.e., left, right, right, left right, left, right, right, left, right, left, left) (infants: $M=0.53$; toddlers: $M=$ 0.52; preschoolers: $M=0.54$ ). This finding suggests that older children showed better memory for faces than younger children when presented with one order but not the other order. Further investigation revealed that for infants, mean PTLT to the novel face for pattern $1(M=0.53)$ was significantly greater than the mean PTLT for pattern $2(M=$ $0.47 ; p=0.016)$. However, for toddlers, those who received order $1(M=0.52)$ demonstrated significantly lower mean PTLTs to the novel faces than those who received pattern $2(M=0.58 ; p=0.03)$. These findings suggest that pattern 1 was associated with novelty preference scores in infants and pattern 2 was associated with novelty preference scores in toddlers. No differences were found between patterns $1(M=0.54)$ versus pattern $2(M=0.57, p>0.1)$ for preschoolers. The lateral positioning patterns for the novel faces on test trials were created randomly, and it is unlikely that the patterns 
themselves were of differential difficulty for infants and toddlers. These differences are thus not explainable.

Secondary analyses were also conducted on the order of presentation for memory load conditions (i.e., low followed by high or high followed by low). Results revealed no significant differences ( $M=0.53$ for low followed by high; $M=0.54$ for high followed by low; $p>0.1$ ). Analyses were also conducted on the two groups of stimuli (set A versus set B). Results revealed no significant differences in memory for the two sets of faces ( $M=0.52$ for set $\mathrm{A} ; M=0.54$ for set $\mathrm{B} ; p>0.1)$.

\section{General Discussion}

The current study is one of the first to directly compare face recognition skills of infants and young children. As stated earlier and indicated in Table I, much of the literature investigating young children's perception and recognition of faces has used static photographs or schematic images of faces. The use of these types of stimuli rather than more ecological dynamic displays of faces does not inform the field of how infants, toddlers, and preschoolers perceive and remember faces in the natural environment. Little research has investigated toddler face perception. Therefore, how face perception and processing develops within this age group remains largely unknown. Similarly, little research has investigated face perception with synchronous speech despite the fact that most social interactions are experienced in a multimodal context with speech playing an important role. The current study investigated face recognition in the context of speech and used dynamic, more ecological stimuli to provide a basis from which to learn how infants, toddlers, and preschoolers recognize faces in conditions that more closely approximate those of the "real world." 
The findings from the current study suggest that face recognition (as tested in a novelty preference paradigm) improves with age. Toddlers, but not infants, demonstrated memory for dynamic faces after a 10 second exposure in both unimodal visual and bimodal synchronous speech. Preschoolers demonstrated memory for dynamic faces after a 10 second exposure to unimodal visual speech. Preschoolers also remembered three faces at once after a 10 second exposure to each face in bimodal synchronous speech. Infants demonstrated significantly poorer memory for the familiarized faces than toddlers and preschoolers. This finding might be attributed to older children's increased experience with faces in their everyday surroundings and improving memory capacities.

In contrast to previous research, children showed no evidence of unimodal facilitation in memory for faces. According to the IRH, unimodal facilitation should occur in early development and in the presence of a difficult task. The current study may have been too difficult for infants to demonstrate memory for faces and unimodal facilitation. However, toddlers and preschoolers demonstrated memory for faces and therefore were expected to show evidence of unimodal facilitation. It is unclear why no evidence of unimodal facilitation was found with older children.

Although a developmental trend in improved face recognition might seem obvious, no research to date has demonstrated this trend when controlling for type of task, memory load, and modality of stimulation. The findings also revealed a developmental improvement in face recognition across low and high memory loads. Toddlers showed better memory for dynamic faces in a low memory load task than infants, whereas, preschoolers showed better memory for dynamic faces in a high memory load task than infants. These findings may be attributed to older children's 
attentional flexibility and more efficient face processing skills. Infants did not demonstrate memory for faces in this procedure. This finding suggests that 10 seconds of familiarization may not have been enough for infants to fully process the faces and more exposure time may have resulted in face memory in this task. Although the literature suggests that infants are skilled perceivers of faces, this conclusion is drawn from studies in which infants are presented with an average of 200 seconds exposure to a single face (Bahrick et al., 2004; Pascalis, et al., 1998).

Research suggests that novelty versus familiarity preferences can shift as a function of task difficulty, which can be manipulated during familiarization or test (see Hunter \& Ames, 1988 for a review). Future research should investigate face recognition in a novelty preference paradigm using longer familiarization periods and memory load as a between subject factor. Further, the current study did not find evidence of enhanced face memory in unimodal visual modality as compared to bimodal synchronous modality conditions. In contrast to infancy research reviewed earlier, no differences between unimodal visual and bimodal synchronous modality conditions were found for infants. However, results suggest that older children showed better face recognition than infants in the unimodal visual modality condition. With respect to memory load, toddlers showed better memory for dynamic faces than infants in the low memory load block. In contrast, preschoolers showed better memory for dynamic faces than infants in the high memory load block. It is possible that for infants the task was too difficult, even with the low memory load. Toddlers were the only age group to demonstrate face recognition that was marginally better in the low memory load than high memory load block, consistent with predictions. Since preschoolers demonstrated high face recognition scores with both low 
and high memory loads, it appears that preschoolers are further along in their development of face expertise and processing efficiency than younger children.

The lack of integration between the literature investigating infants' versus toddlers' versus preschoolers' face perception and recognition can in part be attributed to methodological differences, including type of task and differential memory loads for infants versus older children. The use of identical procedures across age groups in the current study provides a basis for direct developmental comparisons of face recognition from infancy through preschooler. Similarly, manipulating the memory load for infants, toddlers, and preschoolers can provide a better understanding of how attention to faces in older children becomes more flexible and experienced. Thus, preschoolers and toddlers should need less familiarization to faces than infants. The current study provides a foundation from which further investigations regarding developmental change in face recognition can be conducted. Controlling for methodology, exposure time, and stimulus modality is a first step in this direction. Future research should vary the level of familiarization time to faces to determine sufficient processing times for infant face memory.

The results of this study provide important information regarding face recognition skills of typically developing infants, toddlers, and preschoolers. Specifically, toddlers showed face memory on the basis of an average of $60 \%$ of a 10 second exposure to dynamic faces. Similarly, preschoolers showed face memory on the basis of an average of $73 \%$ of a 10 second exposure to dynamic faces. These findings suggest that face recognition can occur after very brief exposure times. This also contradicts previous research which suggests that toddlers and preschoolers show poor face recognition skills 
after substantial interactions with caregivers and nurses (Cain, et al., 2005; Goodman, et al., 1990). The findings from the present study can also be used to potentially identify atypical patterns of face exploration among children at risk for developing Autism Spectrum Disorders (ASD). Children diagnosed with ASD typically demonstrate atypical patterns of attending to faces and social settings (Dawson, Webb, McPartland, 2005; Schultz, 2005; Volkmar, Chawarski, Klin, 2005).

\section{Limitations}

The current study has a few potential limitations that could be addressed in future studies. First, since the majority of the participating families were of Hispanic ethnicity, the sample may not be representative of other ethnic populations. Therefore, caution must be taken in generalizing the current findings to other populations. Second, the role of redundancy was not fully tested since there was no control condition with both audible and visual speech with a lack of redundancy (i.e. bimodal asynchronous speech) included. This control would reveal whether redundancy/synchrony competes for attention and impairs face recognition across infancy to early childhood. Third, the current study may have exposed infants to the stimuli without enough exposure time for them to show memory. It is possible that with additional exposure time, infants may have demonstrated memory. Fourth, it is inferred that toddlers' and preschoolers' visual fixations directly reflect face processing and recognition. However, the procedure in the current study did not provide verbal evidence of their face recognition skills. Future studies should incorporate a verbal component as an additional measure to provide further evidence of face recognition in children with verbal skills. Lastly, the sample size should be increased in order to gain more statistical power. An increase in sample size 
may lead to significant main effects of stimulus modality condition and memory load, as well as the interaction between age, stimulus modality condition, and memory load.

\section{Future Directions}

Future research should investigate the role of intersensory stimulation, memory load, and a longer exposure time for infants with a larger sample size in order to better understand how face expertise develops. The exposure time can be manipulated by increasing or decreasing the familiarization time to determine the optimal exposure time for face recognition in this type of task for infants, toddlers, and preschoolers. A nonredundant audiovisual asynchronous condition should also be conducted in order to directly investigate whether the redundancy between the face and voice hinders face recognition in early development. 


\section{REFERENCES}

Bahrick, L. E., Flom, R., \& Lickliter, R. (2002). Intersensory redundancy facilitates discrimination of tempo in 3-month-old infants. Developmental Psychobiology, 41, 352-363.

Bahrick, L. E., Gogate, L. J., \& Ruiz, I. (2002). Attention and memory for faces and actions in infancy: The salience of actions over faces in dynamic events. Child Development, 73, 1629-1643.

Bahrick, L. E., Hernandez-Reif, M., \& Flom, R. (2005). The development of infant learning about specific face-voice relations. Developmental Psychology, 41, 541552.

Bahrick, L. E., Hernandez-Reif, M., \& Pickens, J. N. (1997). The effect of retrieval cues on visual preferences and memory: Evidence for a four-phase attention function. Journal of Experimental Child Psychology, 67, 1-20.

Bahrick, L. E. \& Lickliter, R. (2000). Intersensory redundancy guides attentional selectivity and perceptual learning in infancy. Developmental Psychology, 36, 190-201.

Bahrick, L. E. \& Lickliter, R. (2002). Intersensory redundancy guides early perceptual and cognitive development. In R. Kail (Ed.), Advances in Child Development and Behavior, 30, (pp.153-187). New York: Academic Press.

Bahrick, L. E. \& Lickliter, R. (2004). Infants’ perception of rhythm and tempo in unimodal and multimodal stimulation: A developmental test of the intersensory redundancy hypothesis. Cognitive, Affective and Behavioral Neuroscience, 4, 137-147.

Bahrick, L. E., Lickliter, R., Vaillant, M., Shuman, M., \& Castellanos, I. (2004, June). The development of face perception in dynamic, multimodal events: Predictions from the intersensory redundancy hypothesis. Fifth Annual Meeting of the International Multisensory Research Forum, Barcelona, Spain.

Bahrick, L. E., Lickliter, R., Castellanos, I., \& Vaillant-Molina, M. (2010). Increasing task difficulty enhances effects of intersensory redundancy: Testing a new prediction of the intersensory redundancy hypothesis. Developmental Science, 13, 731-737.

Bahrick, L. E., Newell, L. C., Shuman, M., \& Ben, Y. (2007, March). Three-month-old Infants Recognize Faces in Unimodal Visual but not Bimodal Audiovisual Stimulation. Presented at the Society for Research in Child Development, Boston, MA. 
Bahrick, L. E. \& Pickens, J. N. (1995). Infant memory for object motion across a period of three months: Implications for a four-phase attention function. Journal of Experimental Child Psychology, 59, 343-371.

Bahrick, L. E., Sorondo, B. M., Castellanos, I., Todd, J. T., Argumosa, M. A., \& VaillantMolina, M. (2008). The development of basic indices of attention to bimodal and unimodal social events across infancy. Presented at the International Society of Developmental Psychobiology, Washington D.C.

Barrera, M. \& Maurer, D. (1981). Recognition of mother’s photographed face by the three-month-old infant. Child Development, 52, 714-716.

Bhatt, R. S., Bertin, E., Hayden, A., \& Reed, A. (2005). Face processing in infancy: Developmental Changes in the use of different kinds of relational information. Child Development, 76, 169-181.

Bigelow, A. E. (2001). Discovering self through other: Infants' preference for social contingency. Bulletin of the Menninger Clinic. Special Issue: Cognitive and interactional foundations of attachment, 65, 335-346.

Blass, E. M. \& Camp, C. A. (2004). The ontogeny of face identity I. Eight- to 21-weekold infants use internal and external face features in identity. Cognition, 92, 305327.

Brace, N. A., Hole, G. J., Kemp, R. I., Pike, G. E., Van Duuren, M., \& Norgate, L. (2001). Developmental changes in the effect of inversion: Using a picture book to investigate face recognition. Perception, 30, 85-94.

Bushnell, I. W. R. (1998). The origins of face perception. In The development of sensory, motor and cognitive capacities in early infancy, Simion, F., Butterworth G (Eds.). Psychology Press: Hove, East Sussex; 69-86.

Bushnell, I. W. R. (2001). Mother's face recognition in newborn infants: Learning and memory. Infant and Child Development: Special Issue: Face Processing in Infancy and Early Childhood, 10, 67-74.

Bushnell, I. W. R., Sai, F., \& Mullin, J. T. (1989). Neonatal recognition of the mother's face. British Journal of Developmental Psychology, 7, 3-15.

Burnham, D. (1993). Visual recognition of mother by young infants: Facilitation by speech. Perception, 22, 1133-1153.

Cain, W. J., Baker-Ward, L., \& Eaton, K. L. (2005). A face in the crowd: The influences of familiarity and delay on preschoolers' recognition. Psychology, Crime \& Law, $11,315-327$. 
Carey, S. (1992). Becoming a face expert. Philosophical Transactions of the Royal Society of London, 335, 95-103.

Carey, S. (1996). Perceptual classification and expertise. In R. Gelman \& T. Kit-Fong Au (Eds.) Perceptual and Cognitive Development (pp. 49-69). San Diego, CA: Academic Press.

Carey, S. \& Diamond, R. (1977). From piecemeal to configurational representation of faces. Science, 195, 312-314.

Caron, R. F. \& Caron, A. J. (1968). The effects of repeated exposure and stimulus complexity on visual fixation in infants. Psychonomic Science, 10, 207-208.

Carver, L. J., Dawson, G., Panagiotides, H., Meltzoff, A. N., McPartland, J., Gray, J., \& Munson, J. (2003). Age-related differences in neural correlates of face recognition during the toddler and preschool years. Developmental Psychobiology, 42, 148159.

Che, Z. \& Siegler, R. S. (2000). Across the great divide: Bridging the gap between understanding of toddlers' and older children's thinking. Monographs of the Society for Research in Child Development, 65, 1-95.

Chung, M. S. \& Thomson, D. M. (1995). Development of face recognition. British Journal of Psychology, 86, 55-87.

Cleveland, A. \& Striano, T. (2008). Televised social interaction and object learning in 14to 18-month-old infants. Infant Behavior \& Development, 31, 326-331.

Cohen, L. B., \& Cashon, C. H. (2001). Do 7-month-old infants process independent features of facial configurations? Infant and Child Development, 10, 83-92.

Cohen, L. B., DeLoache, J. S., \& Pearl, R. A. (1977). An examination of interference effects in infants' memory for faces. Child Development, 48, 88-96.

Collie, R. \& Hayne, H. (1999). Deferred imitation by 6- and 9-month-old infants: More evidence for declarative memory. Developmental Psychobiology, 35, 83-90.

Courage, M. L. \& Howe, M. L. (1998). The ebb and flow of infant attentional preferences: Evidence for long-term recognition memory in 3-month-olds. Journal of Experimental Child Psychology, 70, 26-53.

Davies, G. M. (1993). Children's memory for other people: An integrative review. In C.A. Nelson (series Ed.) and J. Harvey (vol. Ed.), The Minnesota symposium on child psychology: Vol. 26. Memory and Affect (pp. 123-157). Hillsdale, NJ: Lawrence Erlbaum Associates. 
Dawson, G., Webb, S.J., \& McPartland, J. (2005). Understanding the nature of face processing impairment in Autism: Insights from behavioral and electrophysiological studies. Developmental Neuropsychology, 27, 403-424.

DeLoache, J. S. (1976). Rate of habituation and visual memory in infants. Child Development, 47, 145-154.

de Haan, M., Johnson, M. H., Maurer, D. \& Perrett, D. I. (2001). Recognition of individual faces and average face prototypes by 1- and 3-month-old infants. Cognitive Development, 16, 659-678.

de Heering, A., Houthuys, S., \& Rossion, B. (2007). Holistic face processing is mature at 4 years of age: Evidence from the composite face effect. Journal of Experimental Child Psychology, 96, 57-70.

Diamond, R., \& Carey, S. (1986). Why faces are not special: An effect of expertise. Journal of Experimental Psychology: General, 115, 107-117.

Easterbrook, M. A., Kisilevsky, B. S., Hains, S. J., \& Muir, D. W. (1999). Faceness or complexity: Evidence from newborn visual tracking of facelike stimuli. Infant Behavior and Development, 22, 17-35.

Ennaceur, A. \& Delacour, J. (1988). A new one-trial test for neurobiological studies of memory in rats. 1: Behavioral data. Behavioural Brain Research, 31, 47-59.

Fagan, J. F. (1974). Infant recognition memory: The effects of length of familiarization and type of discrimination task. Child Development, 45, 351-356.

Fantz, R. (1963). Pattern vision in newborn infants. Science, 140, 286-297.

Fantz, R. L. (1964). Visual experience in infants: Decreased attention to familiar patterns relative to novel ones. Science, 146, 668-670.

Fernald, A. (1989). Intonation and communicative intent in mother's speech to infants: Is the melody in the message? Child Development, 60, 1497-1510.

Field, T. M., Cohen, D., Garcia, R., \& Greenberg, R. (1984). Mother-stranger face discrimination by the newborn. Infant Behavior and Development, 7, 19-25.

Flom, R. \& Bahrick, L. E. (2007). The development of infant discrimination of affect in multimodal and unimodal stimulation: The role of intersensory redundancy. Developmental Psychology, 43, 238-252. 
Flom, R. \& Bahrick, L. E. (2010). The effects of intersensory redundancy on attention and memory: Infants' long-term memory for orientation in audiovisual events. Developmental Psychology, 46, 428-436.

Freire, A., \& Lee, K. (2001). Face recognition in 4- to 7- year olds: Processing of configural, featural, and paraphernalia information. Journal of Experimental Child Psychology, 80, 347-371.

Gibson, E. J. (1969). Principles of perceptual learning and development. East Norwalk, CT: Appleton-Century-Crofts.

Goodman, G. S., Rudy, L., Bottoms, B. L., \& Aman, C. (1990). Children's concerns and memory: Issues of ecological validity in the study of children's eyewitness testimony. In R. Fivush, \& J.A. Hudson (Eds.), Knowing and remembering in young children (pp. 249-284). Cambridge: Cambridge University Press.

Goren, C. C., Sarty, M., \& Wu, P. Y. K. (1975). Visual following and pattern discrimination of face-like stimuli by newborn infants. Pediatrics, 56, 544-549.

Gunderson, V. M. \& Sackett, G. P. (1984). Development of pattern recognition in infant pigtailed macaques (Macaca nemestrina). Developmental Psychology, 20, 418426.

Gunderson, V. M. \& Swartz, K. B. (1986). Effects of familiarization time on visual recogntion memory in infant pigtailed macaques (Macaca Nemestrina). Developmental Psychology, 22, 477-480.

Hains, S. M. J. \& Muir, D. W. (1996). Effects of stimulus contingency in infant-adult interactions. Infant Behavior and Development, 19, 49-61.

Haith, M. M., Bergman, T., \& Moore, M. (1977). Eye contact and face scanning in early infancy. Science, 198, 853-855.

Hayden, A., Bhatt, R. S., Joseph, J. E., \& Tanaka, J. W. (2007). The other-race effect in infancy: Evidence using a morphing technique. Infancy, 12, 95-104.

Hayden, A., Bhatt, R. S., Reed, A., Corbly, C. R., \& Joseph, J. E. (2007). The development of face processing: Are infants sensitive to normal differences in second-order relational information? Journal of Experimental Child Psychology, 97, 85-98.

Henderson, R. M., McCulloch, D. L., \& Herbert, A. M. (2003). Event-related potentials (ERPs) to schematic faces in adults and children. International Journal of Psychophysiology, 51, 59-67. 
Horowitz, F. D., Paden, L., Bhana, K., \& Self, P. (1972). An infant controlled procedure for studying infant visual fixations. Developmental Psychology, 7, 90.

Hunter, M. A. \& Ames, E. W. (1988). A multifactor model of infant preferences for novel and familiar stimuli. In C. Rovee-Collier \& L.P. Lipsett (Eds.), Advances in Infancy Research: Vol. 5 (pp.69-95). Westport, CT: Ablex Publishing.

Inn, D., Walden, K. J., \& Solso, R. L. (1993). Facial prototype formation in children. Bulletin of the Psychonomic Society, 31, 197-200.

Johnson, M. H., Dziurawiec, S., Ellis, H., \& Morton, J. (1991). Newborns’ preferential tracking of face-like stimuli and its subsequent decline. Cognition, 40, 1-19.

Johnson, M. H. \& Morton, J. (1991). Biology and Cognitive Development. Oxford, UK: Blackwell.

Kelly, D. J., Liu, S., Lee, K., Quinn, P. C., Pascalis, O., Slater, A. M., \& Ge, L. (2009). Development of the other-race effect during infancy: Evidence towards universality? Journal of Experimental Child Psychology, 104, 105-114.

Kelly, D. J., Quinn, P. C., Slater, A. M., Lee, K., Ge, L., \& Pascalis, O. (2007). The other-race effect develops during infancy: Evidence of perceptual narrowing. Psychological Science, 18, 1084-1089.

Langlois, J. H. \& Roggman, L. A. (1990). Attractive faces are only average. Psychological Science, 1, 115-121.

Manns, J. R., Stark, C. E. L., \& Squire, L. R. (2000). The visual-paired comparison task as a measure of declarative memory. Proceedings of the National Academy of Sciences, 97, 12375-12379.

Martin, R. M. (1975). Effects of familiar and complex stimuli on infant attention. Developmental Psychology, 11, 178-185.

Maurer, D. \& Barrera, M. (1981). Infants’ perception of natural and distorted arrangements of a schematic face. Child Development, 52, 196-202.

McKee, R. D. \& Squire, L. R. (1993). On the development of declarative memory. Journal of Experimental Psychology: Learning, Memory, \& Cognition, 19, 397404.

McKone, E. \& Boyer, B. L. (2006). Sensitivity of 4-year-olds to featural and secondorder relational changes in face distinctiveness. Journal of Experimental Child Psychology, 94, 134-162. 
Meltzoff, A. N. (1990). Infant imitation and memory: Nine-month-olds in immediate and deferred tests. In S. Chess \& M.E. Hertzig (Eds.), Annual progress in child psychiatry and child development (pp. 3-17). Philadelphia, PA: Brunner/Mazel.

Mondloch, C., Leis, A., \& Maurer, D. (2006). Recognizing the face of Johnny, Suzy, and me: Insensitivity to the spacing among features at 4 years of age. Child Development, 77(1), 234-243.

Mondloch, C. J., Lewis, T. L., Budreau, D. R., Maurer, D., Dannemiller, J. L., Stephens, B. R., \& Kleiner-Gathercoal, K. A. (1999). Face perception during early infancy. Psychological Science, 10, 419-422.

Morton, J., \& Johnson, M. H. (1991). CONSPEC and CONLERN: A two-process theory of infant face recognition. Psychological Review, 98, 164-181.

Nelson, C. A. (2001). The development and neural bases of face recognition. Infant and Child Development, 10, 3-18.

Newell, L. C., Bahrick, L. E., \& Sternstein, M. L. (2007, March). Face Recognition in Preschool-Aged Children. Presented at the Society for Research in Child Development, Boston, MA.

Pancratz, C. N. \& Cohen, L. B. (1970). Recovery of habituation in infants. Journal of Experimental Child Psychology, 9, 208-216.

Parker, J. F. \& Myers, A. (2001). Attempts to improve children's identifications from sequential-presentation line-ups. Journal of Applied Social Psychology, 31, 796815.

Pascalis, O. \& de Haan, M. (2003). Recognition memory and novelty preference: What model? In H. Hayne \& J.W. Fagan (Eds.), Progress in infancy research: Vol. 3 (pp.95-119). Mahwah, NJ: Lawrence Erlbaum Associates.

Pascalis, O., de Haan, M., \& Nelson, C. A. (2002). Is face processing species-specific during the first year of life? Science, 296, 1321-1323.

Pascalis, O., de Haan, M., Nelson, C. A., \& de Schonen, S. (1998). Long-term recognition memory for faces assessed by visual paired comparison in 3- and 6month-old infants. Journal of Experimental Psychology: Learning, Memory, and Cognition, 24, 249-260.

Pascalis, O. \& de Schonen, S. (1994). Recognition memory in 3- to 4-day-old human neonates. Neuroreport, 5, 1721-1724. 
Pascalis, O., de Schonen, S., Morton, J., Dereulle, C., \& Fabre-Grenet, M. (1995). Mother's face recognition by neonates: A replication and an extension. Infant Behavior and Development, 18, 79-85.

Pellicano, E. \& Rhodes, G. (2003). Holistic processing in faces in preschool children and adults. Psychological Science, 14, 618-622.

Pellicano, E., Rhodes, G. \& Peters, M. (2006). Are preschoolers sensitive to configural information in faces? Developmental Science, 9(3), 270-277.

Piaget (1962). Play, dreams, and imitation in childhood. New York: Norton.

Reddy, V., Hay, D., Murray, L., \& Trevarthen, C. (1997). Communication in infancy: Mutual regulation of affect and attention. In G. Bremner, A. Slater, \& G. Butterworth (Eds.), Infant Development: Recent Advances (pp. 247-273). Hove, England: Psychological Press / Erlbaum (UK) Taylor \& Francis.

Richards, J. E. \& Casey, B. J. (1991). Heart-rate variability during attention phases in young infants. Psychophysiology, 28, 43-53.

Rochat, P. R. (2001). Social contingency detection and infant development. Bulletin of the Menninger Clinic, 65, 347-360.

Rose, S. A. (1983). Differential rates of visual information processing in full-term and preterm infants. Child Development, 54, 1189-1198.

Rose, S. A., Feldman, J. F. \& Jankowski, J. J. (2004). Infant visual recognition memory. Developmental Review, 24, 74-100.

Rose, S. A., Melloy-Carminar, P., Gottfried, A. W., \& Bridger, W. H. (1982). Familiarity and novelty preferences in infant recognition memory: Implications for information processing. Developmental Psychology, 18, 704-713.

Rovee, C. K. \& Rovee, D. T. (1969). Conjugate reinforcement of infant exploratory behavior. Journal of Experimental Child Psychology, 8, 33-39.

Rovee-Collier, C. K. (1997). Dissociations in infant memory: Rethinking the development of implicit and explicit memory. Psychological Review, 104, 467498.

Rubenstein, A. J., Kalankanis, L., \& Langlois, J. H. (1999). Infant preferences for attractive faces: A cognitive explanation. Developmental Psychology, 35, 848855. 
Rudy, L. \& Goodman, G. S. (1991). Effects of participation on children's reports: Implications for children’s testimony. Developmental Psychology, 27, 527-538.

Sai, F. (2005). The role of the mother's voice in developing mother's face preference: Evidence for intermodal perception at birth. Infant and Child Development, 14, 29-50.

Sangrigoli, S. \& de Schonen, S. (2004). Recognition of own-race and other-race faces by three-month-old infants. Journal of Child Psychology and Psychiatry, 45, 12191227.

Schultz, R. T. (2005). Developmental deficits in social perception in autism: The role of the amygdale and fusiform face area. International Journal of Developmental Neuroscience. Special Issue: Autism: Modeling Human Brain Abnormalities in Developing Animal Systems, 23(2-3), 125-141.

Schwarzer, G. \& Zauner, N. (2003). Face processing in 8-month-old infants: Evidence for configural and analytical processing. Vision Research, 43, 2783-2793.

Schwarzer, G., Zauner, N., \& Jovanovic, B. (2007). Evidence of a shift from featural to configural face processing in infancy. Developmental Science, 10, 452-463.

Shaddy, D. J. \& Colombo, J. (2004). Developmental changes in infant attention to dynamic and static stimuli. Infancy, 5, 355-365.

Simion, F., Farroni, T., Macchi Cassia, V., Turati, C., \& Dalla Barbra, B. (2002). Newborns' local processing in schematic facelike configurations. British Journal of Developmental Psychology, 20, 465-478.

Simion, F., Valenza, E., \& Umilta, C. (1998). Mechanisms underlying face preference at birth. In F. Simion and G. Butterworth (Eds.), The development of sensory, motor and cognitive capacities in early infancy: From perception to cognition. East Sussex, UK: Psychology Press.

Slater, A. \& Quinn, P. C. (2001). Face recognition in the newborn infant. Infant and Child Development. Special Issue: Face processing in infancy and early childhood, 10, 21-24.

Soderstrom, M. (2007). Beyond babytalk: Re-evaluating the nature and content of speech input to preverbal infants. Developmental Review, 27, 501-532.

Soderstrom, M., Seidl, A., Nelson, D. G. K., \& Jusczyk, P. W. (2003). The prosodic bootstrapping of phrases: Evidence from prelinguistic infants. Journal of Memory \& Language, 49, 249-267. 
Striano, T., Henning, A., \& Stahl, D. (2006). Sensitivity to interpersonal timing at 3 and 6 months of age. Interaction Studies: Social Behaviour and Communication in Biological and Artificial Systems, 7, 251-271.

Striano, T. \& Rochat, P. (1999). Developmental link between dyadic and triadic social competence in infancy. British Journal of Developmental Psychology, 17, 551562.

Striano, T. \& Stahl, D. (2005). Sensitivity to triadic attention in early infancy. Developmental Science, 8, 333-343.

Striano, T., Tomasello, M., \& Rochat, P. (2001). Social and object support for early symbolic play. Developmental Science, 4, 442-455.

Stormark, K. M. (2004). Skin conductance and heart-rate responses as indices of covert face recognition in preschool children. Infant and Child Development, 13, 423433.

Thompson, L. A., Madrid, V., Westbrook, S., \& Johnston, V. (2001). Infants attend to second-order relational properties of faces. Psychological Bulletin \& Review, 8, 769-777.

Trevarthan, C. (2002). Making sense of infants making sense. Intellectica. Special Issue: Debats actuels sur la cognition chez le bebe (Current Debates on Cognition in Infants), 34, 161-188.

Turati, C., Cassia, V. M., Simion, F., \& Leo, I. (2006). Newborns’ face recognition: Role of inner and outer facial features. Child Development, 77, 297-311.

Turati, C., Valenza, E., Leo, I., \& Simion, F. (2005). Three-month-olds’ visual preference for faces and its underlying visual processing mechanisms. Journal of Experimental Child Psychology, 90, 255-273.

Tyrrell, D. J., Anderson, J. T., Clubb, M., \& Bradbury, A. (1987). Infant recognition of the correspondence between photographs and caricatures of human faces. Bulletin of the Psychonomic Society, 25, 41-43.

Vaillant-Molina, M., Newell, L. C., Castellanos, I., Bahrick, L. E., \& Lickliter, R. (2006). Intersensory redundancy impairs face perception in early development. Presented at the International Conference for Infant Studies, Kyoto, Japan.

Valentine, T., Darling, S., \& Donnelly, M. (2004). Why are averaged faces attractive? The effect of view and averageness on the attractiveness of female faces. Psychonomic Bulletin \& Review, 11, 482-487. 
Volkmar, F., Chawarska, K., \& Klin, A. (2005). Autism in infancy and early childhood. Annual Review of Psychology, 56, 315-336.

Walton, G. E., \& Bower, T. G. R. (1993). Newborns from “prototypes” in less than 1 minute. Psychological Science, 4, 203-205.

Werker, J. F., Cohen, L. B., Lloyd, V. L., Casasola, M., \& Stager, C. L. (1998). Acquisition of word object associations by 14-month-old infants. Developmental Psychology, 34, 1289-1309.

Wild, H. A., Barrett, S. E., Spence, M. J., O’Toole, A. J., Cheng, Y. D., \& Brooke, J. (2000). Recognition and sex categorization of adults' and children's faces: Examining performance in the absence of sex-stereotyped cues. Journal of Experimental Child Psychology, 77, 269-291.

Younger, B. A., \& Cohen, L. B. (1986). Developmental change in infants' perception of correlations among attributes. Child Development, 57, 803-815. 
Figure I: Study design

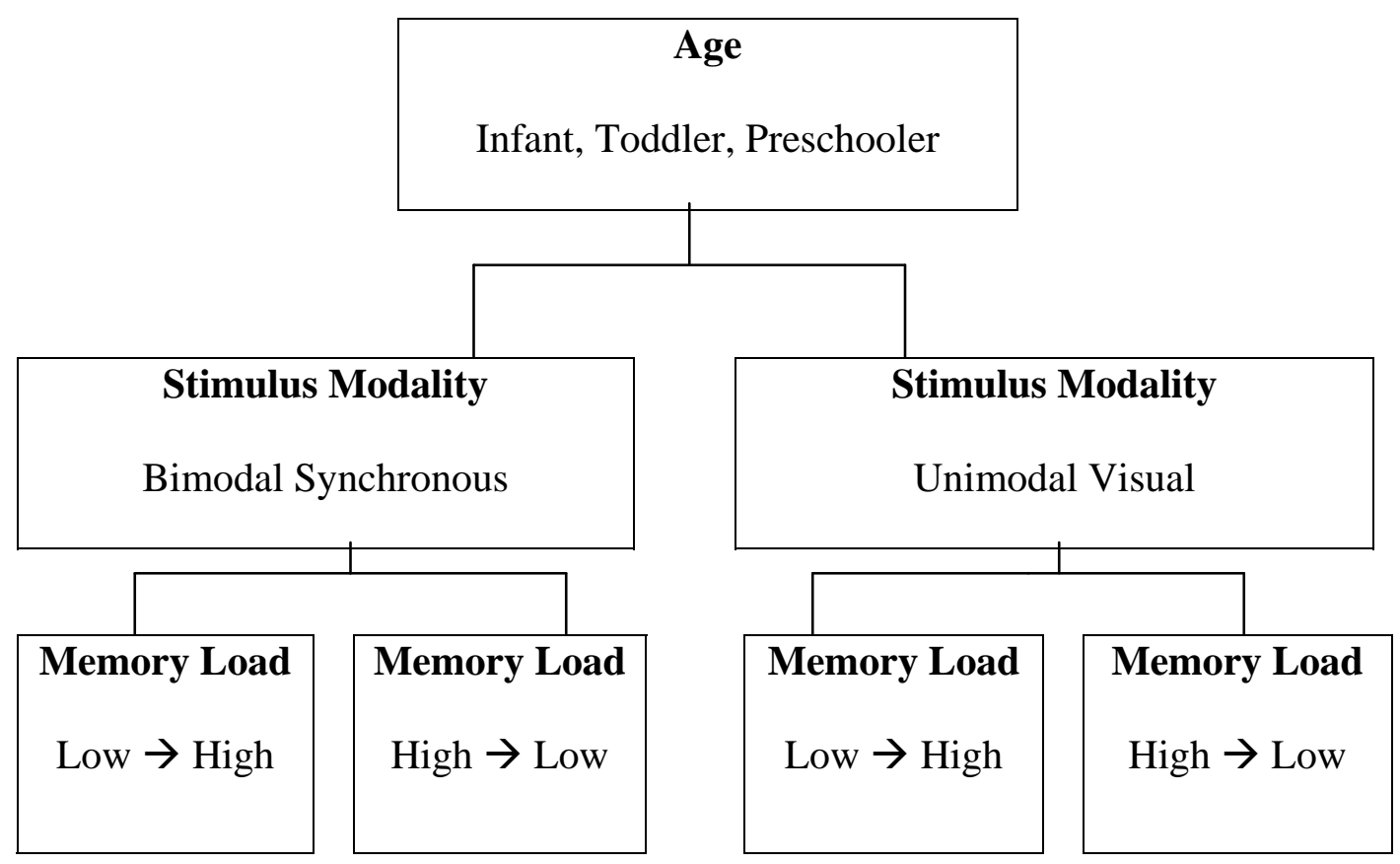


Figure II: Example of low memory load familiarization and test trials (The figure depicts static images taken from the dynamic events)

Familiarization 1

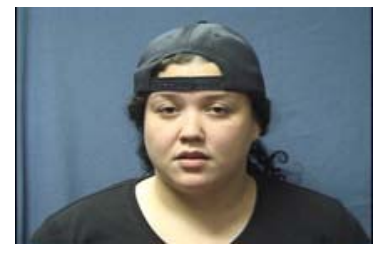

Test 1

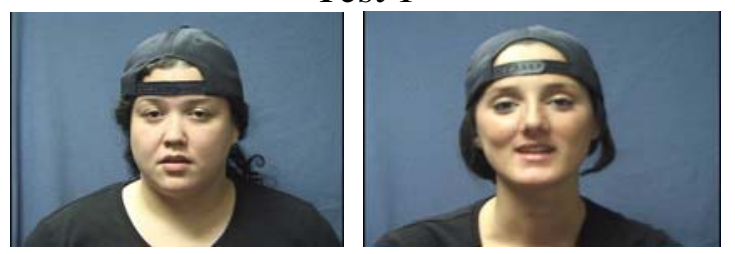

Familiarization 2

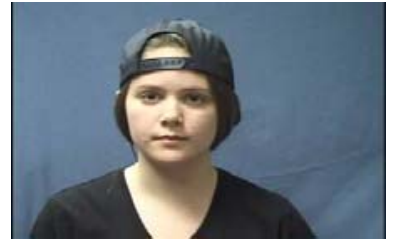

Test 2
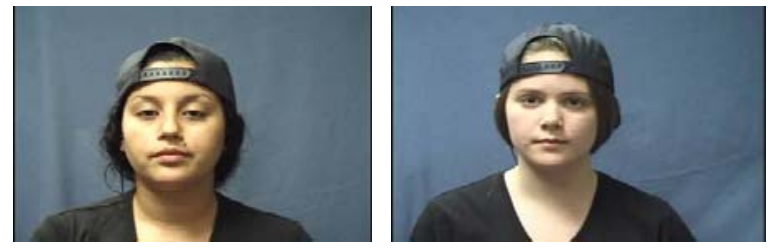

Familiarization 3

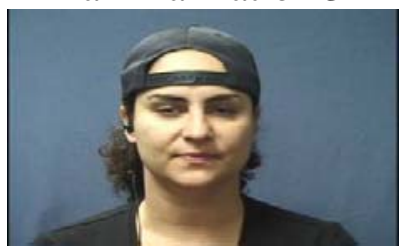

Test 3

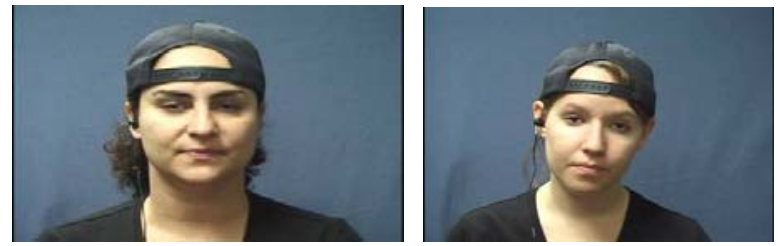


Figure III: Example of high memory load familiarization and test trials (The figure depicts static images taken from the dynamic events)

Familiarization 1-3
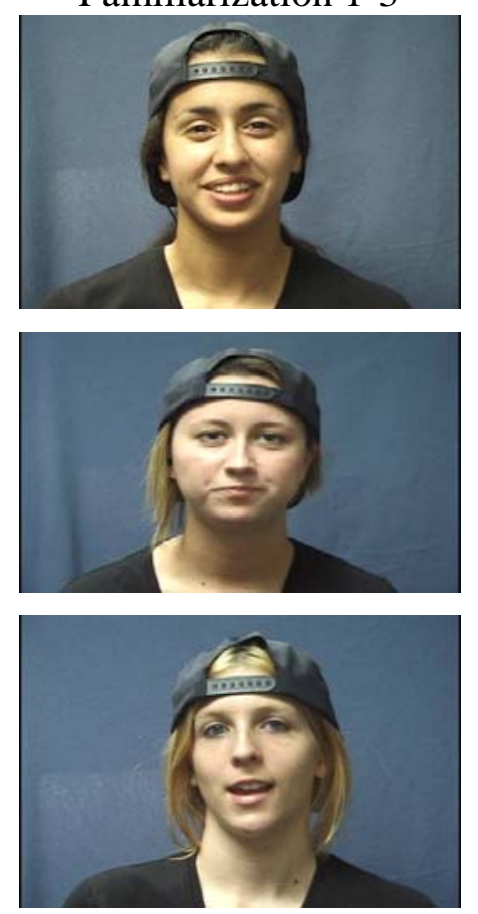

Test 1-3
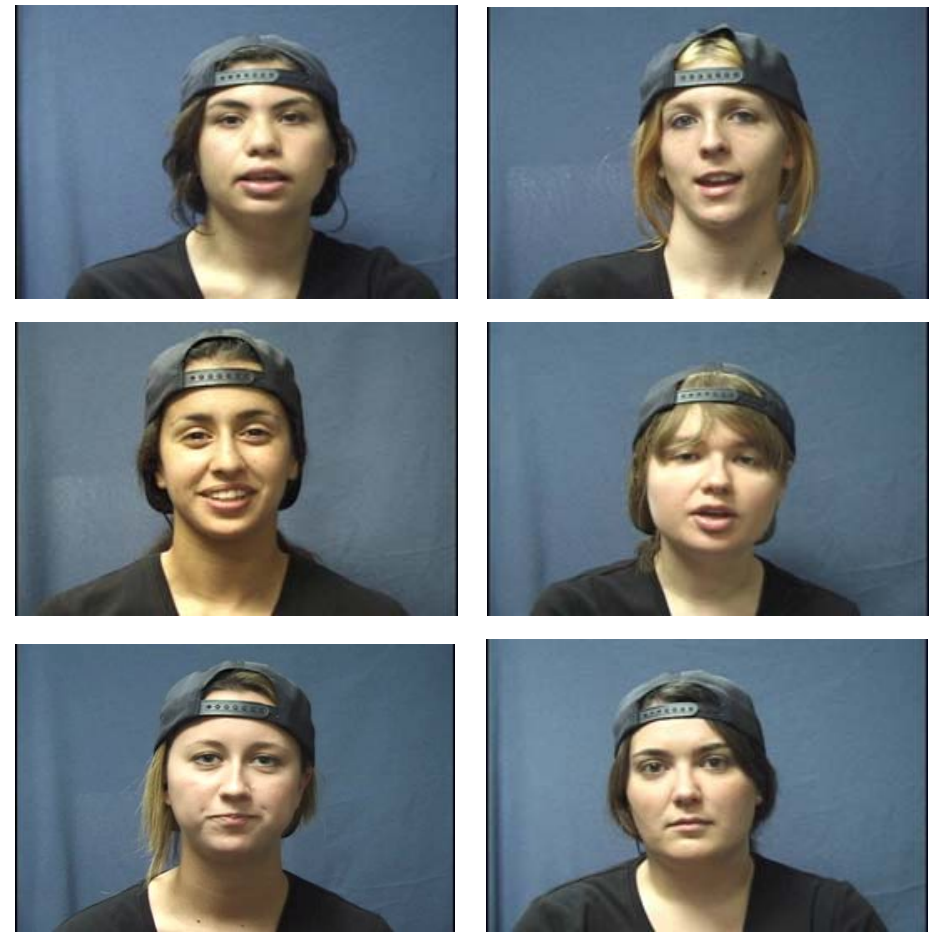
Figure IV: Predicted mean proportion of total looking time (PTLT) to the novel faces as a function of age (infant, toddler, preschool), stimulus modality (unimodal visual, bimodal synchronous), and memory load (low, high)

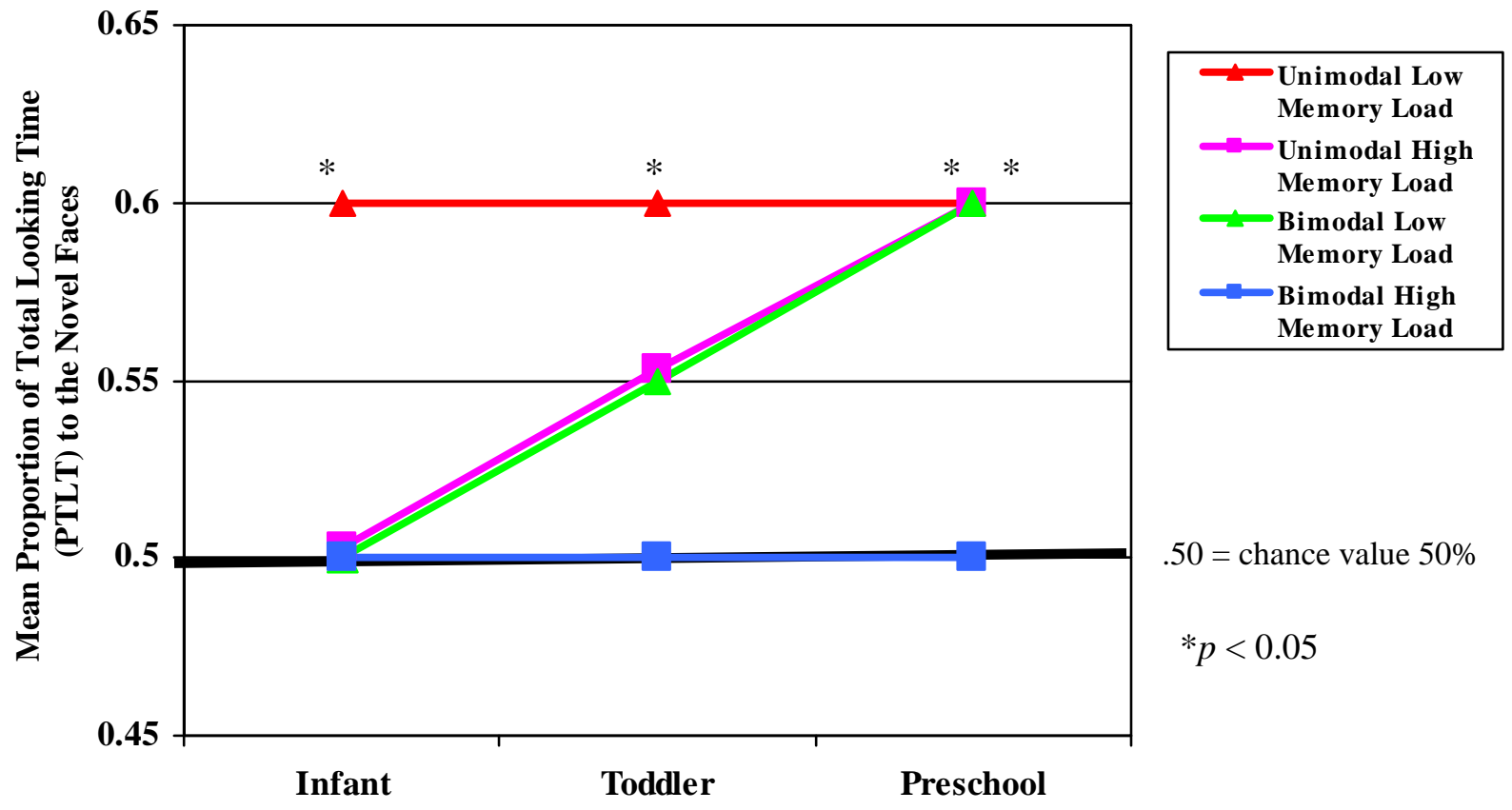

Predicted results:

- Main effect of age: Older children will demonstrate better face recognition than younger children.

- Main effect of stimulus modality: Children in the unimodal visual modality condition will demonstrate better face recognition than children in the bimodal synchronous modality condition.

- Main effect of memory load: All groups will demonstrate better face recognition in the low memory load as compared to the high memory load condition.

- Interaction between age and stimulus modality: Older children will demonstrate better face recognition than younger children in the bimodal synchronous but not in the unimodal visual modality condition.

- Interaction between age and memory load: Older children will demonstrate better face recognition than younger children with high memory load but not in the low memory load.

- Interaction between stimulus modality and memory load: Children in the unimodal visual modality will demonstrate better face recognition than children in the bimodal synchronous modality condition with high memory load but not with low memory load.

- Interaction between age and stimulus modality and memory load: Older children will demonstrate better face recognition than younger children in the unimodal visual modality condition with high memory load but not with low memory load. Older children will demonstrate better face recognition than younger children in the bimodal synchronous modality condition with low memory load but not with high memory load. 
Figure V: Mean proportion of total looking time (PTLT) to the novel faces as a function of age (infant, toddler, preschool)

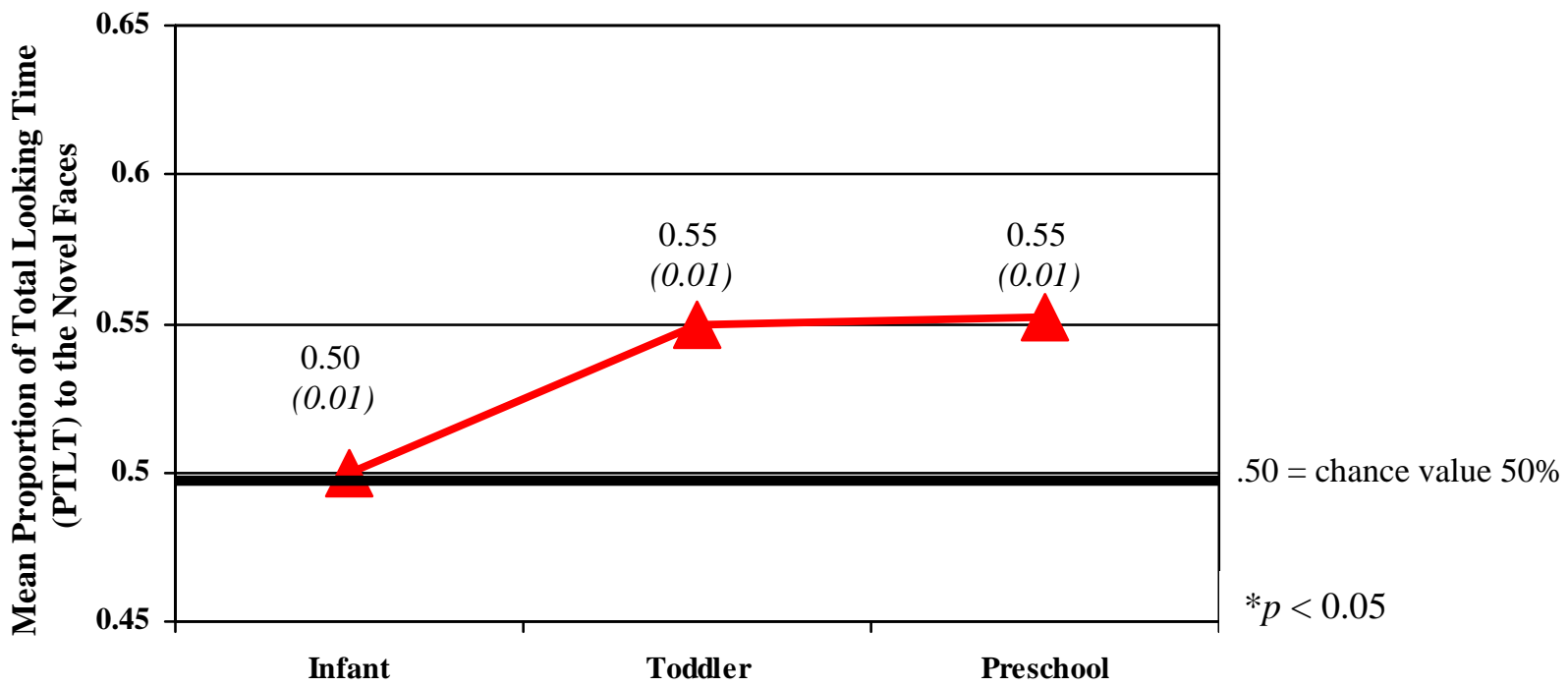

ANOVA results

- $\quad$ Main effect of age, $(F(2,90)=5.00, p=0.009)$

o Toddlers $(M=0.55)$ and preschoolers $(M=0.55)$ showed significantly better memory for faces than infants ( $M=0.50$; toddler vs. infant: $p=0.01$, preschool vs. infant: $p=0.006$ ) 
Figure VI: Mean proportion of total looking time (PTLT) to the novel faces for all children as a function of stimulus modality (unimodal visual, bimodal synchronous)

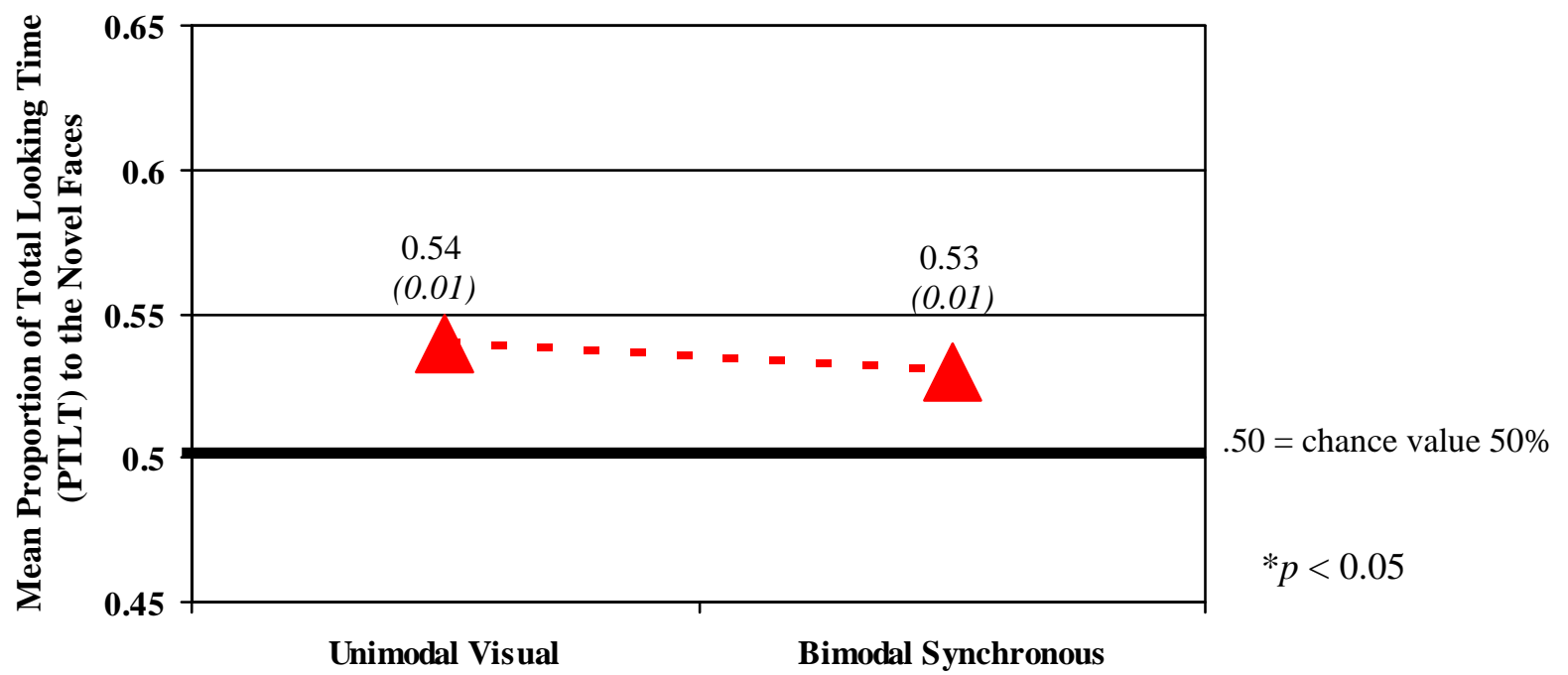

ANOVA results

- $\quad$ Main effect of stimulus modality, $(F(1,90)=0.692, p>0.1)$ 
Figure VII: Mean proportion of total looking time (PTLT) to the novel faces or all children as a function of memory load (low, high)

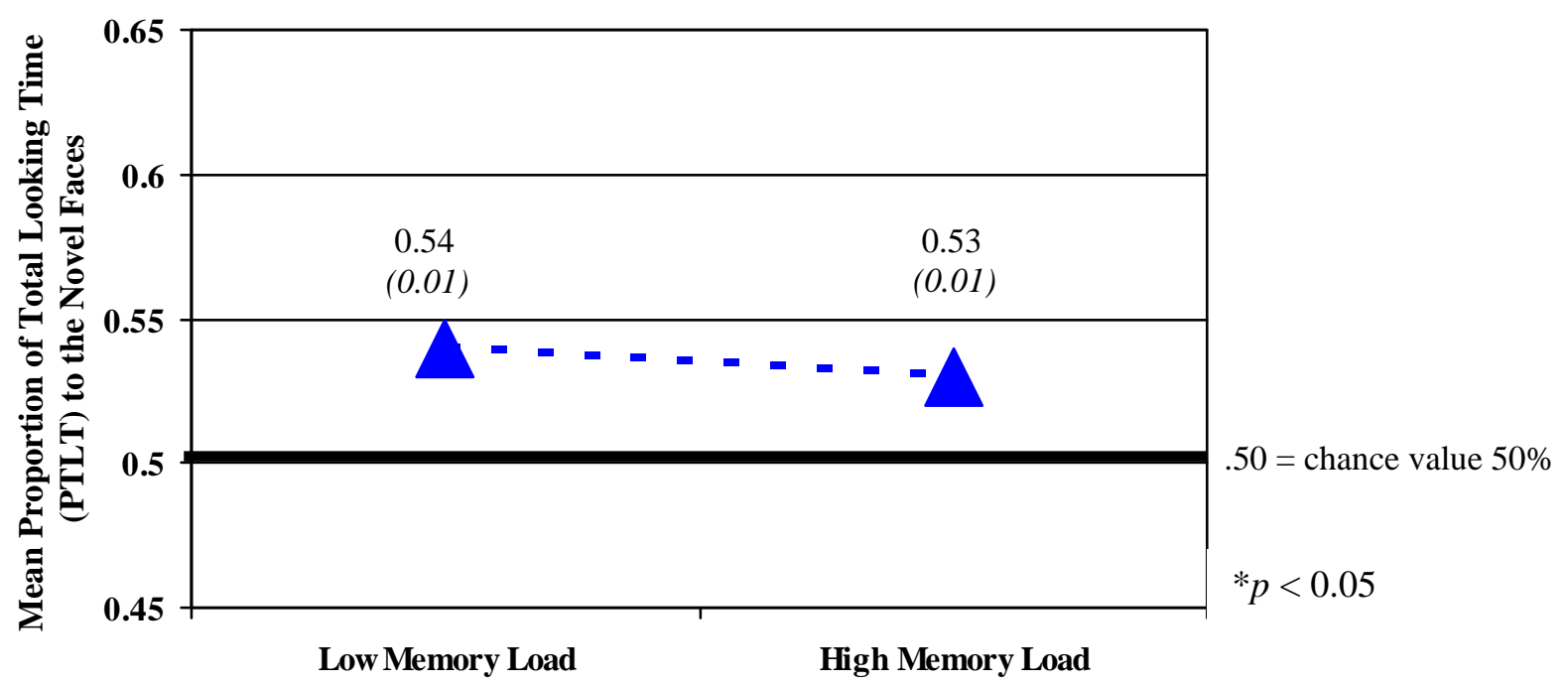

ANOVA results:

- $\quad$ Main effect of memory load, $(F(1,90)=1.214, p>0.1)$ 
Figure VIII: Mean proportion of total looking time (PTLT) to the novel faces as a function of age (infant, toddler, preschool), stimulus modality (unimodal visual, bimodal synchronous), and memory load (low, high)

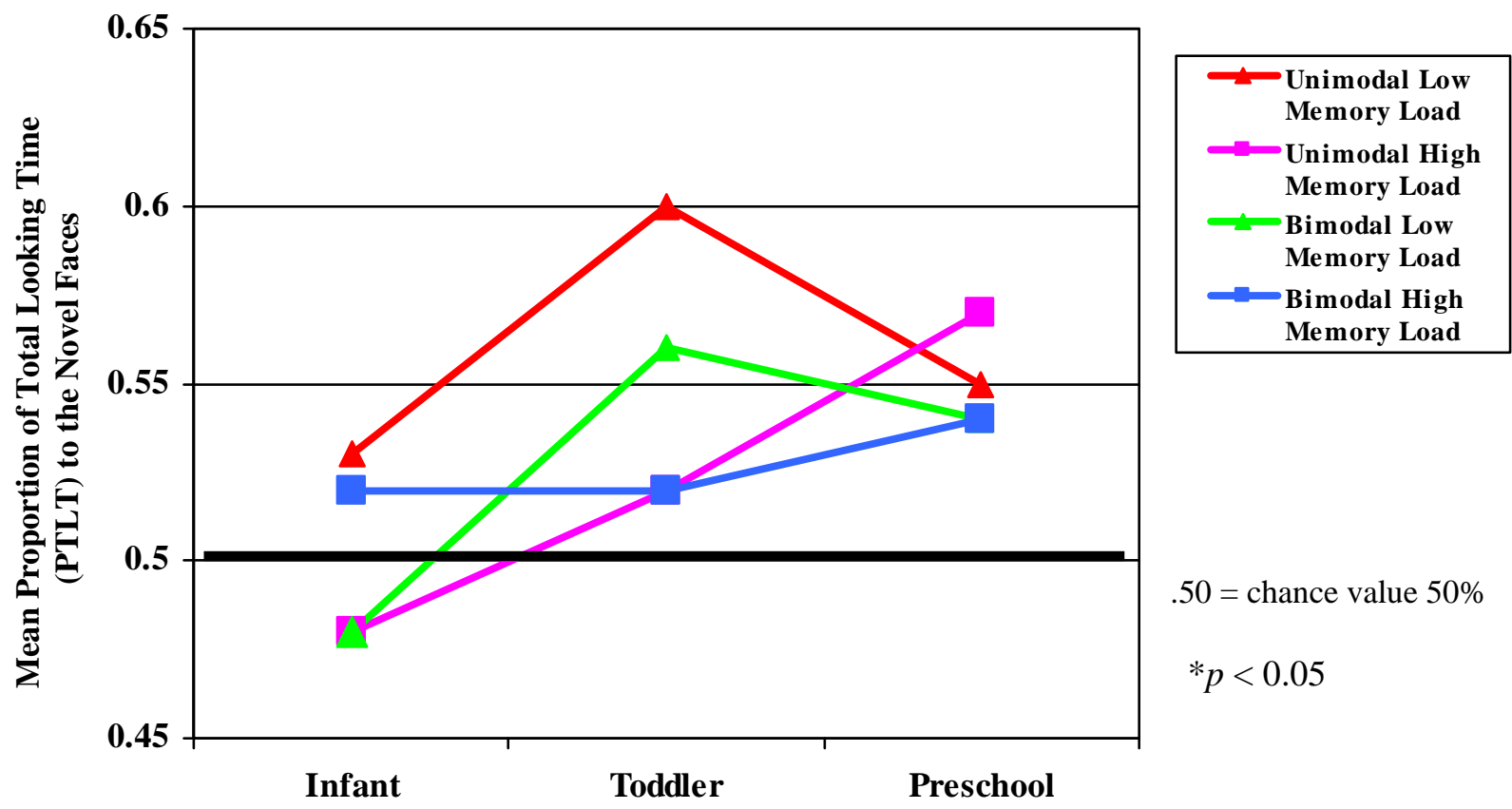

ANOVA results:

- $\quad$ Significant main effect of age, $(F(2,90)=5.00, p=0.009)$

o Toddlers $(M=0.55)$ and preschoolers $(M=0.55)$ showed significantly better memory for faces than infants $(M=0.50$; toddler vs. infant: $p=0.01$, preschool vs. infant: $p=0.006$ )

- $\quad$ Main effect of stimulus modality, $(F(1,90)=0.692, p>0.1)$

- $\quad$ Main effect of memory load, $(F(1,90)=1.214, p>0.1)$

- Interaction between age $\mathrm{x}$ stimulus modality, $(F(2,90)=0.241, p>0.1)$

o Toddlers $(M=0.56)$ and preschoolers $(M=0.56)$ showed significantly better memory for faces infants ( $M=0.50 ; p=0.02, p=0.02$, respectively) in the unimodal visual but not in the bimodal synchronous modality condition.

- Interaction between age $\mathrm{x}$ memory load, $(F(2,90)=1.633, p>0.1)$

o Preschoolers $(M=0.56)$ showed significantly better memory for faces than infants $(M=0.50 ; p=0.03)$ in the high memory load but not in the low memory load block.

o Toddlers $(M=0.58)$ showed significantly better memory for faces than infants $(M=$ $0.50 ; p=0.006$ ) in the low memory load but not in the high memory load block.

- Interaction between stimulus modality x memory load, $(F(1,90)=1.911, p>0.1)$

- Interaction between age $\mathrm{x}$ stimulus modality x memory load, $(F(2,90)=0.881, p>0.1)$

o Preschoolers $(M=0.57)$ showed significantly better memory for faces than infants $(M=0.47)$ in the unimodal visual modality condition in the high $(p=0.01)$ but not in the low memory load condition.

o Toddlers $(M=0.56)$ showed significantly better memory for faces than infants $(M=$ $0.48)$ in the bimodal synchronous modality condition in the low $(p=0.05)$ but not in the high memory load condition. 
Figure IX: Infants' mean proportion of total looking time (PTLT) to the novel faces as a function of stimulus modality (unimodal visual, bimodal synchronous), and memory load (low, high)

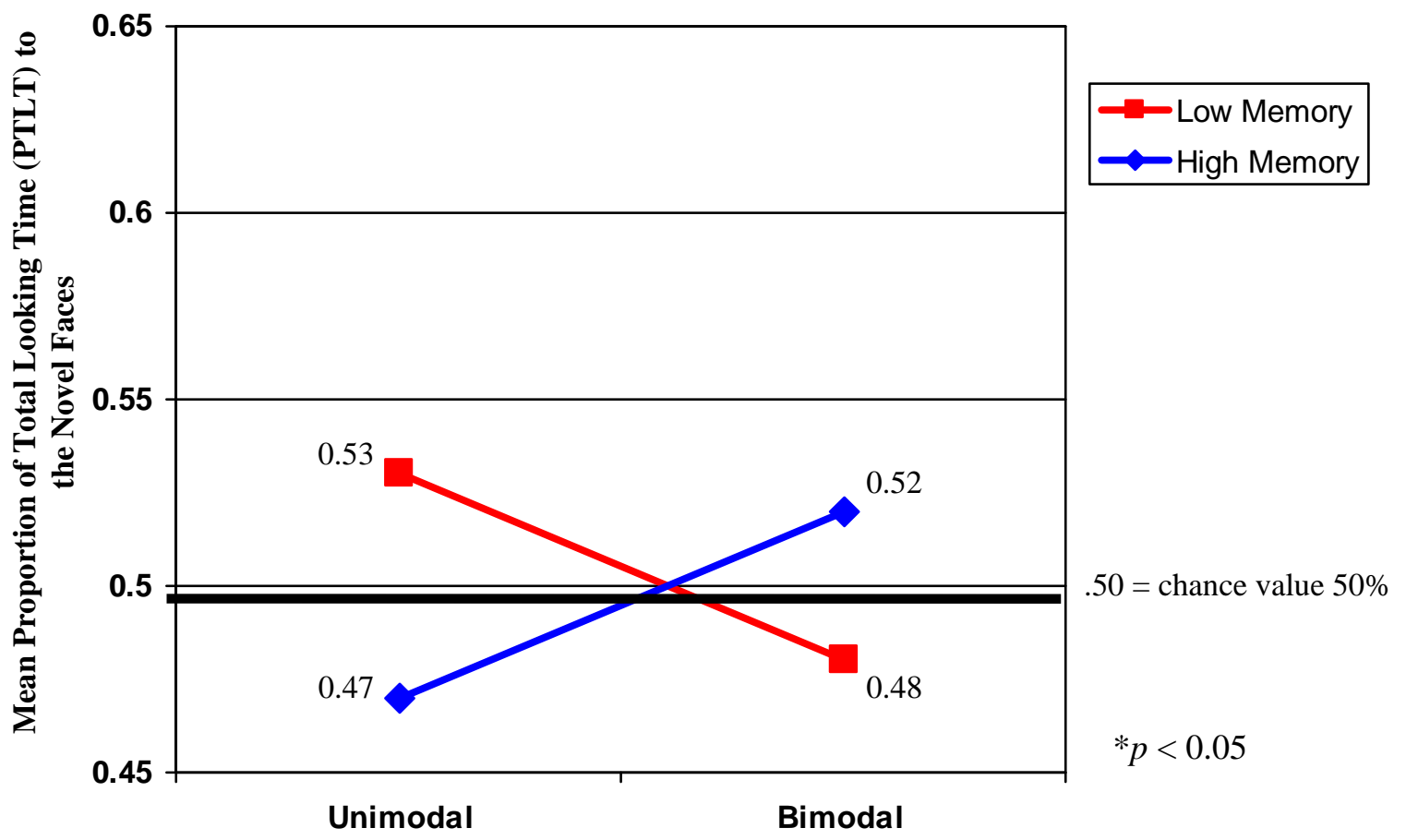

ANOVA results for simple effects:

- $\quad$ Main effect of stimulus modality $(F(1,30)=0.007, p>0.1)$

- $\quad$ Main effect of memory load $(F(1,30)=0.048, p>0.1)$

- Interaction between stimulus modality and memory load $(F(1,30)=2.844, p=0.102)$ 
Figure X: Toddlers' mean proportion of total looking time (PTLT) to the novel faces as a function of stimulus modality (unimodal visual, bimodal synchronous), and memory load (low, high)

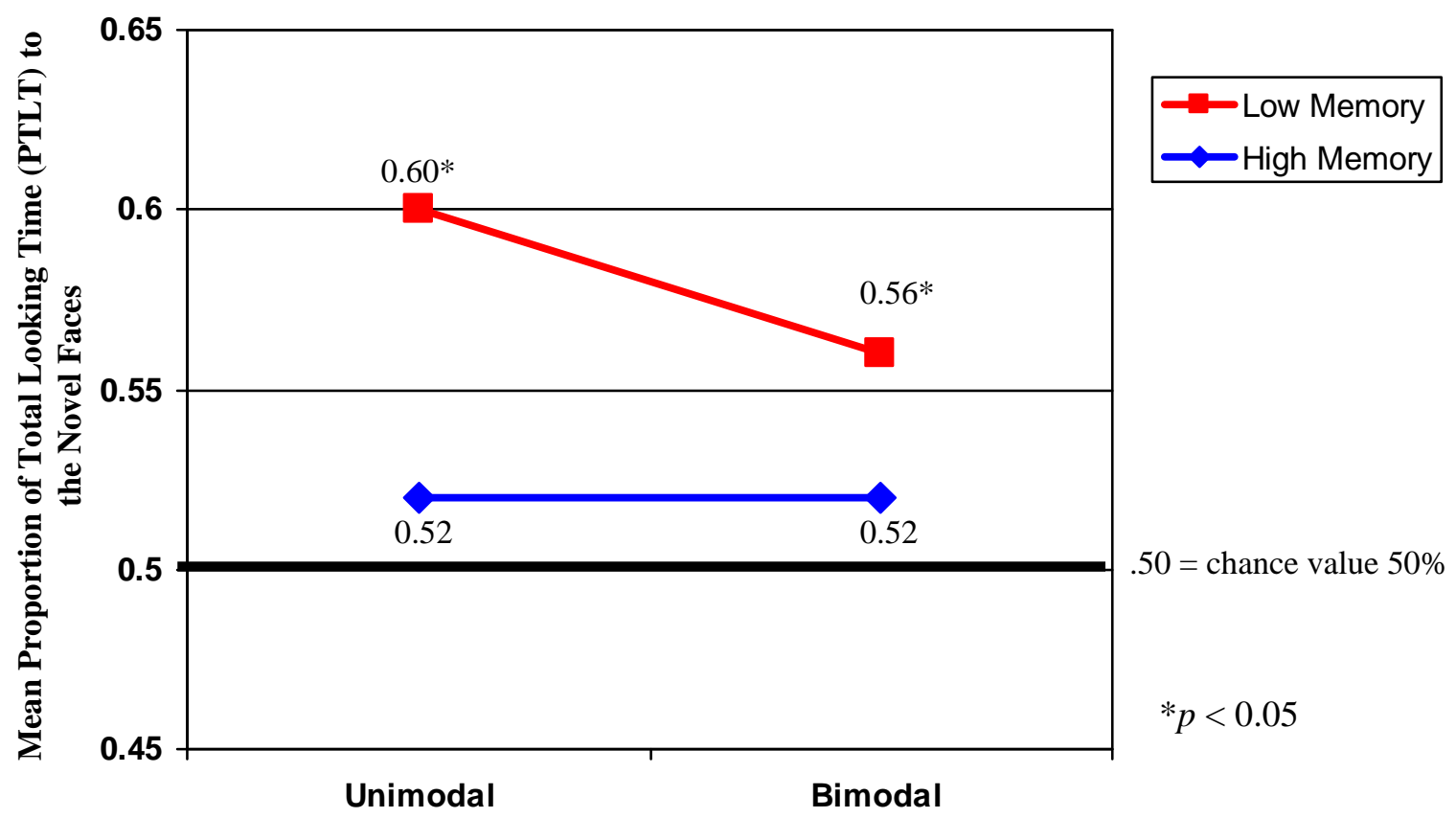

ANOVA results for simple effects:

- $\quad$ Main effect of stimulus modality $(F(1,30)=0.645, p>0.1)$

- $\quad$ Marginally significant main effect of memory load $(F(1,30)=3.778, p=0.061)$

o Low memory load block $(M=0.58)$ marginally significantly greater than the high memory load block $(M=0.52)$

- $\quad$ Interaction for condition and memory load $(F(1,30)=0.663, p>0.1)$

o Unimodal visual modality condition for the low memory load block $(M=0.60)$ was marginally significantly greater than for the high memory load block $(M=0.56)$ 
Figure XI: Preschoolers' mean proportion of total looking time (PTLT) to the novel faces as a function of stimulus modality (unimodal visual, bimodal synchronous), and memory load (low, high)

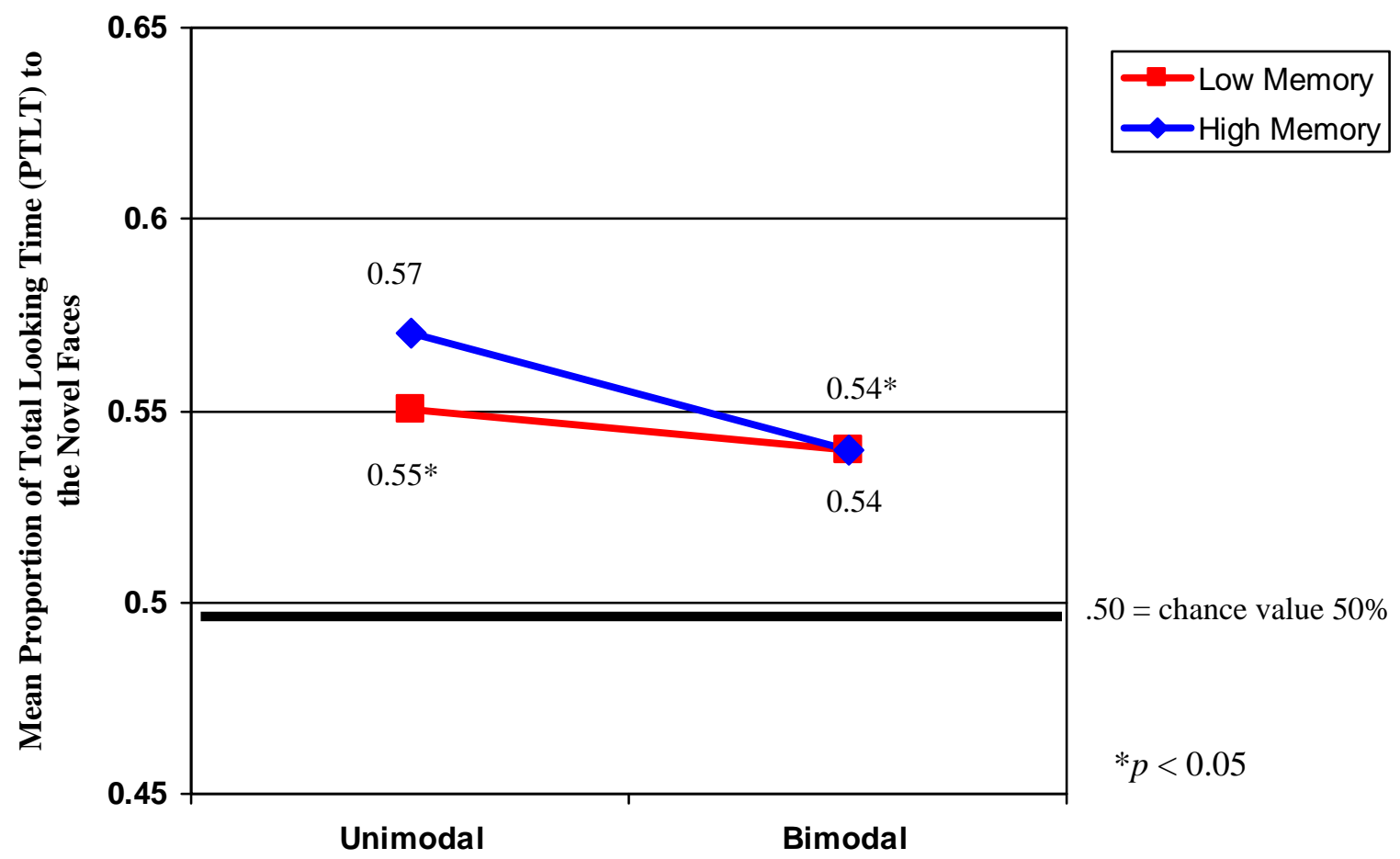

ANOVA results for simple effects:

- $\quad$ Main effect of stimulus modality $(F(1,30)=0.538, p>0.1)$

- $\quad$ Main effect of memory load $(F(1,30)=0.172, p>0.1)$

- Interaction between stimulus modality and memory load $(F(1,30)=0.035, p>0.1)$. 
Figure XII: Mean proportion of available looking time (PALT) during familiarization

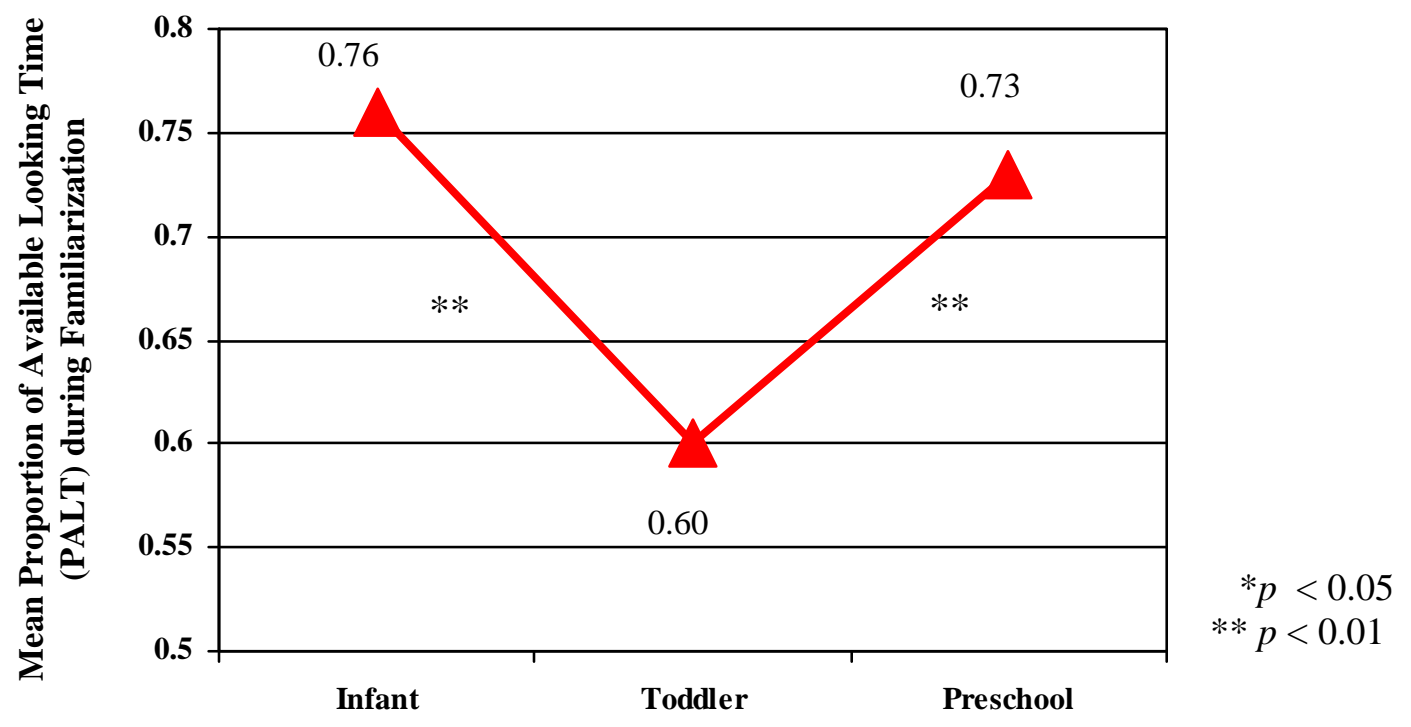

ANOVA results:

- $\quad$ Significant main effect of age $(F(2,90)=9.655, p=0.0002)$

o Infants $(M=0.76)$ showed significantly longer looking to faces during the familiarization than toddlers $(M=0.60, p=0.00007)$.

o Preschoolers $(M=0.73)$ showed significantly longer looking to faces during the familiarization than toddlers $(M=0.60, p=0.001)$. 
Table 1: Evidence of face perception and recognition in infancy and early childhood

\begin{tabular}{|c|c|c|c|c|c|c|}
\hline Age & Method & Stimuli & $\begin{array}{l}\text { Multimodal/ } \\
\text { Unimodal }\end{array}$ & $\begin{array}{l}\text { Static/ } \\
\text { Dynamic }\end{array}$ & $\begin{array}{l}\text { Discriminated/ } \\
\text { Recognized/ } \\
\text { Preferred }\end{array}$ & Reference \\
\hline \multirow[t]{9}{*}{ Newborn } & Habituation & $\begin{array}{l}2 \text { photos unfamiliar women's } \\
\text { faces }\end{array}$ & Unimodal & Static & Discriminated & Turati et al., 2006 \\
\hline & VPC & $\begin{array}{l}\text { Mother's face vs. } \\
\text { unfamiliar woman's face }\end{array}$ & Unimodal & Static & Preferred Mother & Bushnell, 1998 \\
\hline & VPC & $\begin{array}{l}\text { Mother's face vs. } \\
\text { unfamiliar woman's face }\end{array}$ & Unimodal & Static & Preferred mother & Bushnell, 2001 \\
\hline & VPC & $\begin{array}{l}\text { Mother's face vs. unfamiliar } \\
\text { face with odor masked }\end{array}$ & Unimodal & Static & Preferred mother & Bushnell et al., 1989 \\
\hline & VPC & $\begin{array}{l}\text { Mother's face vs. } \\
\text { unfamiliar woman's face }\end{array}$ & Unimodal & Static & Preferred mother & Field et al., 1984 \\
\hline & VPC & $\begin{array}{l}\text { Mother’s face vs. } \\
\text { unfamiliar woman's face }\end{array}$ & Unimodal & Static & Preferred mother & Pascalis et al., 1995 \\
\hline & VPC & $\begin{array}{l}\text { Mother’s face vs. } \\
\text { unfamiliar woman's face }\end{array}$ & Unimodal & Static & $\begin{array}{l}\text { Preferred mother only } \\
\text { when mother's voice was } \\
\text { heard postnatally }\end{array}$ & Sai, 2005 \\
\hline & VPC & $\begin{array}{l}\text { Schematic face-like pattern } \\
\text { vs. scrambled face-like pattern } \\
\text { vs. blank head outline }\end{array}$ & Unimodal & Static & $\begin{array}{l}\text { Newborns track } \\
\text { face-like pattern } \\
\text { more than other stimuli }\end{array}$ & Goren et al., 1975 \\
\hline & VPC & $\begin{array}{l}\text { Schematic face-like pattern } \\
\text { vs. non face-like pattern } \\
\text { vs. blank head outline }\end{array}$ & Unimodal & Static & $\begin{array}{l}\text { Newborns tracked } \\
\text { face-like pattern } \\
\text { more than other stimuli }\end{array}$ & Johnson et al., 1991 \\
\hline
\end{tabular}




\begin{tabular}{|c|c|c|c|c|c|c|}
\hline Age & Method & Stimuli & $\begin{array}{l}\text { Multimodal/ } \\
\text { Unimodal }\end{array}$ & $\begin{array}{c}\text { Staticl } \\
\text { Dynamic }\end{array}$ & $\begin{array}{l}\text { Discriminated/ } \\
\text { Recognized/ } \\
\text { Preferred }\end{array}$ & Reference \\
\hline \multirow[t]{4}{*}{ Newborn } & VPC & $\begin{array}{l}\text { Schematic face-like pattern } \\
\text { vs. non face-like pattern }\end{array}$ & Unimodal & Static & $\begin{array}{l}\text { Newborns prefer } \\
\text { face-like pattern }\end{array}$ & Mondloch et al., 1999 \\
\hline & VPC & $\begin{array}{l}\text { Schematic face-like pattern } \\
\text { vs. non face-like pattern }\end{array}$ & Unimodal & Static & $\begin{array}{l}\text { Newborns prefer } \\
\text { face-like pattern }\end{array}$ & Simion et al., 2002 \\
\hline & VPC & $\begin{array}{l}\text { Schematic face-like pattern } \\
\text { vs. square contour non face-like } \\
\text { pattern }\end{array}$ & Unimodal & Static & $\begin{array}{l}\text { Newborns prefer } \\
\text { face-like pattern }\end{array}$ & Simion et al., 1998 \\
\hline & NP & $\begin{array}{l}2 \text { photos of unfamiliar women's } \\
\text { faces }\end{array}$ & Unimodal & Static & $\begin{array}{l}\text { 3-day-old infants } \\
\text { show novelty pref. } \\
\text { after 2-min. delay }\end{array}$ & $\begin{array}{l}\text { Pascalis \& } \\
\text { de Schonen, } 1994\end{array}$ \\
\hline \multirow[t]{2}{*}{$\begin{array}{l}0-2 \\
\text { Months }\end{array}$} & Habituation & $\begin{array}{l}\text { Schematic face with intact } \\
\text { first-order relations vs. schematic } \\
\text { face with scrambled features }\end{array}$ & Unimodal & Static & $\begin{array}{l}\text { 2-, but not 1-month } \\
\text { old infants disc. }\end{array}$ & $\begin{array}{l}\text { Maurer \& } \\
\text { Barrera, } 1981\end{array}$ \\
\hline & VPC & $\begin{array}{l}\text { Live presentation of mother's } \\
\text { face vs. unfamiliar woman's } \\
\text { face }\end{array}$ & Unimodal & Dynamic & $\begin{array}{l}\text { 1-month-old infants } \\
\text { preferred mother's face } \\
\text { with synch. voice but } \\
\text { not without synch. voice }\end{array}$ & Burnham, 1993 \\
\hline \multirow[t]{2}{*}{$\begin{array}{l}2-3 \\
\text { Months }\end{array}$} & Habituation & $\begin{array}{l}2 \text { videos of unfamiliar women's } \\
\text { faces }\end{array}$ & $\begin{array}{l}\text { Bimodal/ } \\
\text { Unimodal }\end{array}$ & Dynamic & $\begin{array}{l}\text { 2-month-old } \\
\text { infants disc. faces in } \\
\text { unimodal \& asynch. } \\
\text { but not bimodal stim. }\end{array}$ & $\begin{array}{l}\text { Vaillant-Molina } \\
\text { et al., } 2006\end{array}$ \\
\hline & Habituation & $\begin{array}{l}2 \text { videos of unfamiliar women’s } \\
\text { faces }\end{array}$ & $\begin{array}{l}\text { Bimodal/ } \\
\text { Unimodal }\end{array}$ & Dynamic & $\begin{array}{l}\text { 3-month-old infants } \\
\text { disc. faces in bimodal \& } \\
\text { unimodal stim. }\end{array}$ & Bahrick et al., 2004 \\
\hline
\end{tabular}




\begin{tabular}{|c|c|c|c|c|c|c|}
\hline & & & Table 1 (cont. & & & \\
\hline Age & Method & Stimuli & $\begin{array}{l}\text { Multimodal/ } \\
\text { Unimodal }\end{array}$ & $\begin{array}{c}\text { Static/ } \\
\text { Dynamic }\end{array}$ & $\begin{array}{l}\text { Discriminated/ } \\
\text { Recognized/ } \\
\text { Preferred }\end{array}$ & Reference \\
\hline $\begin{array}{l}2-3 \\
\text { Months }\end{array}$ & NP & $\begin{array}{l}\text { Photos of unfamiliar women's } \\
\text { faces }\end{array}$ & Unimodal & Static & $\begin{array}{l}\text { 3-, but not 1-month-old d } \\
\text { infants showed recognition } \\
\text { of an averaged face } \\
\text { (evidence of prototype } \\
\text { formation) }\end{array}$ & de Haan et al., 2001 \\
\hline $\begin{array}{l}3-6 \\
\text { Months }\end{array}$ & Habituation & $\begin{array}{l}2 \text { photos unfamiliar women's } \\
\text { faces }\end{array}$ & Unimodal & Static & Discriminated faces & Cohen et al., 1977 \\
\hline & Habituation & 2 photos unfamiliar women’s & Unimodal & Static & Discriminated & Pascalis et al., 1998 \\
\hline & Habituation & 2 live unfamiliar women’s faces & Unimodal & Dynamic & $\begin{array}{l}\text { 2- to } 5 \text {-month-old infants } \\
\text { disc. with external contours } \\
\text { hidden }\end{array}$ & Blass \& Camp, 2004 \\
\hline & Habituation & $\begin{array}{l}2 \text { videos of unfamiliar women’s } \\
\text { faces }\end{array}$ & $\begin{array}{l}\text { Bimodal/ } \\
\text { Unimodal }\end{array}$ & Dynamic & $\begin{array}{l}\text { 3-month-old infants } \\
\text { recognized unimodal but not } \\
\text { bimodal }\end{array}$ & Bahrick et al., 2007 \\
\hline & Habituation & $\begin{array}{l}\text { Photo of unfamiliar woman's } \\
\text { face with manipulated spacing } \\
\text { between features (upright vs. } \\
\text { inverted) }\end{array}$ & Unimodal & Static & $\begin{array}{l}\text { 5- but not 3-month-old } \\
\text { infants disc. upright } \\
\text { but not inverted faces } \\
\text { with manipulated spacing } \\
\text { between features }\end{array}$ & Bhatt et al., 2005 \\
\hline & Habituation & $\begin{array}{l}\text { Videos of unfamiliar women's } \\
\text { faces }\end{array}$ & Bimodal & Dynamic & $\begin{array}{l}\text { 4- \& 6-, but not 2-month- } \\
\text { old infants disc. a change } \\
\text { in the face/voice relationship }\end{array}$ & $\begin{array}{l}\text { Bahrick, et al., } 2005 \\
\text { p }\end{array}$ \\
\hline & VPC & $\begin{array}{l}2 \text { photos of unfamiliar women's } \\
\text { faces (upright vs. inverted) }\end{array}$ & Unimodal & Static & $\begin{array}{l}\text { 3-month-old infants prefer } \\
\text { upright to inverted faces }\end{array}$ & Turati et al., 2005 \\
\hline
\end{tabular}


Table 1 (cont.)

\begin{tabular}{|c|c|c|c|c|c|c|}
\hline Age & Method & Stimuli & $\begin{array}{l}\text { Multimodal/ } \\
\text { Unimodal }\end{array}$ & $\begin{array}{c}\text { Static/ } \\
\text { Dynamic }\end{array}$ & $\begin{array}{l}\text { Discriminated/ } \\
\text { Recognized/ } \\
\text { Preferred }\end{array}$ & Reference \\
\hline $\begin{array}{l}\text { 3-6 } \\
\text { Months }\end{array}$ & NP & $\begin{array}{l}\text { Videos of unfamiliar women } \\
\text { performing actions }\end{array}$ & Unimodal & Dynamic & $\begin{array}{l}\text { 5-month-old infants } \\
\text { showed novelty pref. } \\
\text { for novel action but not } \\
\text { for novel face (showed } \\
\text { novelty pref. for face when } \\
\text { movement was eliminated) }\end{array}$ & $\begin{array}{l}\text { Bahrick et al., } 2002 \\
\text { ) }\end{array}$ \\
\hline \multirow[t]{4}{*}{$\begin{array}{l}6-10 \\
\text { Months }\end{array}$} & Habituation & $\begin{array}{l}2 \text { photos of unfamiliar women’s } \\
\text { faces }\end{array}$ & Unimodal & Static & $\begin{array}{l}\text { 6- \& 10- , but not } \\
\text { 4-month-old infants disc. } \\
\text { "switched" faces (mouth } \\
\text { switched) }\end{array}$ & Schwarzer et al., 2007 \\
\hline & Habituation & $\begin{array}{l}2 \text { photos of unfamiliar women's } \\
\text { faces (upright vs. inverted) }\end{array}$ & Unimodal & Static & $\begin{array}{l}\text { 7-month-old infants disc. } \\
\text { upright "switched" faces } \\
\text { (composite photo of two } \\
\text { familiarized faces) but not } \\
\text { inverted }\end{array}$ & $\begin{array}{l}\text { Cohen \& Cashon, } \\
2001\end{array}$ \\
\hline & VPC & $\begin{array}{l}2 \text { photos of unfamiliar woman’s } \\
\text { face with spacing manipulated }\end{array}$ & Unimodal & Static & $\begin{array}{l}\text { 7-month-old infants } \\
\text { prefer “normal” spacing } \\
\text { face over manipulated } \\
\text { spacing face }\end{array}$ & Thompson et al., 2001 \\
\hline & NP & $\begin{array}{l}2 \text { photos of unfamiliar women's } \\
\text { faces \& caricature of unfamiliar } \\
\text { woman's face }\end{array}$ & Unimodal & Static & $\begin{array}{l}\text { 7-month-old infants } \\
\text { show novelty pref. after } \\
40 \text { sec. of accumulated look }\end{array}$ & $\begin{array}{l}\text { Tyrrell et al., } 1987 \\
\text { king }\end{array}$ \\
\hline 2-6 yrs. & Storybook & $\begin{array}{l}\text { Videos of unfamiliar women's } \\
\text { faces speaking a nursery rhyme }\end{array}$ & $\begin{array}{l}\text { Unimodal/ } \\
\text { Bimodal }\end{array}$ & Dynamic & $\begin{array}{l}\text { 3.5-, but not 3-year-olds } \\
\text { showed recognition in } \\
\text { unimodal but not bimodal s } \\
\text { after } 4 \text { sec. of familiarizatio }\end{array}$ & $\begin{array}{l}\text { Newell et al., } 2007 \\
\text { stim. } \\
\text { on }\end{array}$ \\
\hline
\end{tabular}




\section{Table 1 (cont.)}

\begin{tabular}{|c|c|c|c|c|c|c|}
\hline Age & Method & Stimuli & $\begin{array}{l}\text { Multimodal/ } \\
\text { Unimodal }\end{array}$ & $\begin{array}{c}\text { Staticl } \\
\text { Dynamic }\end{array}$ & $\begin{array}{l}\text { Discriminated/ } \\
\text { Recognized/ } \\
\text { Preferred }\end{array}$ & Reference \\
\hline \multirow[t]{5}{*}{$2-6$ yrs } & Storybook & $\begin{array}{l}\text { Photos of unfamiliar boys' \& } \\
\text { girls' faces with differences in } \\
\text { the shape of external contours \& } \\
\text { spacing of internal features }\end{array}$ & Unimodal & Static & \multicolumn{2}{|c|}{$\begin{array}{l}\text { target from distractor faces } \\
\text { with differences in external } \\
\text { contours but not with differences } \\
\text { in spacing of internal features }\end{array}$} \\
\hline & $\begin{array}{l}\text { Modified } \\
\text { VPC }\end{array}$ & $\begin{array}{l}\text { Photos of unfamiliar boys' } \\
\text { faces }\end{array}$ & Unimodal & Static & $\begin{array}{l}\text { 4-year-olds detected } \\
\text { differences in facial } \\
\text { distinctiveness \& } \\
\text { featural \& relational } \\
\text { changes }\end{array}$ & $\begin{array}{l}\text { McKone \& Boyer, } \\
2006\end{array}$ \\
\hline & $\begin{array}{l}\text { Composite } \\
\text { Face Paradigm } \\
\text { (Modified } \\
\text { VPC) }\end{array}$ & $\begin{array}{l}\text { Photos of unfamiliar women's } \\
\& \text { men’s faces divided into top } \\
\& \text { bottom segments to create } \\
\text { composite faces (aligned \& } \\
\text { misaligned) }\end{array}$ & Unimodal & Static & $\begin{array}{l}\text { 4-year-olds accurately } \\
\text { identified identical } \\
\text { composite faces when tof } \\
\text { bottom of faces were alig } \\
\text { (evidence of holistic proc }\end{array}$ & $\begin{array}{l}\text { de Heering et al., } 2007 \\
\text { ned } \\
\text { ess.) }\end{array}$ \\
\hline & $\begin{array}{l}\text { Whole-Part } \\
\text { Paradigm } \\
\text { (Modified NP) }\end{array}$ & $\begin{array}{l}\text { Photos of unfamiliar boys'\& girls' } \\
\text { faces that differed on one feature } \\
\text { or photos of features (upright vs. } \\
\text { inverted) }\end{array}$ & Unimodal & Static & $\begin{array}{l}\text { 4-year-olds } \\
\text { accurately identified } \\
\text { features embedded in a } \\
\text { whole face rather than } \\
\text { features alone with uprig } \\
\text { (evidence of holistic proc }\end{array}$ & $\begin{array}{l}\text { Pellicano \& Rhodes, } \\
2003 \\
\text { t faces } \\
\text { ess.) }\end{array}$ \\
\hline & $\begin{array}{l}\text { Whole-Part } \\
\text { Paradigm } \\
\text { (Modified NP) }\end{array}$ & $\begin{array}{l}\text { Photos of unfamiliar boys' \& girls' } \\
\text { faces that differed on one feature, } \\
\text { spacing btw features, or photos of } \\
\text { features alone (upright vs. inverted }\end{array}$ & $\begin{array}{l}\text { Unimodal } \\
\text { ) }\end{array}$ & Static & $\begin{array}{l}\text { 4-year-olds accurately } \\
\text { identified features embed } \\
\text { in original configuration } \\
\text { in new configuration or is } \\
\text { (evidence of holistic proc }\end{array}$ & $\begin{array}{l}\text { Pellicano et al., } 2006 \\
\text { ded } \\
\text { put not } \\
\text { olated } \\
\text { ess.) }\end{array}$ \\
\hline
\end{tabular}




\begin{tabular}{|c|c|c|c|c|c|c|}
\hline Age & Method & Stimuli & $\begin{array}{l}\text { Multimodal/ } \\
\text { Unimodal }\end{array}$ & $\begin{array}{c}\text { Static/ } \\
\text { Dynamic }\end{array}$ & $\begin{array}{l}\text { Discriminated/ } \\
\text { Recognized/ } \\
\text { Preferred }\end{array}$ & Reference \\
\hline \multirow[t]{5}{*}{ 2-6 yrs. } & Storybook & $\begin{array}{l}\text { Target photos of unfamiliar boys' } \\
\& \text { eight distractor photos (upright } \\
\text { vs. inverted) }\end{array}$ & Unimodal & Static & \multicolumn{2}{|c|}{$\begin{array}{l}\text { recognized target faces. } 2 \text { yr. } \\
\text { olds showed faster reaction time } \\
\text { to identify inverted than upright faces. } \\
\text { (evidence of inversion effect at 6yrs) }\end{array}$} \\
\hline & VPC & $\begin{array}{l}\text { Photos of mother's face \& } \\
\text { unfamiliar woman's face }\end{array}$ & Unimodal & Static & \multicolumn{2}{|c|}{$\begin{array}{l}\text { larger ERP's to mother's } \\
\text { face than to unfamiliar woman; } \\
\text { 3.5-4-year-olds showed } \\
\text { larger ERP's to unfamiliar } \\
\text { woman's face than mother }\end{array}$} \\
\hline & VPC & $\begin{array}{l}\text { Photos of schematic upright } \\
\text { face, schematic jumbled face, } \\
\& \text { schematic inverted face }\end{array}$ & Unimodal & Static & $\begin{array}{l}\text { 4-year-olds showed no } \\
\text { differences in ERPs for } \\
\text { inverted vs. upright faces }\end{array}$ & $\begin{array}{l}\text { Henderson et al., } \\
2003\end{array}$ \\
\hline & $\begin{array}{l}\text { Eyewitness } \\
\text { lineup } \\
\text { procedure }\end{array}$ & $\begin{array}{l}\text { Photos of target caregivers' } \\
\text { faces \& distractor faces }\end{array}$ & Unimodal & Static & $\begin{array}{l}\text { 2-3-year-olds failed to } \\
\text { accurately recognize care } \\
\text { following 3-month delay }\end{array}$ & $\begin{array}{l}\text { Cain et al., } 2005 \\
\text { givers }\end{array}$ \\
\hline & $\begin{array}{l}\text { Eyewitness } \\
\text { lineup }\end{array}$ & $\begin{array}{l}\text { Photos of distractor unfamiliar } \\
\text { women’s faces (nurses) }\end{array}$ & Unimodal & Static & $\begin{array}{l}\text { 3-year-olds did not } \\
\text { accurately recognize } \\
\text { a nurse with whom they } \\
\text { interacted after } 2 \text { wks. }\end{array}$ & Goodman et al., 1990 \\
\hline
\end{tabular}


Table 1I: Mean proportion of total looking time (PTLT \& standard deviation) as a function of age, stimulus modality, and memory load

\begin{tabular}{|c|c|c|c|c|c|c|c|c|}
\hline & \multicolumn{2}{|c|}{ Infant } & \multicolumn{2}{|c|}{ Toddler } & \multicolumn{2}{|c|}{ Preschooler } & \multicolumn{2}{|c|}{ Overall Means } \\
\hline & $\begin{array}{c}\text { Low } \\
\text { Memory }\end{array}$ & $\begin{array}{c}\text { High } \\
\text { Memory }\end{array}$ & $\begin{array}{c}\text { Low } \\
\text { Memory }\end{array}$ & $\begin{array}{c}\text { High } \\
\text { Memory }\end{array}$ & $\begin{array}{c}\text { Low } \\
\text { Memory }\end{array}$ & $\begin{array}{c}\text { High } \\
\text { Memory }\end{array}$ & $\begin{array}{c}\text { Low } \\
\text { Memory }\end{array}$ & $\begin{array}{c}\text { High } \\
\text { Memory }\end{array}$ \\
\hline Unimodal & $\begin{array}{c}0.53 \\
(0.12)\end{array}$ & $\begin{array}{c}0.48 \\
(0.09)\end{array}$ & $\begin{array}{c}0.60 * * \\
(0.11)\end{array}$ & $\begin{array}{c}0.52 \\
(0.12)\end{array}$ & $\begin{array}{l}0.55^{*} \\
(0.08)\end{array}$ & $\begin{array}{c}0.57 \\
(0.13)\end{array}$ & $\begin{array}{c}0.56 \\
(0.02)\end{array}$ & $\begin{array}{c}0.52 \\
(0.01)\end{array}$ \\
\hline Bimodal & $\begin{array}{c}0.48 \\
(0.08)\end{array}$ & $\begin{array}{c}0.52 \\
(0.12)\end{array}$ & $\begin{array}{c}0.56^{*} \\
(0.09)\end{array}$ & $\begin{array}{c}0.52 \\
(0.09)\end{array}$ & $\begin{array}{c}0.54 \\
(0.11)\end{array}$ & $\begin{array}{l}0.54 * \\
(0.07)\end{array}$ & $\begin{array}{c}0.53 \\
(0.02)\end{array}$ & $\begin{array}{c}0.53 \\
(0.02)\end{array}$ \\
\hline $\begin{array}{l}\text { Overall } \\
\text { Means }\end{array}$ & $\begin{array}{c}0.50 \\
(0.02)\end{array}$ & $\begin{array}{c}0.50 \\
(0.02)\end{array}$ & $\begin{array}{c}0.58 \\
(0.02)\end{array}$ & $\begin{array}{c}0.52 \\
(0.02)\end{array}$ & $\begin{array}{c}0.55 \\
(0.02)\end{array}$ & $\begin{array}{c}0.56 \\
(0.02)\end{array}$ & $\begin{array}{c}0.54 \\
(0.01)\end{array}$ & $\begin{array}{c}0.52 \\
(0.01)\end{array}$ \\
\hline
\end{tabular}

$$
\begin{aligned}
* p & <0.05 \\
* * & <0.01
\end{aligned}
$$


Table 1I cont.

\begin{tabular}{|c|c|c|c|}
\hline & \multicolumn{2}{|c|}{ Infant } & \\
\hline & Low Memory Load & High Memory Load & $\begin{array}{c}\text { Overall } \\
\text { Means }\end{array}$ \\
\hline Unimodal & 0.53 & 0.48 & $\mathbf{0 . 5 0}$ \\
& $(0.12)$ & $(0.09)$ & $\mathbf{( 0 . 0 2 )}$ \\
\hline Bimodal & 0.48 & 0.52 & $\mathbf{0 . 5 0}$ \\
& $(0.08)$ & $(0.12)$ & $\mathbf{( 0 . 0 2 )}$ \\
\hline Overall Means & $\mathbf{0 . 5 0}$ & $\mathbf{0 . 5 0}$ & $\mathbf{0 . 5 0}$ \\
& $\mathbf{( 0 . 0 2 )}$ & $\mathbf{( 0 . 0 2 )}$ & $\mathbf{( 0 . 0 2 )}$ \\
\hline
\end{tabular}

\begin{tabular}{|c|c|c|c|}
\hline & \multicolumn{2}{|c|}{ Toddler } & \\
\hline & Low Memory Load & High Memory Load & $\begin{array}{c}\text { Overall } \\
\text { Means }\end{array}$ \\
\hline Unimodal & $0.60^{* *}$ & 0.52 & $\mathbf{0 . 5 6}$ \\
& $(0.11)$ & $(0.12)$ & $\mathbf{( 0 . 0 2 )}$ \\
\hline Bimodal & $0.56^{*}$ & 0.52 & $\mathbf{0 . 5 4}$ \\
& $(0.09)$ & $(0.09)$ & $\mathbf{( 0 . 0 2 )}$ \\
\hline Overall Means & $\mathbf{0 . 5 8}$ & $\mathbf{0 . 5 2}$ & $\mathbf{0 . 5 5}$ \\
& $\mathbf{( 0 . 0 2 )}$ & $\mathbf{( 0 . 0 2 )}$ & $\mathbf{( 0 . 0 2 )}$ \\
\hline
\end{tabular}

\begin{tabular}{|c|c|c|c|}
\hline & \multicolumn{2}{|c|}{ Preschool } & \\
\hline & Low Memory Load & High Memory Load & $\begin{array}{c}\text { Overall } \\
\text { Means }\end{array}$ \\
\hline Unimodal & $0.55^{*}$ & 0.57 & $\mathbf{0 . 5 6}$ \\
& $(0.08)$ & $(0.13)$ & $\mathbf{( 0 . 0 2 )}$ \\
\hline Bimodal & 0.54 & $0.54^{*}$ & $\mathbf{0 . 5 4}$ \\
& $(0.11)$ & $(0.07)$ & $\mathbf{( 0 . 0 2 )}$ \\
\hline Overall Means & $\mathbf{0 . 5 5}$ & $\mathbf{0 . 5 6}$ & $\mathbf{0 . 5 5}$ \\
& $\mathbf{( 0 . 0 2 )}$ & $\mathbf{( 0 . 0 2 )}$ & $\mathbf{( 0 . 0 2 )}$ \\
\hline
\end{tabular}


Table II cont.

Across All Ages

\begin{tabular}{|c|c|c|c|}
\hline & Low Memory Load & High Memory Load & $\begin{array}{c}\text { Overall } \\
\text { Means }\end{array}$ \\
\hline Unimodal & 0.56 & 0.52 & $\mathbf{0 . 5 4}$ \\
& $(0.02)$ & $(0.01)$ & $\mathbf{( 0 . 0 1 )}$ \\
\hline Bimodal & 0.53 & 0.53 & $\mathbf{0 . 5 3}$ \\
& $(0.02)$ & $(0.02)$ & $(\mathbf{0 . 0 1})$ \\
\hline Overall Means & $\mathbf{0 . 5 4}$ & $\mathbf{0 . 5 2}$ & $\mathbf{0 . 5 3}$ \\
& $\mathbf{( 0 . 0 1 )}$ & $\mathbf{( 0 . 0 1 )}$ & $\mathbf{( 0 . 0 1 )}$ \\
\hline
\end{tabular}


Table III: Mean proportion of available looking time (PALT \& standard deviation) as a function of age, stimulus modality and memory load

\begin{tabular}{|c|c|c|c|c|c|c|c|c|}
\hline & \multicolumn{2}{|c|}{ Infant } & \multicolumn{2}{|c|}{ Toddler } & \multicolumn{2}{|c|}{ Preschooler } & \multicolumn{2}{|c|}{ Overall Means } \\
\hline & $\begin{array}{c}\text { Low } \\
\text { Memory }\end{array}$ & $\begin{array}{c}\text { High } \\
\text { Memory }\end{array}$ & $\begin{array}{c}\text { Low } \\
\text { Memory }\end{array}$ & $\begin{array}{l}\text { High } \\
\text { Memory }\end{array}$ & $\begin{array}{c}\text { Low } \\
\text { Memory }\end{array}$ & $\begin{array}{c}\text { High } \\
\text { Memory }\end{array}$ & $\begin{array}{c}\text { Low } \\
\text { Memory }\end{array}$ & $\begin{array}{c}\text { High } \\
\text { Memory }\end{array}$ \\
\hline Unimodal & $\begin{array}{c}0.75 \\
(0.15)\end{array}$ & $\begin{array}{c}0.71 \\
(0.18)\end{array}$ & $\begin{array}{c}0.56 \\
(0.18)\end{array}$ & $\begin{array}{c}0.59 \\
(0.19)\end{array}$ & $\begin{array}{c}0.69 \\
(0.14)\end{array}$ & $\begin{array}{c}0.74 \\
(0.09)\end{array}$ & $\begin{array}{c}0.67 \\
(0.16)\end{array}$ & $\begin{array}{c}0.68 \\
(0.15)\end{array}$ \\
\hline Bimodal & $\begin{array}{c}0.80 \\
(0.18)\end{array}$ & $\begin{array}{c}0.80 \\
(0.17)\end{array}$ & $\begin{array}{c}0.64 \\
(0.13)\end{array}$ & $\begin{array}{c}0.65 \\
(0.17)\end{array}$ & $\begin{array}{c}0.82 \\
(0.11)\end{array}$ & $\begin{array}{c}0.80 \\
(0.11)\end{array}$ & $\begin{array}{c}0.75 \\
(0.14)\end{array}$ & $\begin{array}{c}0.75 \\
(0.15)\end{array}$ \\
\hline $\begin{array}{l}\text { Overall } \\
\text { Means }\end{array}$ & $\begin{array}{c}0.77 \\
(0.17)\end{array}$ & $\begin{array}{c}0.76 \\
(0.18)\end{array}$ & $\begin{array}{c}0.60 \\
(0.16)\end{array}$ & $\begin{array}{c}0.62 \\
(0.18)\end{array}$ & $\begin{array}{c}0.76 \\
(0.13)\end{array}$ & $\begin{array}{c}0.77 \\
(0.10)\end{array}$ & $\begin{array}{c}0.71 \\
(0.15)\end{array}$ & $\begin{array}{c}0.72 \\
(0.15)\end{array}$ \\
\hline
\end{tabular}


Table III cont.

\begin{tabular}{|c|c|c|c|}
\hline & \multicolumn{2}{|c|}{ Infant } & \\
\hline & Low Memory Load & High Memory Load & $\begin{array}{c}\text { Overall } \\
\text { Means }\end{array}$ \\
\hline Unimodal & 0.75 & 0.71 & $\mathbf{0 . 7 3}$ \\
& $(0.15)$ & $(0.18)$ & $\mathbf{( 0 . 1 7 )}$ \\
\hline Bimodal & 0.80 & 0.80 & $\mathbf{0 . 8 0}$ \\
& $0.18)$ & $(0.17)$ & $(\mathbf{0 . 1 8})$ \\
\hline Overall Means & $\mathbf{0 . 7 7}$ & $\mathbf{0 . 7 6}$ & $\mathbf{0 . 7 7}$ \\
& $\mathbf{( 0 . 1 7 )}$ & $\mathbf{( 0 . 1 8 )}$ & $\mathbf{( 0 . 1 8 )}$ \\
\hline
\end{tabular}

\begin{tabular}{|c|c|c|c|}
\hline & \multicolumn{2}{|c|}{ Toddler } & \\
\hline & Low Memory Load & High Memory Load & $\begin{array}{c}\text { Overall } \\
\text { Means }\end{array}$ \\
\hline Unimodal & 0.56 & 0.59 & $\mathbf{0 . 5 8}$ \\
& $(0.18)$ & $(0.19)$ & $\mathbf{( 0 . 1 9 )}$ \\
\hline Bimodal & 0.64 & 0.65 & $\mathbf{0 . 6 5}$ \\
& $(0.13)$ & $(0.17)$ & $(\mathbf{0 . 1 5 )}$ \\
\hline Overall Means & $\mathbf{0 . 6 0}$ & $\mathbf{0 . 6 2}$ & $\mathbf{0 . 6 1}$ \\
& $\mathbf{( 0 . 1 6 )}$ & $\mathbf{( 0 . 1 8 )}$ & $\mathbf{( 0 . 1 7 )}$ \\
\hline
\end{tabular}

\begin{tabular}{|c|c|c|c|}
\hline & \multicolumn{2}{|c|}{ Preschool } & \\
\hline & Low Memory Load & High Memory Load & $\begin{array}{c}\text { Overall } \\
\text { Means }\end{array}$ \\
\hline Unimodal & 0.69 & 0.74 & $\mathbf{0 . 7 2}$ \\
& $(0.14)$ & $(0.09)$ & $\mathbf{( 0 . 1 2 )}$ \\
\hline Bimodal & 0.82 & 0.80 & $\mathbf{0 . 8 1}$ \\
& $(0.11)$ & $(0.11)$ & $\mathbf{0 . 1 1}$ \\
\hline Overall Means & $\mathbf{0 . 7 6}$ & $\mathbf{0 . 7 7}$ & $\mathbf{0 . 7 7}$ \\
& $\mathbf{( 0 . 1 3 )}$ & $\mathbf{( 0 . 1 0 )}$ & $\mathbf{( 0 . 1 2 )}$ \\
\hline
\end{tabular}


Table III cont.

Across All Ages

\begin{tabular}{|c|c|c|c|}
\hline & Low Memory Load & High Memory Load & $\begin{array}{c}\text { Overall } \\
\text { Means }\end{array}$ \\
\hline Unimodal & 0.67 & 0.68 & 0.68 \\
& $(0.16)$ & $(0.15)$ & $(0.16)$ \\
\hline Bimodal & 0.75 & 0.75 & 0.75 \\
& $(0.14)$ & $(0.15)$ & $(0.15)$ \\
\hline Overall Means & 0.71 & 0.72 & 0.72 \\
& $(0.15)$ & $(0.15)$ & $(0.15)$ \\
\hline
\end{tabular}


VITA

MELISSA ANN ARGUMOSA

Born, Woonsocket, Rhode Island

2001

B.A., Psychology

Florida International University

Miami, Florida

2001

Outstanding Service to the Department of

Psychology

Florida International University

Miami, Florida

2001

National Institute of Health Human Subjects

Training Certification

2005-2009

MBRS RISE (Research Initiative for Scientific

Enhancement)

Program/Fellowship

Florida International University

2006

Responsible Conduct of Research Program Training Certification

2008

M.S., Psychology

Florida International University

Miami, Florida

Teaching Assistant

Florida International University

Miami, Florida

Graduate Research Assistant

Florida International University

Miami, Florida

\section{PUBLICATIONS AND PRESENTATIONS}

Argumosa, M. A. \& Bahrick, L. E. (In preparation). Five-month-old infants detect and remember face-affect relations.

Argumosa, M. A. \& Bahrick, L. E. (October 2008). The development of face recognition from infancy to young childhood. Florida International University MBRS and MARC

U*STAR Mini-Symposium, Miami, FL. 
Bahrick, L. E., Argumosa, M.. A., Lopez, H., \& Todd, J. T. (October 2009). Face discrimination in preschool-aged children. Poster presented at the Cognitive Development Society Biennial Meeting, San Antonio, TX.

Bahrick, L. E., Castellanos, I. \& Argumosa, M. A. (In preparation). Infant's perception of infantdirected speech: The role of intersensory redundancy.

Bahrick, L. E., Castellanos, I., Shuman, M. A., Vaillant-Molina, M., Newell, L. C., \& Sorondo, B. M. (May 2008). Self-perception and social orienting in young children with autism. Poster presented at the International Meeting for Autism Research, London, England.

Bahrick, L. E., Grossman, R., Castellanos, I., Argumosa, M. A., Newell, L. C. (March 2010). Audiovisual interactions in infant categorization: Voice gender biases face categorization. Poster presented at the International Conference of Infant Studies, Baltimore, MD.

Bahrick, L. E., Sorondo, B. M., Castellanos, I., Todd, J., Argumosa, M.. A. \& Vaillant-Molina, M. (November 2008). The development of basic indices of attention to bimodal and unimodal events across infancy. Poster presented at the International Society for Developmental Psychobiology, Washington, D.C.

Bahrick, L. E., Todd, J., Castellanos, I., Sorondo, B. M., Vaillant-Molina, M., \& Argumosa, M. A. (May 2009). The role of intersensory redundancy in the typical development of social orienting across infancy: A new hypothesis for Autism. Poster presented at the International Meeting for Autism Research, Chicago, IL.

Bahrick, L. E., Todd, J., Vaillant-Molina, M., Sorondo, B. M., Castellanos, I., \& Argumosa, M. A. (March 2009). Development of basic indices of attention to nonsocial events: Effects of unimodal versus bimodal stimulation. Poster presented at the Society for Research in Child Development, Denver, CO.

Newell, L. C., Bahrick, L. E., Vaillant-Molina, M., Shuman, M. A., \& Castellanos, I. (May 2007). Intersensory Perception and Attention Disengagement in Young Children with Autism. Poster presented at the International Meeting for Autism Research, Seattle, WA.

Shuman, M. A., Castellanos, I., \& Bahrick, L. E. (November 2005). Infant detection of prosodic information conveying approval vs. prohibition was facilitated by intersensory redundancy in audiovisual speech. International Academy of Linguistics, Behavioral, and Social Sciences Annual Meeting, Miami, FL.

Shuman, M. A., \& Bahrick, L. E. (March 2007). Infants' perception of face-affect relations in multimodal events. Poster presented at the Society for Research in Child Development, Boston, MA. 